\title{
IMPACT OF COMPOSITION AND HEAT TREATMENT ON PORE SIZE IN POROUS WALLED HOLLOW GLASS MICROSPHERES
}

\author{
F. C. Raszewski \\ E. K. Hansen \\ S. D. Mann \\ R. F. Schumacher \\ D. K. Peeler
}

December 2007

Processing Science \& Engineering Section Savannah River National Laboratory Aiken, SC 29808

Prepared for the U.S. Department of Energy Under Contract Number DEAC09-96SR18500

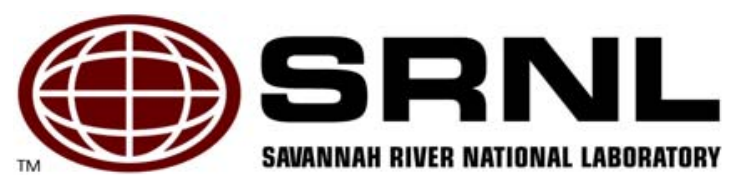


WSRC-STI-2007-00605

Revision 0

\section{DISCLAIMER}

This report was prepared by Washington Savannah River Company (WSRC) for the United States Department of Energy under Contract No. DE-AC09-96SR18500 and is an account of work performed under that contract. Neither the United States Department of Energy, nor WSRC, nor any of their employees makes any warranty, expressed or implied, or assumes any legal liability or responsibility for the accuracy, completeness, or usefulness, of any information, apparatus, or product or process disclosed herein or represents that its use will not infringe privately owned rights. Reference herein to any specific commercial product, process, or service by trademark, name, manufacturer or otherwise does not necessarily constitute or imply endorsement, recommendation, or favoring of same by WSRC or by the United States Government or any agency thereof. The views and opinions of the authors expressed herein do not necessarily state or reflect those of the United States Government or any agency thereof.

\section{Printed in the United States of America \\ Prepared For U.S. Department of Energy}

The Savannah River National Laboratory is operated for the U.S. Department of Energy by Washington Savannah River Company. 
Keywords: Microsphere, glass, HGMs, PWHGMs, porosity

Retention: permanent

\section{IMPACT OF COMPOSITION AND HEAT TREATMENT ON PORE SIZE IN POROUS WALLED HOLLOW GLASS MICROSPHERES}

F. C. Raszewski

E. K. Hansen

S. D. Mann

R. F. Schumacher

D. K. Peeler

December 2007

Processing Science \& Engineering Section Savannah River National Laboratory Aiken, SC 29808

Prepared for the U.S. Department of Energy Under Contract Number DEAC09-96SR18500

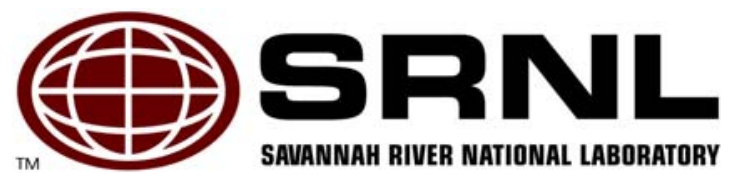




\section{REVIEWS AND APPROVALS}

\section{AUTHORS:}

F.C. Raszewski, Process Science and Engineering Date

\begin{tabular}{lc}
\hline E.K. Hansen, Process Science and Engineering Date & Dat
\end{tabular}

S.D. Mann, Process Science and Engineering Date

R.F. Schumacher, Process Science and Engineering Date

D.K. Peeler, Process Science and Engineering Date

\section{TECHNICAL REVIEWER:}

K.M. Fox, Process Science and Engineering

Date

\section{APPROVERS:}

D.A. Crowley, Manager, Stabilization Science Research

Date

R.E. Edwards, Manager, Process Science and Engineering Section

Date 


\section{EXECUTIVE SUMMARY}

The Savannah River National Laboratory (SRNL) developed a new geometric form: hollow glass microspheres (HGMs), with unique porous walls. The new geometric form combines the existing technology of HGMs with basic glass science knowledge in the realm of glassin-glass phase separation. Conceptually, the development of a HGM with porous walls (referred to as a PWHGM) provides a unique system in which various media or filling agents can be incorporated into the PWHGM (via transport through the porous walls) and ultimately has the capacity to serve as a functional delivery system in various industrial applications. Applications of these types of systems could range from hydrogen storage, molecular sieves, drug and bioactive delivery systems, to environmental, as well as chemical and biological indicators, relevant to Energy, Environmental Processing and Homeland Security fields. As a specific example, previous studies at SRNL have introduced materials capable of hydrogen storage (as well as other materials) into the interior of the PWHGMs.

The goal of this project was to determine if the microstructure (i.e., pore size and pore size distribution) of a PWHGM could be altered or tailored by varying composition and/or heat treatment (time and/or temperature) conditions. The ability to tailor the microstructure through composition or heat treatments could provide the opportunity to design the PWHGM system to accommodate different additives or fill agents. To meet this objective, HGMs of various alkali borosilicate compositions were fabricated using a flame forming apparatus installed at the Aiken County Technical Laboratory (ACTL). HGMs were treated under various heat treatment conditions to induce and/or enhance glass in glass phase separation. Heat treatment temperatures ranged from $580^{\circ} \mathrm{C}$ to $620^{\circ} \mathrm{C}$, while heat treatment times were either 8 or 24 hours.

Of the two primary variables assessed in this study, heat treatment temperature was determined to be most effective in changing the porosity of PWHGMs. Pore diameter in a non-heat treated baseline sample is approximately $100 \AA$ and with heat treatment at $600^{\circ} \mathrm{C}$ for 8 hours, the diameter is approximately $1000 \AA$; an increase of a factor of 10 . The results of this study also indicate significant microstructural differences with only a $20^{\circ} \mathrm{C}$ difference in heat treatment temperature $\left(580^{\circ} \mathrm{C}\right.$ and $\left.600^{\circ} \mathrm{C}\right)$ for constant times. The microstructural changes observed via electron microscopy as a function of heat treatment temperature were confirmed by mercury porosimetry measurements, where considerable increases in pore volume were measured.

Under constant heat treatment conditions, composition may impose a secondary effect on the resulting microstructure as micrographs indicate variations in the degree of porosity. Although microstructural differences were observed among the compositions assessed, the magnitude of the impact (i.e., difference in pore size or pore volume) appears to be smaller than that associated with heat treatment temperature.

With respect to heat treatment time, the results suggest that the change in the degree of porosity is minimal for samples heat treated between 8 and 24 hours (it should be noted that the assessment of the impact of time on the resulting microstructure was limited to two compositions). The minimal impact of heat treatment time (on the two glasses evaluated) 
was confirmed by mercury porosimetry measurements indicating that there was a very slight shift in pore diameter and very little (if any) increase in pore volume in the baseline sample.

Another important parameter, which will need to be considered under manufacturing or operational conditions, is the yield of the HGM and/or PWHGM and the characteristics of the final product (i.e., not only microstructure characteristics, but perhaps strength of the PWHGM for use under certain applications). In this report, yield is defined as the percentage of feed material converted to HGMs or the percentage of HGMs converted to PWHGMs. The yield of HGM formation was found to be a strong function of composition. As the $\mathrm{SiO}_{2}$ and $\mathrm{B}_{2} \mathrm{O}_{3}$ contents are increased or decreased from the baseline composition, the yield is reduced. PWHGM yield does not appear to be influenced by composition, but there is a noticeable increase in yield when comparing the non-heat treated samples to those that were heat treated prior to acid leaching.

The results of this study suggest that PWHGM microstructures (pore size and pore volume) can be tailored or specifically designed to meet different end-user needs within certain limitations. The primary effect on the resulting microstructure is heat treatment temperature, which can produce a significant shift in pore size or volume even with a very small difference in heat treatment temperature $\left(20^{\circ} \mathrm{C}\right)$. The ability to control the microstructure of PWHGMs provides the opportunity to design the PWHGM system to accommodate different additives or fill agents as required. 


\section{TABLE OF CONTENTS}

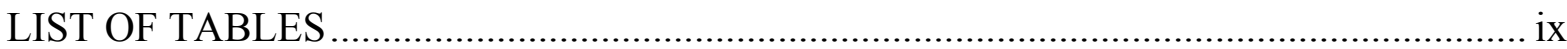

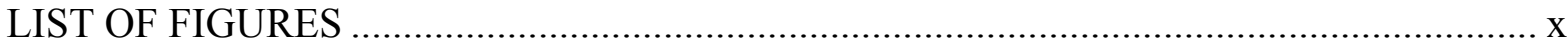

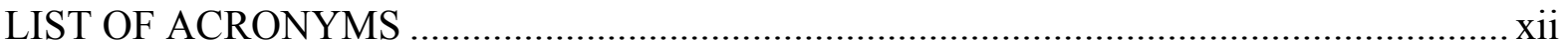

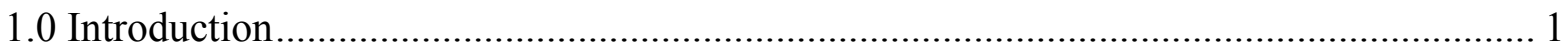

1.1 Production of Porous Glasses, HGMs and PWHGMs ............................................... 1

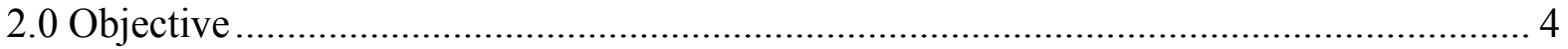

2.1 Mapping the Immiscibility Dome........................................................................ 4

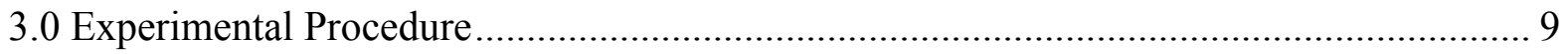

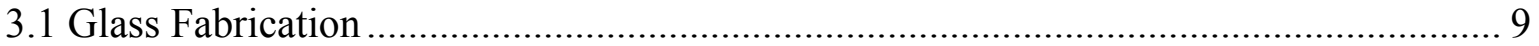

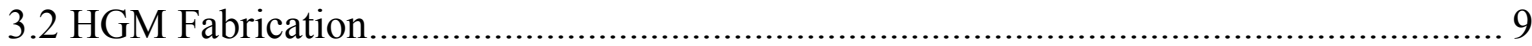

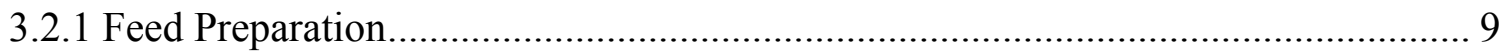

3.2.2 Flame Process and HGM Separation ............................................................... 10

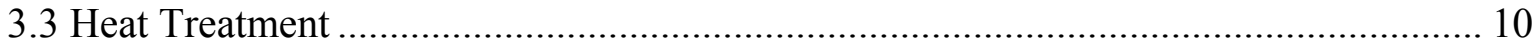

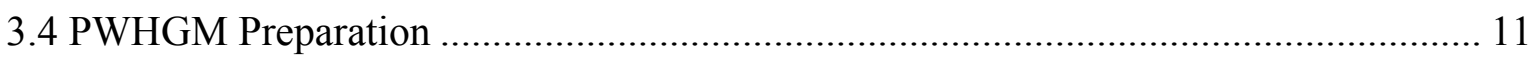

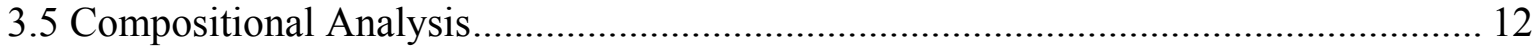

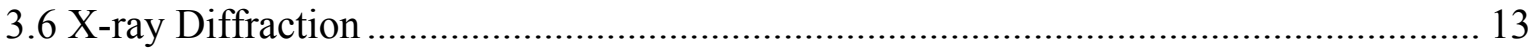

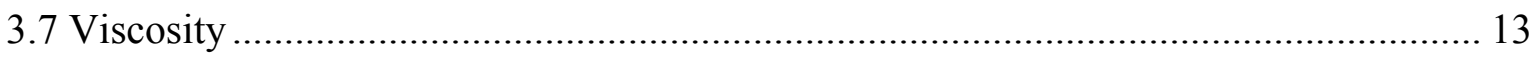

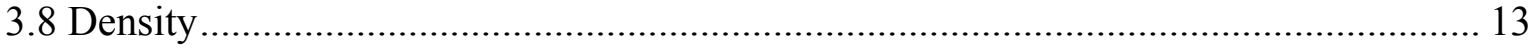

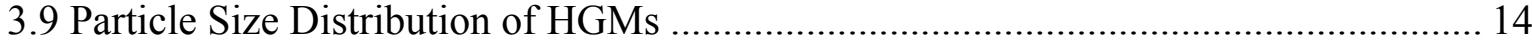

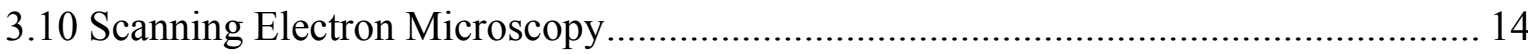

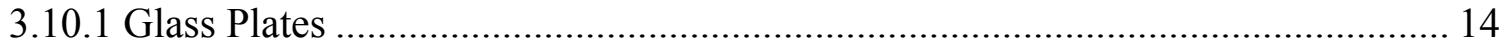

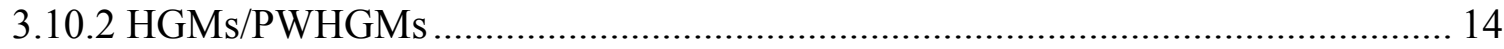

3.10.2.1 Hitachi 4800 Field Emission Scanning Electron Microscope ...................................... 14

3.10.2.2 Hitchachi HD2000 Scanning Transmission Electron Microscope ............................... 14

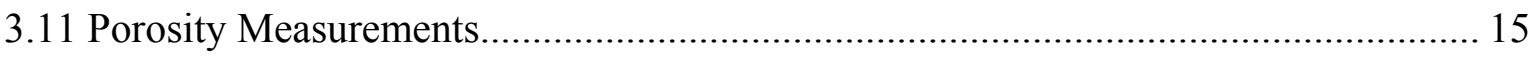

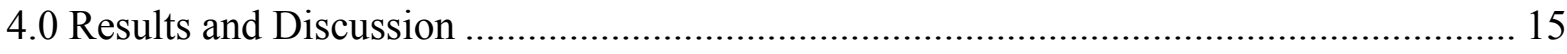

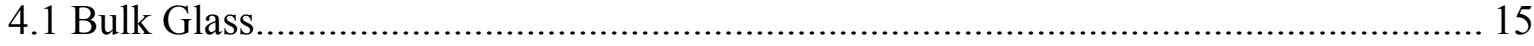

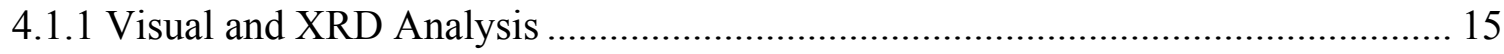

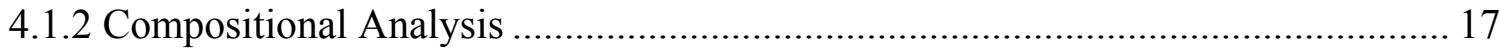

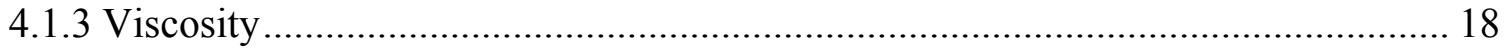




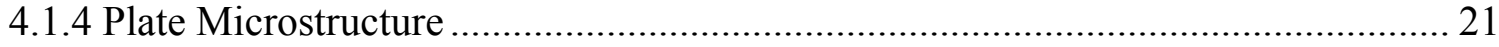

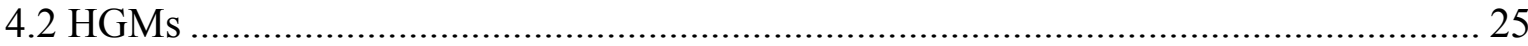

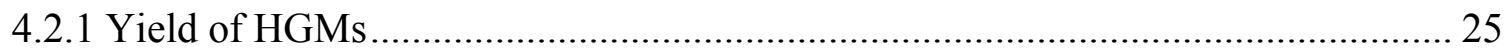

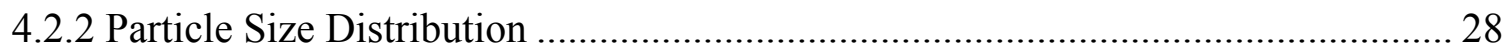

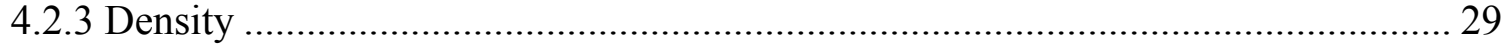

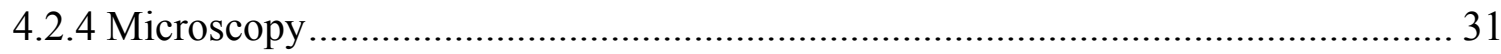

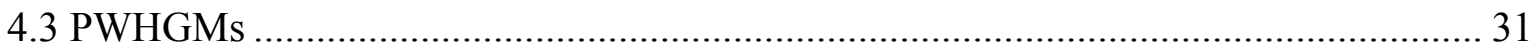

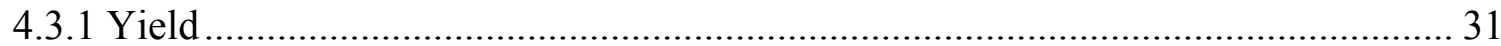

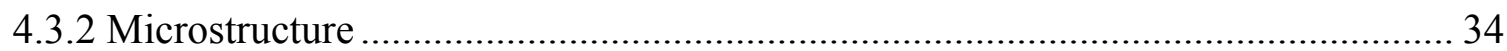

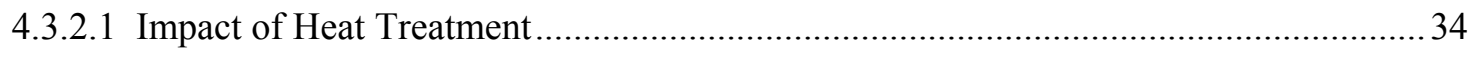

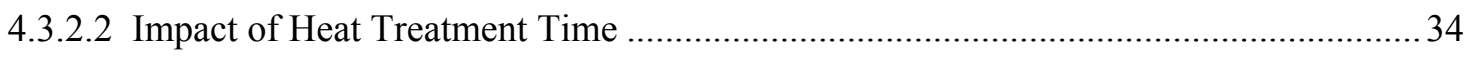

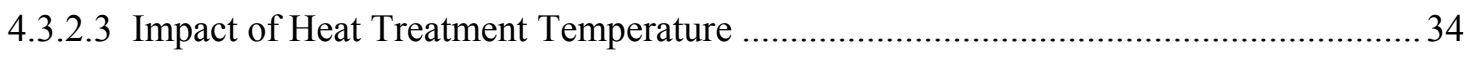

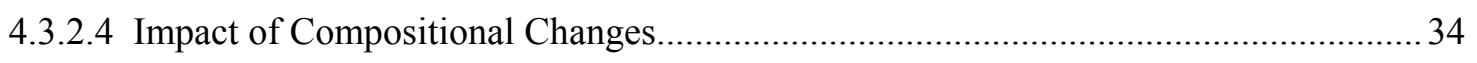

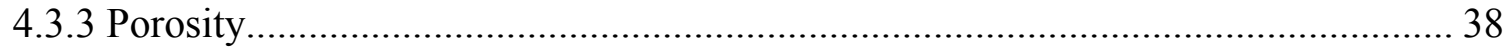

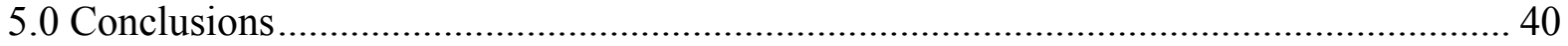

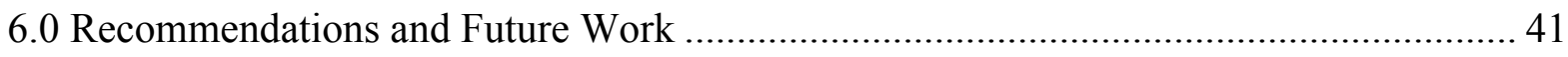

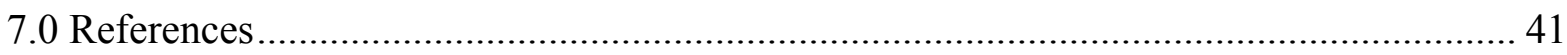

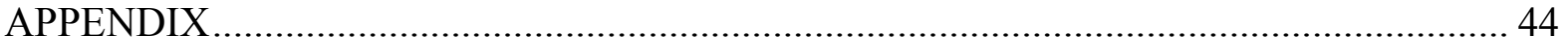




\section{LIST OF TABLES}

Table 1. Glass Compositions of Commercial HGMs (HGMA) and Vycor ${ }^{\mathrm{TM}}$.................................... 5

Table 2. Approximate Compositions (wt\%) of LDRD Test Matrix Glasses and "Charles" Glasses .... 7

Table 3. Chemical Compositions of the "Zero Glasses" ................................................................ 9

Table 4. Composition and Heat Treatment Conditions Used to Make PWHGMs ............................ 12

Table 5. Measured and Target Compositions of the LDRD Glasses............................................... 17

Table 6. Chemical Composition Comparison of the PDRD Target Glass Composition to the Composition of the HGMs Before and After Acid Leaching ............................................ 18

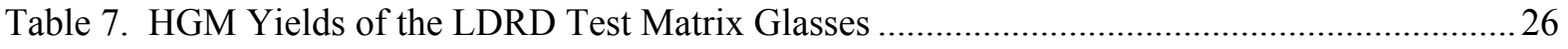

Table 8. HGM Particle Size Distributions of Select LDRD Compositions.........................................28

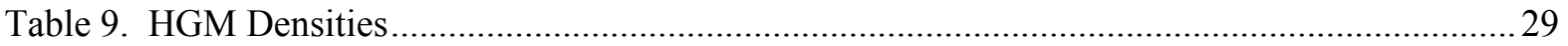

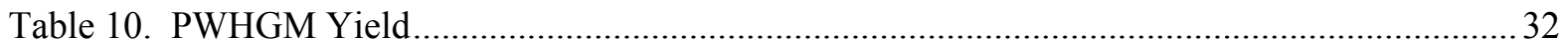




\section{LIST OF FIGURES}

Figure 1. Microstructures of (a) spinodal decomposition and (b) nucleation and growth....................2

Figure 2. Conceptual representation of a PWHGM. ...................................................................... 3

Figure 3. Simplistic view of mapping a two component immiscibility dome. Note: LDRD compositions are located within a multi-component immiscibility dome. ........................6

Figure 4. Images of the as-fabricated LDRD glasses.................................................................... 16

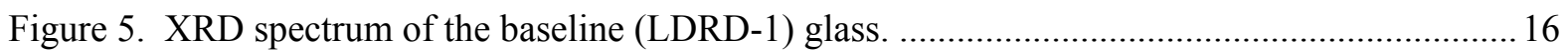

Figure 6. Measured viscosities as a function of temperature for glasses with variations in silica content. Viscosity of the commercial (HGMA) glass is included for reference............. 19

Figure 7. Measured viscosities as a function of temperature for glasses with variations in $\mathrm{B}_{2} \mathrm{O}_{3}$ content. Viscosity of the commercial (HGMA) glass is included for reference.

Figure 8. Measured viscosities as a function of temperature for the "Charles" series of glasses. Viscosity of the commercial (HGMA) glass is included for reference. 20

Figure 9. Scanning electron micrograph of the as-fabricated baseline (LDRD-1) bulk glass plate....21

Figure 10. Scanning electron micrograph of the as-fabricated $+6 \mathrm{SiO}_{2}(\mathrm{LDRD}-3)$ bulk glass plate. . 22

Figure 11. Scanning electron micrograph of the as-fabricated $-6 \mathrm{SiO}_{2}(\mathrm{LDRD}-5)$ bulk glass plate. .. 22

Figure 12. Scanning electron micrograph of the as-fabricated B/R +0.5 (LDRD-6) bulk glass plate. 23

Figure 13. Scanning electron micrograph of the as-fabricated B/R -0.5 (LDRD-7) bulk glass plate. 23

Figure 14. SEM micrographs of as-cast and heat treated $-6 \mathrm{SiO}_{2}$ bulk glass plates.......................... 24

Figure 15. HGM yield and viscosity (at $1200^{\circ} \mathrm{C}$ ) as a function of $\mathrm{SiO}_{2}$ content.............................26

Figure 16. $\mathrm{HGM}$ yield and viscosity $\left(\right.$ at $\left.1200^{\circ} \mathrm{C}\right)$ and as a function of $\mathrm{B}_{2} \mathrm{O}_{3}$ content. ....................2 27

Figure 17. Schematic identifying region of maximum HGM yield in compositional space..............27

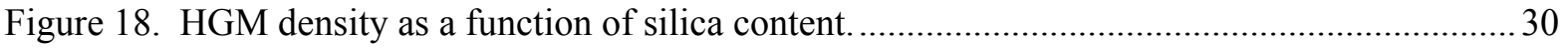

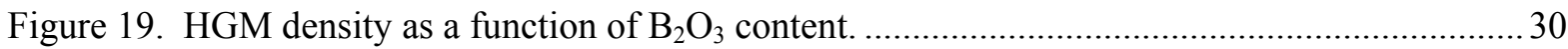

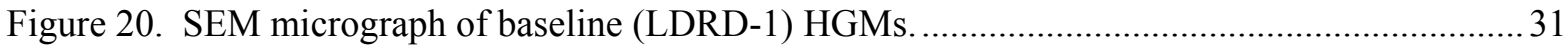

Figure 21. PWHGM yield as a function of silica content for non heat treated samples.....................33

Figure 22. PWHGM yield as a function of silica content for samples treated at $600^{\circ} \mathrm{C}$ for 8 hours... 33

Figure 23. Scanning electron micrograph of a baseline (LDRD-1) PWHGM that was not heat treated prior to acid leaching. 
Figure 24. Scanning electron micrograph of a baseline (LDRD-1) PWHGM that was heat treated at $600^{\circ} \mathrm{C}$ for 8 hours prior to acid leaching.

Figure 25. Scanning electron micrograph of a baseline (LDRD-1) PWHGM treated at $580^{\circ} \mathrm{C}$ for 8 hours.

Figure 26. Scanning electron micrograph of a baseline (LDRD-1) PWHGM treated at $580^{\circ} \mathrm{C}$ for 24 hours. Note that apparent cracking is due to sample preparation. 36

Figure 27. Scanning electron micrographs of LDRD 1-7 PWHGMs treated at $600^{\circ} \mathrm{C}$ for 8 hours prior to acid leaching. All images were taken at the same magnification.

Figure 28. Typical mercury porosimetry curve.

Figure 29. Porosity as a function of heat treatment conditions for the baseline (LDRD-1) composition 39

Figure A1. SEM micrograph of the cross-section of a typical PWHGM........................................ 45

Figure A2. SEM micrograph of the outer layer (layer 1) of the PWHGM........................................ 46

Figure A3. SEM micrograph of the outer layer in which layer 2 is exposed. ...................................46

Figure A4. Comparison of the outer layer microstructures of the same composition as a function of

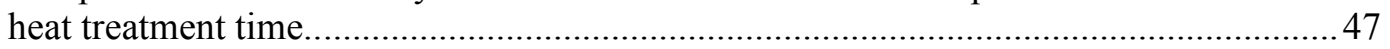

Figure A5. SEM micrograph of the inner layer (layer 3) of a PWHGM......................................... 47

Figure A6. SEM micrograph of the PWHGM outer layer (layer 1) that has spalled off to reveal the interconnected microstructure of layer 2 . 


\section{LIST OF ABBREVIATIONS}

$\begin{array}{ll}\text { ACTL } & \text { Aiken County Technical Laboratory } \\ \text { EDS } & \text { Energy Dispersive Spectroscopy } \\ \text { FESEM } & \text { Field Emission Scanning Electron Microscope } \\ \text { HGMs } & \text { Hollow glass microspheres } \\ \text { IC } & \text { Ion Chromatography } \\ \text { ICP-AES } & \text { Inductively Coupled Plasma - Atomic Emission Spectroscopy } \\ \text { LDRD } & \text { Laboratory Directed Research and Development } \\ \text { LM } & \text { Lithium-metaborate } \\ \text { PDRD } & \text { Plant Directed Research and Development } \\ \text { PF } & \text { Peroxide Fusion } \\ \text { PFW } & \text { Peroxide Fusion with water } \\ \text { PSAL } & \text { Process Science Analytical Laboratory } \\ \text { PSD } & \text { Particle Size Distribution } \\ \text { PWHGMs } & \text { Porous walled hollow glass microspheres } \\ \text { SEM } & \text { Scanning electron microscopy } \\ \text { SRNL } & \text { Savannah River National Laboratory } \\ \text { Wt\% } & \text { Weight Percent } \\ \text { XRD } & \text { X-ray Diffraction }\end{array}$


WSRC-STI-2007-00605

Revision 0

\subsection{Introduction}

Over the last fifty years, porous glasses have been prepared by various means and in many geometric forms, including solid beads, fibers, hollow fibers, and membranes. ${ }^{1}$ These porous materials have been used for several purposes including catalyst supports, gas filtration, and molecular filters. Recently, the Savannah River National Laboratory (SRNL) developed a new geometric form: hollow glass microspheres (HGMs), with unique porous walls. The new geometric form combines the existing technology of HGMs with basic glass science knowledge in the realm of glass-in-glass phase separation. Conceptually, the development of a HGM with porous walls (referred to as a PWHGM) provides a unique system in which various media or filling agents can be incorporated into the PWHGM (via transport through the porous walls) and ultimately has the capacity to serve as a functional delivery system in various industrial applications. Applications of these types of systems could range from hydrogen storage, molecular sieves, drug and bioactive delivery systems, to environmental, as well as chemical and biological indicators, relevant to Energy, Environmental Processing and Homeland Security fields. As a specific example, previous studies at SRNL have introduced materials capable of hydrogen storage (as well as other materials) into the interior of the HGMs. ${ }^{2}$

Although the ability to store hydrogen in PWHGMs has been demonstrated to various degrees in a previous study, the glass composition and resulting porosity have not been optimized. $^{2} \quad$ A fundamental understanding of the compositional and kinetic effects that ultimately control the pore morphology, size and distribution in the PWHGMs has not been achieved.

The primary objective of this study is to obtain a fundamental understanding of the compositional and/or heat treatment (time and/or temperature) effects on pore morphology, size and/or pore distribution. The ability to tailor the microstructure through composition and/or heat treatments could provide the opportunity to tailor or optimally design the PWHGM system to accommodate different additives or fill agents as required or which require (or desire) different end-state physical characteristics. Other key physical attributes for PWHGMs that could play a significant role in defining specific applications include strength of the porous shell as well as wall thickness; however, these factors were not evaluated in this study.

\subsection{Production of Porous Glasses, HGMs and PWHGMs}

In general, preparation of porous glasses can be based on the unique phase separation (or immiscibility) characteristics of certain alkali and alkaline-earth borosilicate glass systems. Consider Figure 1, which shows an immiscibility dome defined for a specific compositional range (x-axis) and temperature (y-axis). ${ }^{3}$ Within the immiscibility dome phase boundary or miscibility gap, there exist two general mechanisms in which amorphous phase separation can occur: (1) nucleation and growth and (2) spinodal decomposition. Compositions lying within the spinodal region are characterized by two separate phases, with each phase being highly interconnected and/or continuous (see Figure 1 (a)). ${ }^{4}$ In contrast, compositions within the nucleation and growth region are characterized by spherical forms of one phase isolated 
within a continuous matrix of a second glass phase (see Figure 1 (b)). ${ }^{4}$ In certain glass compositions, both types of amorphous phase separation produce varying degrees of opalescence in the glass; however, in some glasses, the phase separation is so fine that the glass appears to be homogeneous. The specific mechanism that dictates the final glass microstructure is highly dependent upon composition (location of the composition with respect to the immiscibility boundary) and thermal heat treatment (which dictates the kinetics of the process). Therefore, in systems prone to "glass in glass" or amorphous phase separation, the potential to affect or target specific microstructural characteristics via compositional and heat treatment effects exists.

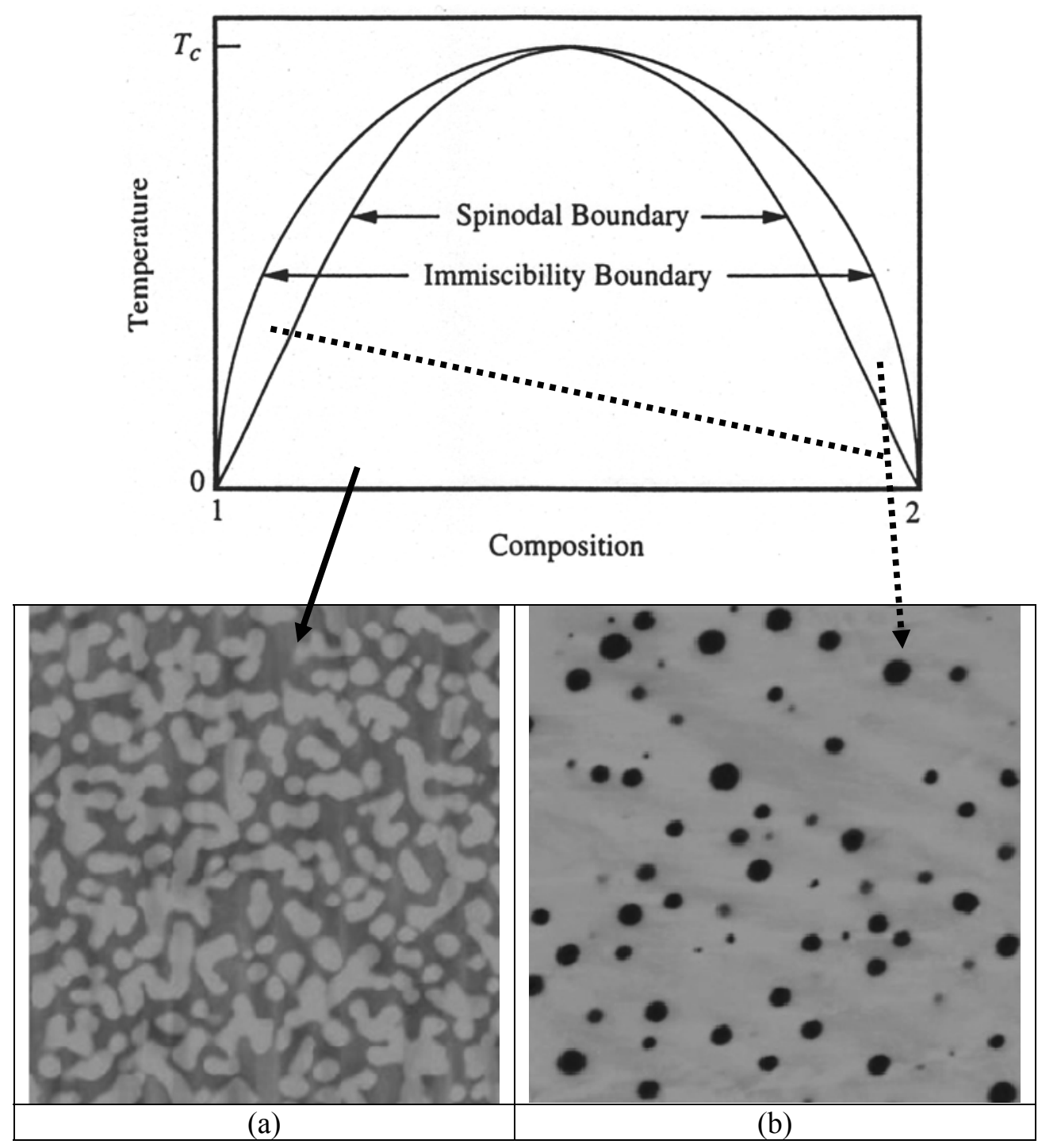

Figure 1. Microstructures of (a) spinodal decomposition and (b) nucleation and growth. 
The production of a porous glass takes advantage of the interconnected or spinodal type of microstructure and the fact that one of the phases is high in silica content while the other, silica-poor phase consists of the more soluble constituents (boron, alkali, and/or alkalineearths). The phase-separated glass is typically leached in a warm strong mineral acid bath, in which the more soluble (silica-poor) glass phase is dissolved. Fabrication of the well known commercial glass, Vycor ${ }^{\mathrm{TM}}$ (an interconnected matrix resulting from spinodal decomposition), is based on this process.

HGMs are typically produced by a flame forming process, in which a pre-fabricated glass frit containing a blowing agent is passed through a flame at high temperature. The decomposition of the blowing agent results in the generation of gases, which cause the glass particles to expand. Spherical glass shells (HGMs) are formed due to surface tension. The diameter and wall thickness of the HGM is highly dependent on the process conditions, such as flame temperature, residence time in the flame, etc., as well as the composition, viscosity and blowing agent content of the incoming feed.

As previously mentioned, the production of PWHGMs combines the existing technology of HGMs with basic glass science knowledge associated with spinodal decomposition used to produce porous glasses. In general, a glass composition prone to amorphous phase separation is used to produce a HGM. The HGM is heat treated to enhance or develop the interconnected microstructure. The heat-treated HGM is then subjected to a leaching process, which results in a sponge-like network structure or a PWHGM, consisting mainly of silica. PWHGMs are characterized by channels and openings that can permit the transport of species of interest into and out of the HGMs. A conceptual representation of a PWHGM is shown in Figure 2.

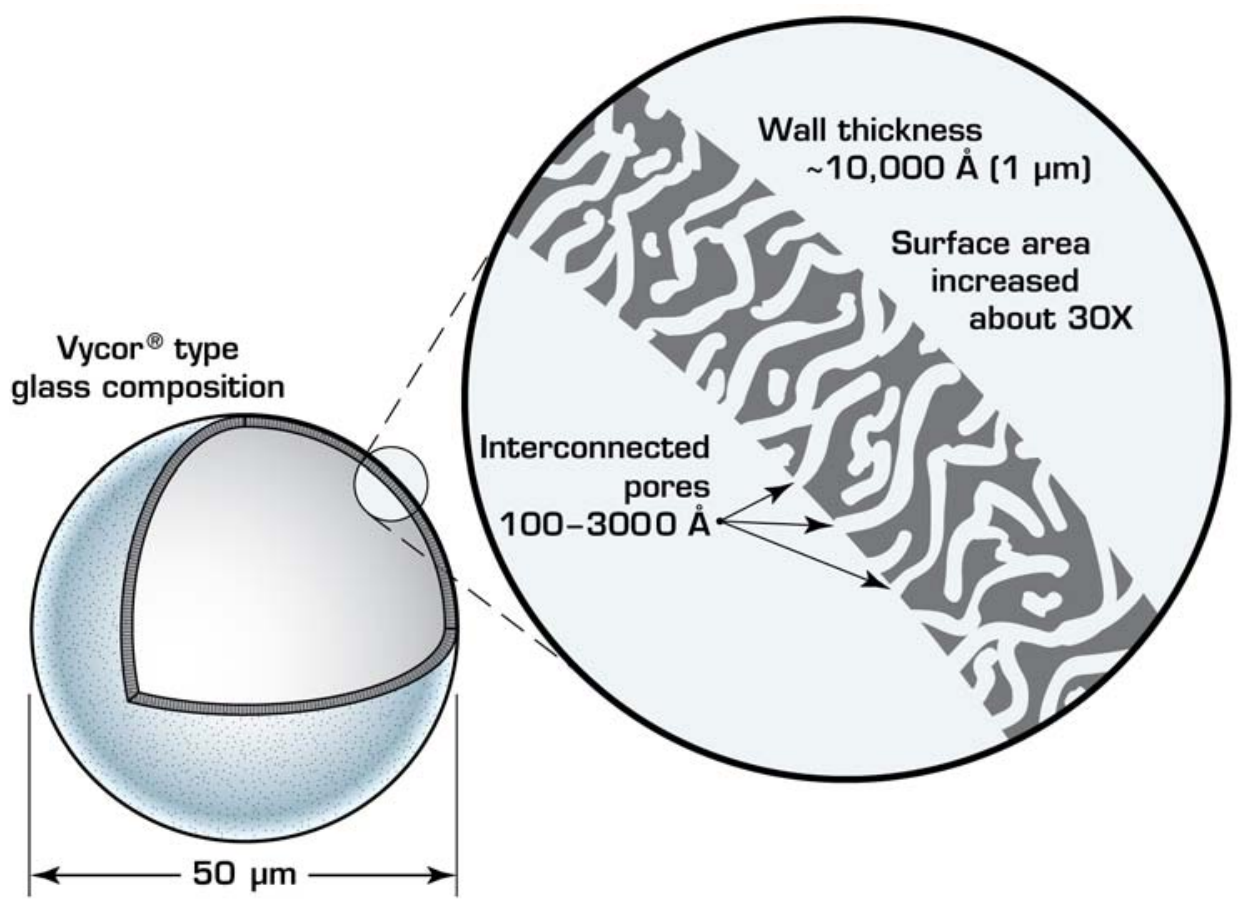

Figure 2. Conceptual representation of a PWHGM. 


\subsection{Objective}

The primary objective of this research is to demonstrate the ability to influence pore size and/or pore size distribution in PWHGMs through composition and/or heat treatment (time and/or temperature). The impacts of these parameters can be understood through studies on PWHGMs specifically or, potentially, through more fundamental parametric studies on phase separated glass plates. ${ }^{\mathrm{a}}$

A successful outcome of this research will be a roadmap (even if preliminary), from which specific process parameters can be controlled to tailor PWHGM microstructures to meet specific customer needs. Again, the ability to tailor the microstructure through composition or heat treatments could provide the opportunity to design the PWHGM system to accommodate different additives or fill agents as required. The roadmap will be a common source of information and will serve as the gateway (or springboard) for developing and supporting multiple existing or proposed applications in both federal and commercial sectors. The results will essentially provide a "technical key" for other programs. This work was funded through SRNL's FY 2007, Laboratory Directed Research and Development (LDRD) program. ${ }^{5}$

\subsection{Mapping the Immiscibility Dome}

Although the concept of immiscibility domes is rather simplistic, developing a fundamental understanding of the compositional and/or heat treatment effects for a specific glass forming system of interest can be rather challenging - especially a multi-component system such as the one to be evaluated in this study. More specifically, upon selecting a baseline glass composition region of interest to support the production of HGMs or PWHGMs, questions regarding the size of the immiscibility dome arise rather quickly, such as, how sensitive or dependent is the size and/or shape of the immiscibility dome to changes in composition? Therefore, defining or mapping the immiscibility dome within the compositional region of interest was a key parameter in this study.

In order to map the immiscibility dome, an alkali-alkaline earth-borosilicate composition, from which PWHGMs have been successfully produced in an earlier study, was used as the basis for establishing the baseline. ${ }^{2}$ The LDRD baseline composition will be referred to as LDRD-1. Although this composition was not optimized, it has been shown to produce PWHGMs in which certain materials have been introduced through the pores. It is this baseline composition that will serve as the "centroid" from which the impacts of compositional and heat treatment effects will be compared and from which the definition of the immiscibility dome can be based.

The LDRD-1 glass is essentially a blend of two commercial glasses; one known to produce HGMs (referred to as HGMA) and one known to produce the spinodal decomposition microstructure (Vycor $\left.{ }^{\mathrm{TM}}\right)$. ${ }^{1,6}$ Table 1 shows the nominal compositions of these two commercial glasses. The LDRD-1 glass not only produces HGMs, but forms two continuous

\footnotetext{
${ }^{a}$ Developing relationships among composition, heat treatment, and microstructures on glass forms other than HGMs or PWHGMs does have technical risks given potentially significant differences in formation and production kinetics.
} 
glass phases after heat treatment. It is known that one of the continuous phases is rich in alkali and borate and is therefore readily leached in heated mineral acid. The residual glass structure, consisting mostly of silica, is porous with channels connecting the exterior of the HGM to the interior void.

Table 1. Glass Compositions of Commercial HGMs (HGMA) and Vycor ${ }^{\text {TM }}$

\begin{tabular}{|c|c|c|c|c|c|c|c|c|c||}
\hline \hline Glass & $\mathrm{SiO}_{2}$ & $\mathbf{B}_{\mathbf{2}} \mathbf{O}_{3}$ & $\mathbf{C a O}$ & $\mathbf{F}$ & $\mathbf{Z n O}$ & $\mathbf{N a}_{2} \mathbf{O}$ & $\mathbf{P}_{\mathbf{2}} \mathbf{O}_{5}$ & $\mathbf{S O}_{3}$ & $\mathbf{A l}_{2} \mathbf{O}_{3}$ \\
\hline HGMA & 68.95 & 7.10 & 6.09 & 2.03 & 1.76 & 12.90 & 0.77 & 0.39 & - \\
\hline Vycor $^{\text {TM }}$ & 62.70 & 26.90 & - & - & - & 6.60 & - & - & 3.50 \\
\hline
\end{tabular}

To meet the stated objectives, a test matrix to "compositionally map" the immiscibility dome within this glass system is required. ${ }^{7}$ More specifically, compositional adjustments or changes are required to identify the boundaries of the immiscibility dome and how location within the immiscibility dome influences pore size and/or pore size distribution upon heat treatment around the LDRD-1 baseline composition. A number of questions were raised, such as, i) Does the LDRD-1 baseline fall within the center of the immiscibility dome or near an edge? ii) What is the magnitude of the compositional changes that can be used to gauge how large (or how small) the immiscibility region is for the system of interest?

It was anticipated that small composition changes to the baseline glass would have significant effects on the ability to produce HGMs, much less than the ability to remain within the spinodal decomposition region required to make PWHGMs. For example, minor changes to $\mathrm{SiO}_{2}$ and/or fluorine (F) could result in significant differences in viscosity and could impact either the ability to produce HGMs or have a significant impact on the size of the HGMs. As another example, minor changes in the blowing agent (i.e., the component providing the gas source to blow a glass bubble or HGM during the flame forming process)), composition or concentration could have an impact. Therefore, one of the initial challenges to the program was the definition of specific glass compositions that would be extreme enough to define boundaries of the immiscibility dome while minimizing the potential to produce a test matrix that would yield very little insight into the key objectives of the program. It should be mentioned that due to programmatic budget constraints only a limited number of glasses were developed and tested, so a detailed mapping of the immiscibility region was not feasible.

Figure 3 (a) and (b) demonstrates the challenge of defining the immiscibility dome of the LDRD-1 baseline glass system. ${ }^{8}$ As previously mentioned, the LDRD-1 glass (shown as a blue point) is known to lie within the spinodal decomposition region of the immiscibility dome. The exact location of LDRD-1 within the multi-component glass system; however, is unknown. Assuming LDRD-1 is centrally located (Figure 3 (a)), "symmetric compositional changes" to the baseline glass could result in a high number of glasses which would ultimately provide insight into the shape and/or location of the immiscibility dome. If the LDRD-1 baseline composition lies near an edge (Figure 3 (b)), then applying those same "symmetric compositional changes" could result in a large portion of the glasses falling outside the immiscibility dome altogether. Again, the initial challenge to the LDRD program was the strategy taken to define the compositional changes to be made to the LDRD-1 
baseline glass to balance the desire to map the immiscibility region without compromising or producing a large fraction of glasses that would be of little value to programmatic objectives. Determining how far one can modify the compositions to identify that boundary, while limiting the number of glasses within the nucleation and growth region is a significant challenge, especially in a multi-component glass system.

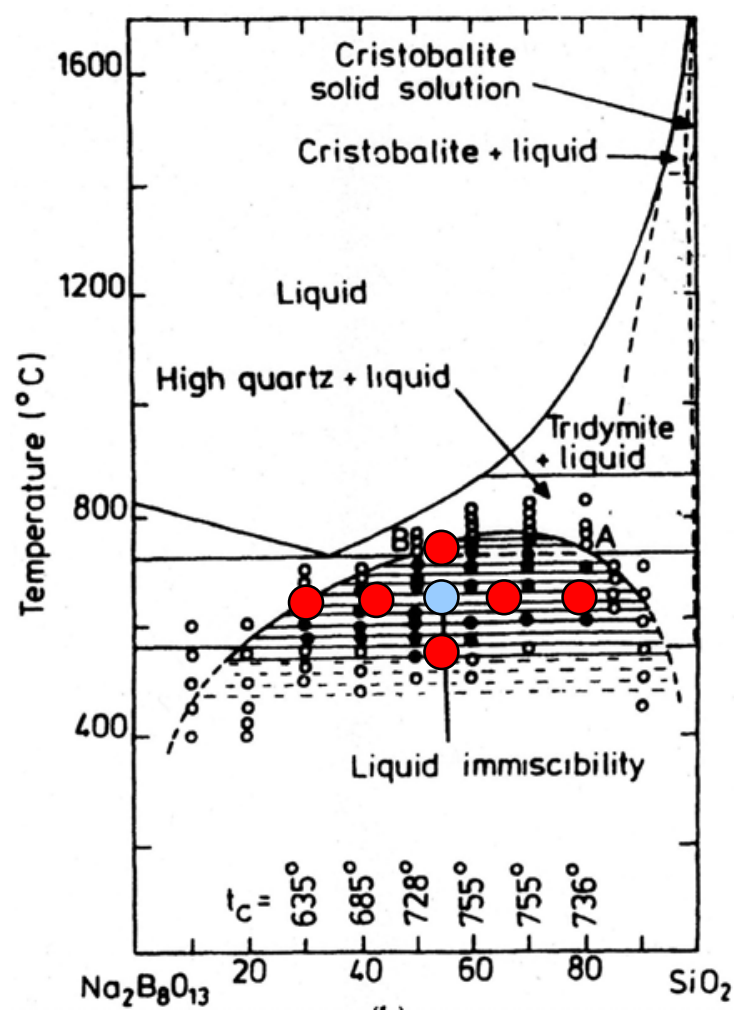

(a)

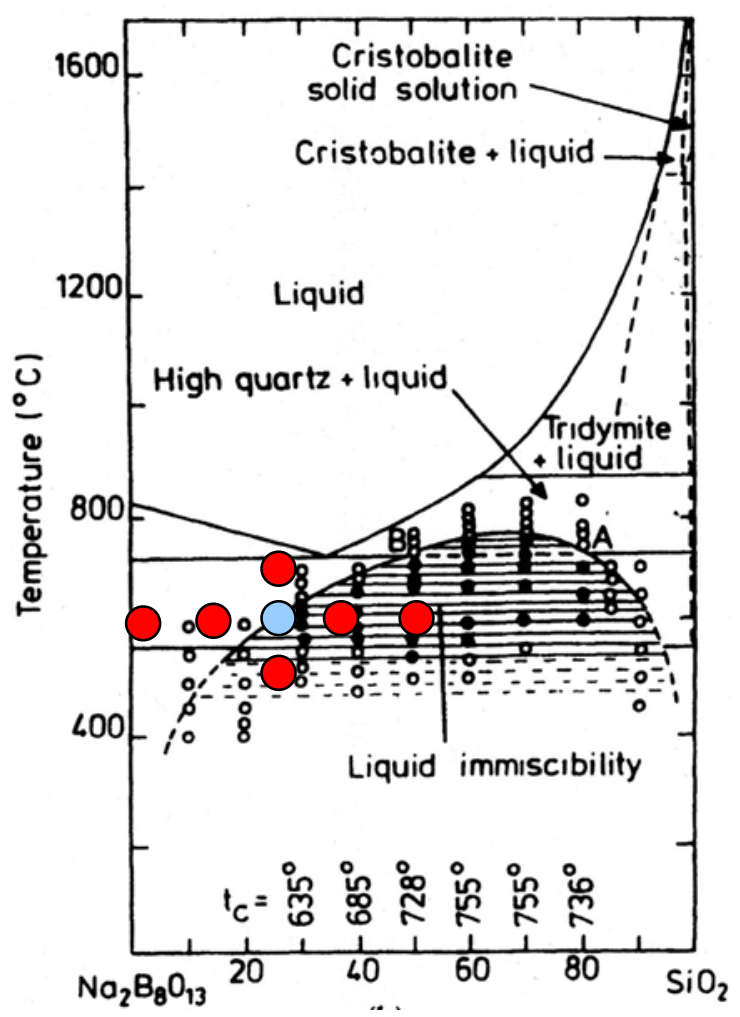

(b)

Figure 3. Simplistic view of mapping a two component immiscibility dome. Note: LDRD compositions are located within a multi-component immiscibility dome.

The selection strategy was based on the fact that two of the primary chemical parameters for porous glass production are the silica concentration and the molar $\mathrm{B} / \mathrm{R}$ ratio, which is the ratio of the $\mathrm{B}_{2} \mathrm{O}_{3}$ content and the alkali oxide content $\left(\mathrm{R}_{2} \mathrm{O}\right)$. For the LDRD task, the $\mathrm{R}_{2} \mathrm{O}$ components are $\mathrm{Na}_{2} \mathrm{O}$ and $\mathrm{Li}_{2} \mathrm{O}$.

Varying the silica concentration in the glass causes the concentration of the leachable alkali borate phase in the glass to vary in the opposite direction. In general, the silica concentration should be between about $60 \mathrm{wt} \%$ and $75 \mathrm{wt} \%$ of the glass. In the simple $\mathrm{R}_{2} \mathrm{O}-\mathrm{B}_{2} \mathrm{O}_{3}-\mathrm{SiO}_{2}$ system, the molar $\mathrm{B} / \mathrm{R}$ ratio controls the ability to form the two continuous phases, and molar ratios between about 3:1 and 5:1 are possible. 9 The substitution of $\mathrm{Li}_{2} \mathrm{O}$ for $\mathrm{Na}_{2} \mathrm{O}$ somewhat expands this Vycor ${ }^{\mathrm{TM}}$ phase separation region. LDRD-1 has a molar $\mathrm{B} / \mathrm{R}$ ratio of only about $2: 1$, but has surprisingly been shown to exhibit phase separation. This may be due to the influence of the $\mathrm{Li}_{2} \mathrm{O}$ and other components such as $\mathrm{ZnO}, \mathrm{F}$, and $\mathrm{P}_{2} \mathrm{O}_{5}$ on the immiscibility 
dome. Thus, the need to define the compositional bounds that define the distorted phase separation region within the glass system of interest is centered about the baseline composition of LDRD-1.

Given the significance of the $\mathrm{SiO}_{2}$ concentration and the molar $\mathrm{B} / \mathrm{R}$ ratio on the immiscibility dome, these two parameters have been varied while holding the concentration (weight percent [wt\%]) of the "minor" components constant in the LDRD test matrix. As previously mentioned, it is probable that dramatic compositional changes would reduce the ability to form HGMs and/or push the glass into the nucleation and growth region and defeat the ability of the HGM to accept materials into its core (i.e., no development of interconnected porosity). Therefore, the compositional changes made in this study around the baseline LDRD-1 glass were based on glass science knowledge and model predictions related to viscosity.

Table 2 shows the nominal LDRD glass compositions developed to investigate the immiscibility dome. The compositions shown in Table 2 are approximate compositions on a weight percent oxide basis. HGMA and LDRD-1 are considered "baseline" glasses and were carried forward to provide comparative characterization data from an HGM forming perspective. The HGMA glass is not expected to demonstrate phase separation, but will produce HGMs. Again, the LDRD-1 glass is the baseline glass known to phase separate and produce PWHGMs from previous studies. ${ }^{2}$

Table 2. Approximate Compositions (wt\%) of LDRD Test Matrix Glasses and "Charles" Glasses

\begin{tabular}{|c|c|c|c|c|c|c|}
\hline \multirow{2}{*}{\multicolumn{2}{|c|}{ Glass ID }} & \multicolumn{4}{|c|}{ Weight Percent } & \multirow{3}{*}{$\begin{array}{c}\begin{array}{c}\text { Molar } \\
\text { B/R }\end{array} \\
0.49\end{array}$} \\
\hline & & \multirow{2}{*}{$\begin{array}{c}\mathrm{SiO}_{2} \\
69\end{array}$} & \multirow{2}{*}{$\frac{\mathbf{B}_{\mathbf{2}} \mathbf{O}_{3}}{7}$} & \multirow{2}{*}{$\begin{array}{c}\mathbf{R}_{\mathbf{2}} \mathbf{O} \\
13\end{array}$} & \multirow{2}{*}{$\begin{array}{c}\text { minor } \\
11\end{array}$} & \\
\hline HGMA & Commercial & & & & & \\
\hline LDRD-1 & Baseline & 60 & 22 & 7 & 11 & 1.94 \\
\hline LDRD-2 & $+3 \mathrm{SiO}_{2}$ & 63 & 20 & 6 & 11 & 1.94 \\
\hline LDRD-3 & $+6 \mathrm{SiO}_{2}$ & 66 & 18 & 5 & 11 & 1.94 \\
\hline LDRD-4 & $-3 \mathrm{SiO}_{2}$ & 57 & 24 & 8 & 11 & 1.94 \\
\hline LDRD-5 & $-6 \mathrm{SiO}_{2}$ & 54 & 27 & 8 & 11 & 1.94 \\
\hline LDRD-6 & $\mathrm{B} / \mathrm{R}+\mathbf{0 . 5}$ & 60 & 23 & 6 & 11 & 2.44 \\
\hline LDRD-7 & B/R -0.5 & 60 & 20 & 9 & 11 & 1.44 \\
\hline Charles & \multirow{3}{*}{ Literature } & 61 & 29 & 10 & 0 & 2.64 \\
\hline Charles+S & & 61 & 29 & 9 & 1 & 2.64 \\
\hline Charles $+S+F$ & & 60 & 28 & 10 & 2 & 2.64 \\
\hline
\end{tabular}

The $\mathrm{SiO}_{2}$ content of LDRD-2 through LDRD-5 was varied from 54 to $66 \mathrm{wt} \%$, while maintaining a constant concentration of the minor components $\left(\mathrm{CaO}, \mathrm{F}, \mathrm{ZnO}, \mathrm{P}_{2} \mathrm{O}_{5}\right.$, and $\left.\mathrm{SO}_{3}\right)$ and a constant molar $\mathrm{B} / \mathrm{R}$ ratio of 1.94. For each composition, the $\mathrm{B}_{2} \mathrm{O}_{3}$ and $\mathrm{R}_{2} \mathrm{O}\left(\mathrm{Na}_{2} \mathrm{O}\right.$ and 
$\mathrm{Li}_{2} \mathrm{O}$ ) contents were adjusted to maintain an overall $100 \mathrm{wt} \%$ oxide basis. Holding the minor components constant at a level known to produce HGMs eliminates one variable, thus increasing the likelihood of success to compositionally map the immiscibility dome.

The molar B/R ratio was varied from approximately 2.5 to 1.5 in LDRD-6 and LDRD-7, respectively, while maintaining constant concentrations of $\mathrm{SiO}_{2}$ and minor components. These glasses should demonstrate (provide insight into) the influence of the molar $\mathrm{B} / \mathrm{R}$ ratio on the phase separation properties. $\mathrm{A} \pm 0.5$ change in the molar $\mathrm{B} / \mathrm{R}$ ratio was thought to be sufficient to meet the stated objectives. Again, the challenge was to select a compositional space that is covered within the allotted funding without compromising the ability to meet the stated objectives.

The final series of glasses (referred to as "Charles") are based on a simple, but well documented phase separable glass obtained from literature. ${ }^{10}$ These compositions are of special interest because of the relatively large scale of the phase separated regions. These glasses phase separate into two continuous phases with approximate diameters between 0.25 to $2.0 \mu \mathrm{m}$, depending on the composition, and heat treatment temperature and time. Heat treatment of the glass at temperatures above $650^{\circ} \mathrm{C}$ tends to convert the microstructure from continuous phase separation to droplet formation. This glass was further modified by the addition of $\mathrm{SO}_{3}$ and/or $\mathrm{F}$, while keeping the $\mathrm{B} / \mathrm{R}$ molar ratio fixed with respect to the original "Charles" glass. The addition of $\mathrm{SO}_{3}$ and/or $\mathrm{F}$ is thought to increase the probability of producing HGMs and/or PWHGMs and, if successful, could lead to a much simpler glass composition for certain applications. The primary intent of the "Charles" glasses was to assess the ability to produce HGMs and, if successful, evaluate the anticipated larger microstructure on the ability to produce PWHGMs.

Based on initial results $\mathrm{b}^{\mathrm{b}}$, an additional set of four glasses (referred to as the "zero glasses") were developed to perform a one-at-a-time component study to identify the impact of the minor components on HGM yield. ${ }^{c}$ The "zero glasses" are based on the LDRD-1 composition with one of the minor components, either $\mathrm{CaO}, \mathrm{ZnO}, \mathrm{P}_{2} \mathrm{O}_{5}$, or F, omitted from the original composition. The baseline $\mathrm{SiO}_{2}$ and molar $\mathrm{B} / \mathrm{R}$ ratio were renormalized to compensate for the omitted minor component. The approximate compositions are listed in Table 3. The baseline composition (LDRD-1) has been provided for reference.

\footnotetext{
${ }^{\mathrm{b}}$ The HGM yield of the Charles S+F glass was so poor (0.47\%) that no further HGM/PWHGM work was done with the "Charles" glasses.

${ }^{\mathrm{c}}$ Due to programmatic constraints, only HGM yield was assessed for the "zero glasses." Recommendations to assess the compositional impacts on the resulting microstructures would be warranted in further studies.
} 
Table 3. Chemical Compositions of the "Zero Glasses"

\begin{tabular}{|c|c|c|c|c|c|}
\hline \multirow{2}{*}{ Glass ID } & \multirow{2}{*}{$\begin{array}{c}\text { Omitted minor } \\
\text { component }\end{array}$} & \multicolumn{4}{|c|}{ Weight Percent } \\
\cline { 3 - 6 } & $\mathbf{S i O}_{\mathbf{2}}$ & $\mathbf{B}_{\mathbf{2}} \mathbf{O}_{\mathbf{3}}$ & $\mathbf{R}_{\mathbf{2}} \mathbf{O}$ & Minor \\
\hline LDRD-1 & $\mathrm{NA}$ & 60 & 22 & 7 & 11 \\
\hline Zero-1 & $\mathrm{CaO}$ & 64 & 24 & 7 & 5 \\
\hline Zero-2 & $\mathrm{ZnO}$ & 61 & 23 & 7 & 9 \\
\hline Zero-3 & $\mathrm{P}_{2} \mathrm{O}_{5}$ & 60 & 22 & 7 & 11 \\
\hline Zero-4 & $\mathrm{F}$ & 61 & 23 & 7 & 9 \\
\hline
\end{tabular}

\subsection{Experimental Procedure}

\subsection{Glass Fabrication}

In general, each LDRD test matrix glass, "Charles" glass, and "zero glass" were prepared using reagent-grade metal oxides, carbonates, $\mathrm{H}_{3} \mathrm{BO}_{3}$, and salts to yield approximately 600 grams of glass using standard batching and melting procedures. The raw materials were thoroughly mixed and placed into two $95 \%$ platinum / 5\% rhodium, $600 \mathrm{~mL}$ crucibles. The crucibles were placed into a furnace at room temperature and the temperature was linearly ramped to $1300^{\circ} \mathrm{C}$. After an isothermal hold at $1300^{\circ} \mathrm{C}$ for 1 to 3 hours, the crucibles were removed from the furnace and the glasses were poured onto a clean, stainless steel plate and allowed to air cool (quench). The glasses were crushed, blended together, placed into a single $600 \mathrm{~mL}$ crucible and re-melted at $1300^{\circ} \mathrm{C}$ for 1 hour to promote homogeneity in the final glass. After the final melt, the glass was poured onto a clean, stainless steel plate and allowed to air cool on the plate. " The "zero glasses" were heated from room temperature to $1300^{\circ} \mathrm{C}$; however, the isothermal hold was for 3 hours and there was no re-melt. Like the LDRD test matrix glasses, these glasses were also poured onto a stainless steel plate and allowed to air cool (quench).

\subsection{HGM Fabrication}

\subsubsection{Feed Preparation}

Glass from the final pour patty was reduced to a granular size similar to sugar, using a hammer and stainless steel plate. For further particle size reduction, the granular glass material was either placed in a mechanical grinder for 10 minutes or a ball mill with alumina media for several hours to make glass powder. If a ball mill was used, the glass powder was separated from the ball media using a $595 \mu \mathrm{m}$ screen. The glass powder was sieved through two different sized sieves, $63 \mu \mathrm{m}$ and $44 \mu \mathrm{m}$ mesh screens. The materials passing through

\footnotetext{
${ }^{\mathrm{d}}$ To support preliminary assessments of the immiscibility dome, glass discs or plates were produced by pouring a portion of the glass into a stainless steel mold where it was pressed into a thin disc of about 2 inch diameter and $1 / 8$ th to $1 / 4$ inch thick. The mold/plunger provided the initial quench, after which time the samples were air cooled. The glass melt was reheated and additional discs prepared. The discs were broken into fragments and portions heated for the appropriate heat treatment temperatures and times.
} 
the $44 \mu \mathrm{m}$ screen were further processed to narrow the particle size distribution (PSD). The fine particles $(<10 \mu \mathrm{m})$ were removed from this feed material using six decantations in water allowing 10 minutes between each decantation for particle settling. If needed, a surfactant was added to the $10-44 \mu \mathrm{m}$ particles to improve dispersion. The final feed material (10$44 \mu \mathrm{m}$ particles) and fines were separated from the liquid and dried overnight at $90-95^{\circ} \mathrm{C}$. The $10-44 \mu \mathrm{m}$ glass powder was used as the feed for HGMs production.

\subsubsection{Flame Process and HGM Separation}

This unit operation converts the pre-screened glass feed materials into HGMs followed by a separation process. In general, $50-100 \mathrm{~g}$ of sized feed material $(10-44 \mu \mathrm{m})$ are fed into a flame forming process during which the particles are heated, gas evolution occurs, thus expanding the particles. HGMs are formed based on a complex relationship among glass composition, viscosity and the gas source. To the extent possible, forming conditions, such as powder feed rate, gas/air ratio, and quench water flow rate were kept constant throughout the study. HGMs, as well as any other products resulting from the flame process (feed particles, solid glass spheres, broken HGMs or HGM defects), were collected in pails along with the quench water. After the flame forming was complete, the pails were allowed to stand for 10 to 30 minutes to separate the floating HGMs from the sinking/sunken materials. HGMs were collected using a vacuum system and separated using filtration. A surfactant was added to the HGMs prior to vacuum filtration to improve dispersion during the drying sequence. The sunken materials were processed using filtration. Both HGMs and sunken materials were dried overnight at $90-95^{\circ} \mathrm{C}$ in separate containers. HGMs and all sunken materials were weighed after drying. HGM yield is defined as a percentage of the total mass of HGMs recovered from the flame process as shown by:

$$
\text { HGM Yield }(\%)=\frac{H G M s \text { Recovered }(g)}{H G M s+\operatorname{Sinkers}(g)} \cdot 100
$$

A certain degree of error in this calculation exists as material is lost throughout each step of the process (i.e. flame forming process, separation, filtration, drying, etc.). There is a programmatic interest in assessing the potential impacts of compositional effects on HGM yield given certain applications may be driven strictly by HGM/PWHGM yield (regardless of pore size or volume). It is anticipated that the compositional changes for the test matrix glasses will have a significant effect on glass viscosity (see Section 4.1.3), which could in turn could have dramatic impacts on the yields of HGM production (see Section 4.2.1).

\subsection{Heat Treatment}

To support preliminary assessments, isothermal heat treatments of bulk glass disks were conducted for 8 and 24 hours at $580^{\circ} \mathrm{C}, 600^{\circ} \mathrm{C}$ and $620^{\circ} \mathrm{C}$. The impacts of heat treatment (time or temperature) could also be assessed through parametric studies on phase separated glass plates. Developing relationships among composition, heat treatment, and microstructures on glass forms other than HGMs or PWHGMs does have technical risks given potentially significant differences in formation and production kinetics. Although these risks exist, limited testing was performed on the bulk glass plates to identify if 
differences among bulk plates, HGMs, and/or PWHGM microstructures exist. If no differences exist, then future studies could benefit by avoiding the fabrication costs of HGM and PWHGM to assess compositional and/or heat treatment effects on the resulting microstructure.

HGMs were treated for 8 and 24 hours at $600^{\circ} \mathrm{C}$, while only select HGM samples were also treated at $580^{\circ} \mathrm{C}$. Higher heat treatment temperatures (e.g. $620^{\circ} \mathrm{C}$ ) for HGMs were initially tried, but were avoided due to the formation of HGM agglomerates (bonding among the individual HGMs) that could not be separated without creating additional breakage. After each heat treatment, HGMs were allowed to air cool and screened to less than $177 \mu \mathrm{m}$. It should be noted that not all HGMs were heat treated; non-heat treated (as-fabricated) samples of each composition were kept for acid leaching in order to determine if PWHGMs could be formed (i.e., does one have to implement a heat treatment unit operation in order to make PWHGMs?).

\subsection{PWHGM Preparation}

A summary of the composition and heat treatment conditions used to make PWHGMs (denoted by a $\checkmark$ ) is shown in Table 4. Non-heat treated or heat treated HGMs were processed in warm hydrochloric acid solution, followed by a wash using tap water to remove acid. Any HGMs that remained floating after the acid treatment were collected prior to washing with water, leaving only the PWHGMs (sinking particles) in the vessel; development of pores within the wall due to acid leaching causes the interior void space to become filled with liquid, thus forcing the PWHGM to sink. The PWHGMs were then processed with dilute sodium hydroxide solution in an attempt to remove any reaction layer that had formed during the acid leaching process. The final step consisted of a rinse with deionized water. HGMs were removed by decantation and separated by vacuum filtration. HGMs and PWHGMS were dried overnight at $90-95^{\circ} \mathrm{C}$. PWHGM yield is defined as the percentage of PWHGMs recovered from the acid leaching process as shown by

$$
\text { PWHGM Yield }(\%)=\frac{\text { PWHGMs Recovered }(g)}{\text { Initial Amount of HGMs }(g)} \cdot 100
$$

As in the HGM yield calculation, there is also some uncertainty in this yield equation as there is loss of material during leaching, separations and drying. 
Table 4. Composition and Heat Treatment Conditions Used to Make PWHGMs

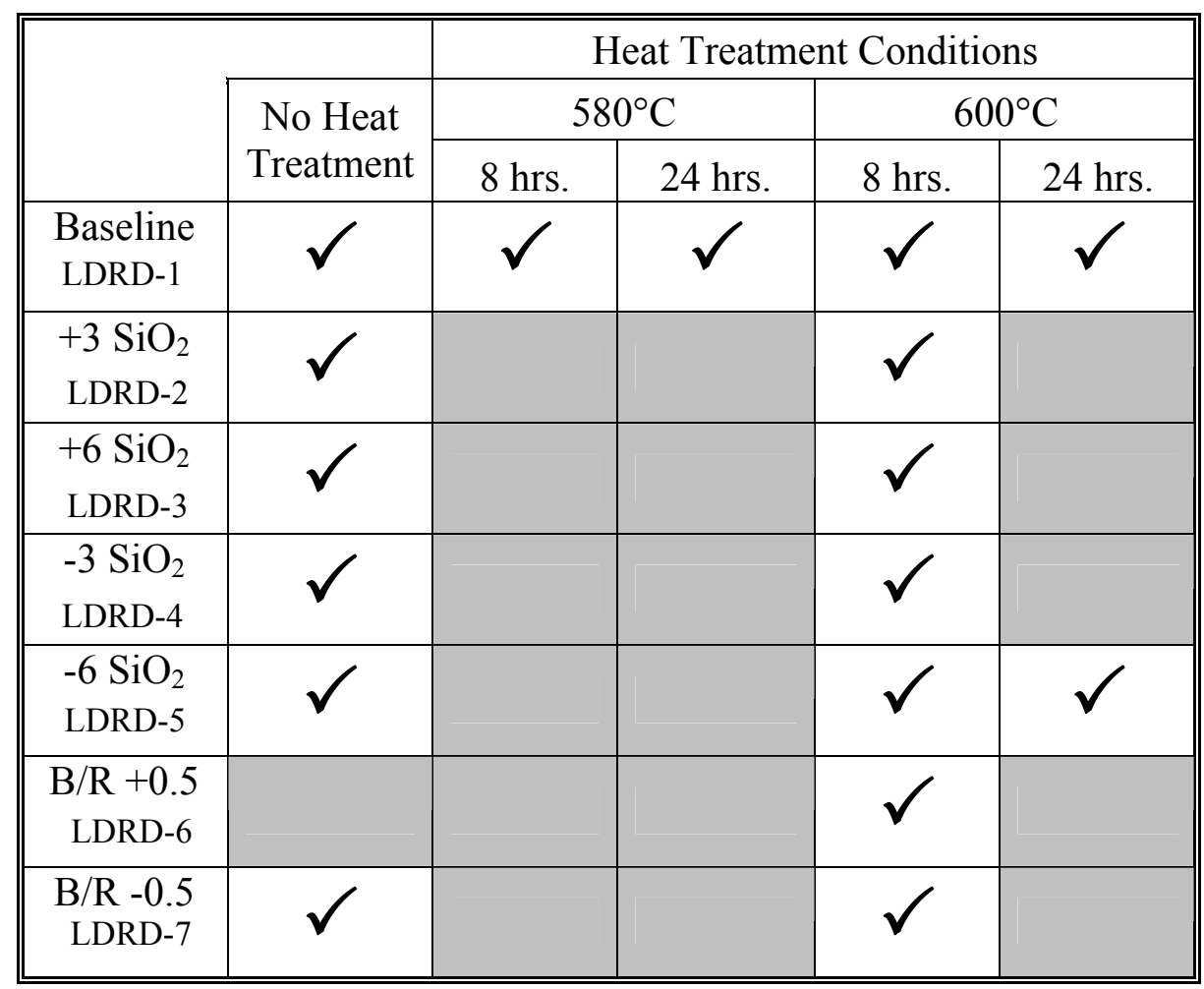

\subsection{Compositional Analysis}

Samples of each LDRD test matrix glass, taken from the pour patty (as-fabricated glass), were submitted to the SRNL Process Science Analytical Laboratory (PSAL) for chemical analysis using two dissolution techniques, sodium peroxide fusion with a hydrochloric acid (HCl) take-up (PF) and lithium-metaborate (LM) fusion. Each glass was prepared in duplicate for each dissolution technique. All of the prepared samples were analyzed (twice for each element of interest) by Inductively Coupled Plasma - Atomic Emission Spectroscopy (ICP-AES). Elemental F content was determined via sodium peroxide fusion with a water $\left(\mathrm{H}_{2} \mathrm{O}\right)$ take-up (PFW) and Ion Chromatography (IC). Due to financial resources, time restraints and limited sample, analysis was not performed on HGMs or PWHGMs.

The intent of this analysis was to verify if there were any compositional differences between the targeted and the "as-fabricated" glasses. These analyses provide a technical basis that the starting glass materials (feed stock to the flame forming process) meet the glass selection strategy. It is noted, that a compositional trace of the materials resulting from each step of the process (as fabricated glass or feed stock, HGMs, and PWHGMs) would be required to monitor the compositional changes that occur during each unit operation. For example, assuming the as-fabricated glass (or flame forming feed stock) met targeted compositions, there is the possibility of composition changes when the feed stock is processed through the flame forming system. Any changes to the HGM glass composition could then have an impact on the links or discussions regarding compositional impacts on the PWHGM systems 
and the placement or position of each glass within the immiscibility dome.

\subsection{X-ray Diffraction}

Samples of the original as-fabricated LDRD test matrix glasses were submitted for X-ray diffraction (XRD) analysis. Each sample was measured between 3 and $70^{\circ} 2 \theta$, with a $0.02^{\circ} 2 \theta$ step size and 1 second dwell time. The XRD results would identify any crystallization in the feed stock materials which could in turn have negative impacts on HGM and/or PWHGM production. It should be emphasized that the presence of amorphous phase separation is not detected by XRD analysis.

\subsection{Viscosity}

Viscosity was measured as a function of temperature using a Brookfield DV-II+ high temperature spindle viscometer for each as-fabricated LDRD test matrix glass. The measurements were obtained using standard procedures, which are compliant with ASTM C $965-81 .{ }^{11}$

In general, the glass was heated to $\sim 1200^{\circ} \mathrm{C}$ or $\sim 1250^{\circ} \mathrm{C}$ in a platinum alloy crucible and maintained until thermal equilibrium was achieved. An initial torque reading (at a constant spindle speed) was taken at this temperature with subsequent measurements at both higher and lower temperatures ranging from $\sim 1050^{\circ} \mathrm{C}$ to $1300^{\circ} \mathrm{C}$ using a hysteresis approach (to the extent possible). The hysteresis approach provides the opportunity to detect any issues associated with either volatilization and/or devitrification over the temperature range of interest. For example, assume the initial measurement was at $1200^{\circ} \mathrm{C}$ followed by multiple higher temperature measurements. Prior to going to temperatures less than $1200^{\circ} \mathrm{C}$, a second measurement was obtained at $1200^{\circ} \mathrm{C}$ to assess the potential impacts of volatility. If significant volatility occurred, then the second measurement at $1200^{\circ} \mathrm{C}$ would not be consistent with the initial measurement, leading to questionable data. Note that the temperature range over which viscosity measurements were taken is rather limited (i.e., no measurements was performed above the $1300^{\circ} \mathrm{C}$ melt temperature). This is a result of an upper temperature limit of the viscometer of approximately $1300^{\circ} \mathrm{C}$. A glass viscosity standard was used to determine the geometric constant of the spindle/cup based on torque and speed. This constant is corrected for temperature effects.

\subsection{Density}

The true density of the HGMs was measured using gas pycnometry under a nitrogen atmosphere with a Quantachrome Stereopycnometer. The system was calibrated before each set of measurements using a stainless steel sphere of known volume supplied by the manufacturer (volume $=56.559 \mathrm{~cm}^{3}$ ). Three measurements were collected for each sample, the average of these measurements being the true particle (HGM) density. 
WSRC-STI-2007-00605

Revision 0

\subsection{Particle Size Distribution of HGMs}

A sample of known mass ( $\sim \mathrm{g})$ was separated using $106 \mu \mathrm{m}, 90 \mu \mathrm{m}, 75 \mu \mathrm{m}, 53 \mu \mathrm{m}, 45 \mu \mathrm{m}$ and $38 \mu \mathrm{m}$ ASTM screens using an ATM Ultrasonic Sifter for 5 minutes, with automatic amplitude pulses. Use of too much sample could result in blockages in the screens, impacting the PSD. An amplitude pulse setting of 8 was used for all samples. The PSD was determined from the amount of material remaining in each screen divided by the starting mass.

\subsection{Scanning Electron Microscopy}

Scanning electron microscopy (SEM) was performed at the electron microscopy laboratory at the Advanced Materials Research Laboratory (ARML) at Clemson University. Various methods of sample preparation as well as two different scanning electron microscopes were used for the analyses of glass plates, HGMs, and PWHGMs as described in the following sections.

\subsubsection{Glass Plates}

Glass discs or plates of baseline, $+6 \mathrm{SiO}_{2}$ (LDRD-3), $-6 \mathrm{SiO}_{2}$ (LDRD-5), $\mathrm{B} / \mathrm{R}+0.5$ (LDRD-6) and $\mathrm{B} / \mathrm{R}-0.5$ (LDRD-7) compositions were sent in the as-fabricated state to Clemson's ARML. Preparation of the glass plates at the ARML included polishing and sputter coating samples with a thin layer of platinum ( $\sim 400-600 \mathrm{~nm}$ thick) to reduce charging effects. The glass plates were viewed with a high resolution Hitachi 4800 Field Emission Scanning Electron Microscope (FESEM). A $5.0 \mathrm{kV}$ acceleration voltage was used for a majority of the glass plates; however, this value was reduced to $1.0 \mathrm{kV}$ if there was significant sample charging.

\subsubsection{HGMs/PWHGMs}

Microscopy analysis of HGMs and PWHGMs were performed under two types of sample preparation and two different microscopes at Clemson.

\subsubsection{Hitachi 4800 Field Emission Scanning Electron Microscope}

Whole HGMs/PWHGMs were gently sprinkled on a sample stub covered with conductive carbon tape. To assess or gain insight into wall thickness and morphologies of the inner and outer surfaces, additional HGMs/PWHGMs were broken between a hard surface and a glass slide. These broken HGMs/PWHGMs were also sprinkled onto a sample stub covered with carbon tape. Samples were sputter coated with a thin layer of platinum $(\sim 400-600 \mathrm{~nm}$ thick) to reduce charging. A $5.0 \mathrm{kV}$ acceleration voltage was used.

\subsubsection{Hitchachi HD2000 Scanning Transmission Electron Microscope}

The PWHGMs were placed in BEEM ${ }^{\circledR} 7 \mathrm{~mL}$ Embedding Capsules with Conical Tip. LR 
White $^{\mathrm{TM}}$ Medium Grade Acrylic Resin, kept at a temperature of $0-4^{\circ} \mathrm{C}$ to prevent polymerization, was poured over the PWHGMs in the capsule. Samples were kept at $0-4^{\circ} \mathrm{C}$ for $1-2$ days to prevent polymerization and allow the resin to completely fill the pores of the PWHGMs. The sample capsules were then placed in an oven at $60^{\circ} \mathrm{C}$ for approximately 8 hours to cause the resin to polymerize. The capsule was removed and the resin sample was cut at a $4^{\circ}$ angle with a diamond knife using a Reichert - Jung UltraCut E Microtome. The slices were approximately $90-100 \mathrm{~nm}$ thick.

\subsection{Porosity Measurements}

Mercury intrusion and extrusion analysis was conducted by Micromeritics Analytical Services on select PWHGMs. ${ }^{12}$ Mercury intrusion porosimetry involves placing the sample in a special sample cup (penetrometer), then surrounding the sample with mercury. Mercury is a non-wetting liquid to most materials and resists entering voids, doing so only when pressure is applied. The pressure at which mercury enters a pore is inversely proportional to the size of the opening to the void. As mercury is forced to enter pores within the sample material, it is depleted from a capillary stem reservoir connected to the sample cup. The incremental volume depleted after each pressure change is determined by measuring the change in capacitance of the stem. This intrusion volume is recorded with the corresponding pressure or pore size. Pore volume distribution of pores was measured between 360 and $0.003 \mu \mathrm{m}$ in diameter.

\subsection{Results and Discussion}

\subsection{Bulk Glass}

\subsubsection{Visual and XRD Analysis}

While the commercial glass (HGMA) and the "Charles" glasses are transparent in the asfabricated state, all of the as-fabricated LDRD glasses (LDRD 1-7) are white and opalescent as shown in Figure 4. Although not shown, the as-fabricated "zero glasses" are similar in appearance to the LDRD 1-7 glasses. The lack of any well-defined peaks in the XRD spectra of HGMA, LDRD matrix glasses and the "Charles" glasses confirm that these are amorphous materials. As all the XRD spectra are the same for the LDRD glasses, an example is shown in Figure 5. The amorphous hump, centered at approximately $22^{\circ} 2 \theta$, is indicative of some atomic short range order and is characteristic of all the LDRD glasses. The white, opalescent nature of the LDRD glasses is a result of amorphous phase separation, which provides some indication of the rapid kinetics. More specifically, these glasses were made by pouring the molten glass onto a stainless steel plate; glass making contact with the plate is initially quenched and the remaining bulk of the glass cools via natural convection and radiative heat transfer. This type of cooling results in the development of the amorphous phase separation in the bulk glasses. The presence of $\mathrm{CaO}$ in the LDRD glasses helps promote larger scale phase separation during cooling. ${ }^{13}$. 


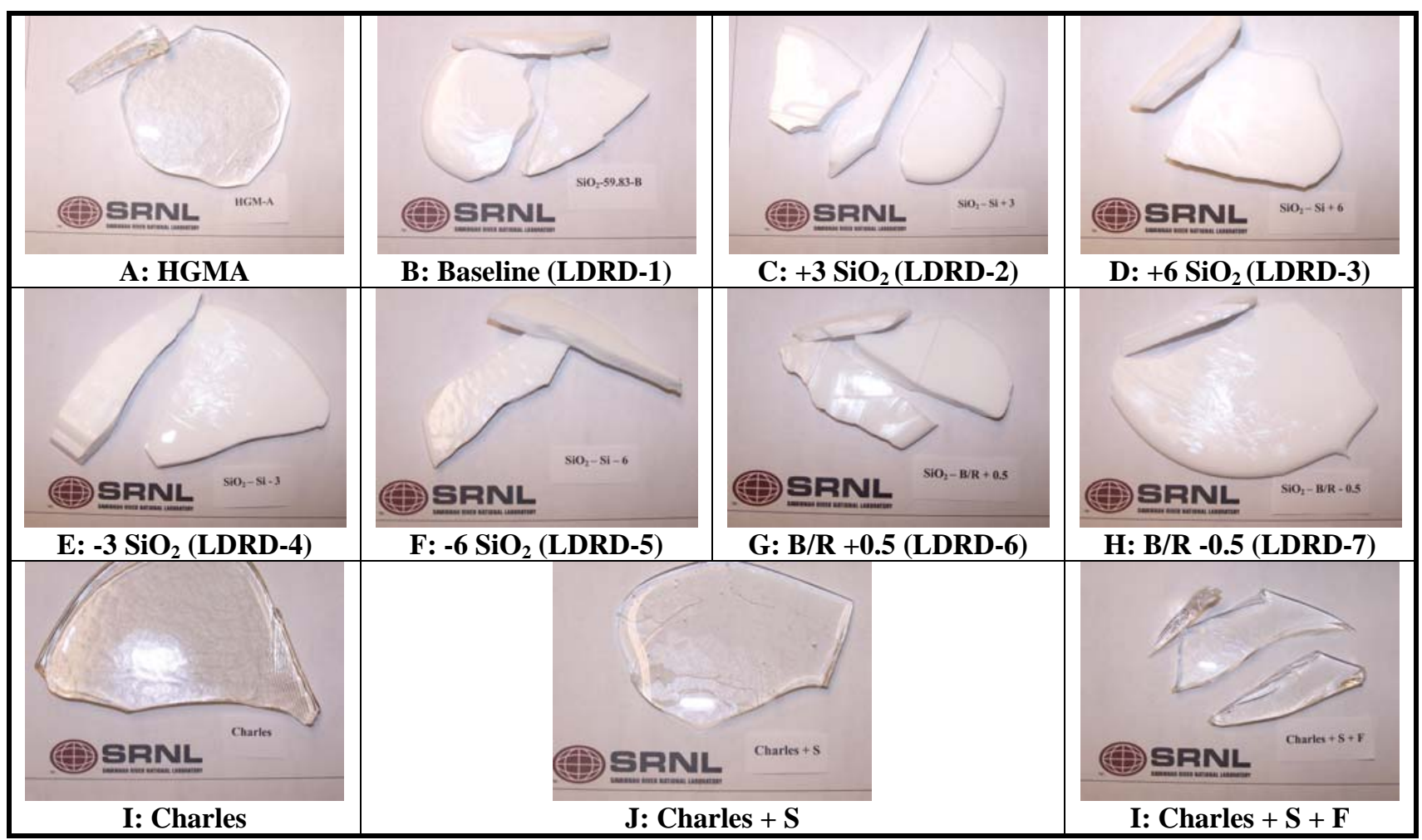

Figure 4. Images of the as-fabricated LDRD glasses.

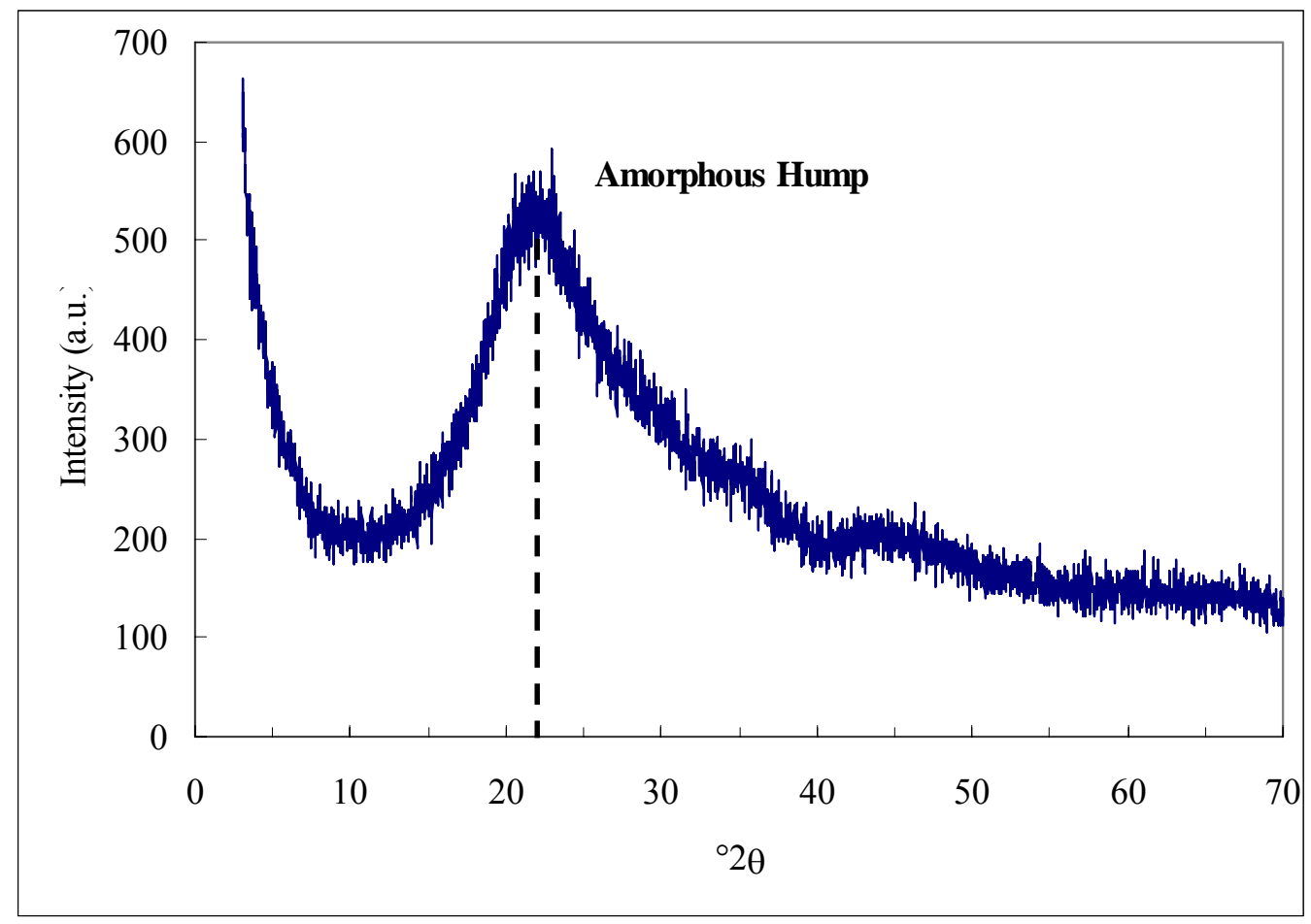

Figure 5. XRD spectrum of the baseline (LDRD-1) glass. 


\subsubsection{Compositional Analysis}

To confirm that the targeted compositions were obtained, a comprehensive statistical analysis regarding the characterization of the initial compositions of the as-fabricated LDRD test matrix glasses was performed. While a detailed assessment of these results is documented in SRNL-SCS-2007-00039, only a short overview is provided in this report. ${ }^{14}$ In general, the measured concentrations (average of four measurements) of the glass components are in good agreement with the target compositions as shown in Table 5. There are disparities in the $\mathrm{SiO}_{2}$ content of some of the compositions, specifically HGMA, -6 $\mathrm{SiO}_{2}$ (LDRD-5) and $\mathrm{B} / \mathrm{R}-0.5$ (LDRD-7). The cause of these errors is unknown at this time, but based on the property data (to be discussed in the following sections) it appears to be related to instrumental and/or experimental error. Ideally, original glasses would be submitted along with the HGMs and PWHGMs to monitor compositional changes throughout each process step. This type of measurement could not be completed due to budget/schedule constraints and the lack of HGMs/PWHGMs samples; however, a previous study monitored compositional changes for a similar baseline composition from HGMs to PWHGMs. The results indicate that significant differences are observed between the feed stock (assuming the as fabricated compositions were in line with target composition) and the resulting HGMs. More specifically, the flame forming process appears to have volatilized significant fractions of alkali and borate - which could shift the location of the target composition within the immiscibility dome. As expected, acid leaching of the HGMs to form PWHGM results in a majority of alkali, alkaline earths and borate being removed (Table 6). ${ }^{2}$ PWHGMs are almost fully composed of silica. Similar results are expected for the LDRD $1-7$ HGMs and PWHGMs.

Table 5. Measured and Target Compositions of the LDRD Glasses

\begin{tabular}{|c|c|c|c|c|c|c|c|c|}
\hline \multirow{3}{*}{ Glass } & \multicolumn{8}{|c|}{ Weight Percent } \\
\hline & \multicolumn{2}{|c|}{$\mathrm{SiO}_{2}$} & \multicolumn{2}{|c|}{$\mathbf{B}_{2} \mathbf{O}_{3}$} & \multicolumn{2}{|c|}{$\mathbf{R}_{2} \mathbf{O}$} & \multicolumn{2}{|c|}{ Minor } \\
\hline & Measured & Target & Measured & Target & Measured & Target & Measured & Target \\
\hline HGMA & 65 & 69 & 8 & 7 & 13 & 13 & 12 & 11 \\
\hline LDRD-1 & 60 & 60 & 21 & 22 & 4 & 4 & 14 & 14 \\
\hline LDRD-2 & 63 & 63 & 19 & 20 & 4 & 4 & 14 & 13 \\
\hline LDRD-3 & 66 & 66 & 18 & 18 & 4 & 3 & 13 & 13 \\
\hline LDRD-4 & 58 & 57 & 23 & 24 & 4 & 4 & 14 & 15 \\
\hline LDRD-5 & 58 & 54 & 27 & 27 & 5 & 5 & 15 & 14 \\
\hline LDRD-6 & 59 & 60 & 22 & 23 & 3 & 3 & 14 & 14 \\
\hline LDRD-7 & 64 & 60 & 20 & 20 & 5 & 5 & 15 & 15 \\
\hline Charles & 62 & 61 & 27 & 29 & 10 & 10 & 1 & $\mathbf{0}$ \\
\hline Charles+S & 62 & 61 & 27 & 29 & 10 & 9 & 1 & 1 \\
\hline Charles + S $+F$ & 61 & 60 & 27 & 28 & 9 & 10 & 2 & 2 \\
\hline
\end{tabular}


WSRC-STI-2007-00605

Revision 0

Table 6. Chemical Composition Comparison of the PDRD Target Glass Composition to the Composition of the HGMs Before and After Acid Leaching

\begin{tabular}{||c|c|c|c||}
\hline \multirow{2}{*}{ Sample } & \multicolumn{3}{|c||}{$\begin{array}{c}\text { Approximate Composition } \\
\text { (wt\%) }\end{array}$} \\
\cline { 2 - 4 } & $\mathrm{SiO}_{2}$ & $\mathrm{~B}_{2} \mathrm{O}_{3}$ & $\mathrm{R}_{2} \mathrm{O}$ \\
\hline Target & 60 & 22 & 7 \\
\hline HGMs & 70 & 16 & 5 \\
\hline PWHGMs & 88 & 5 & 1 \\
\hline
\end{tabular}

Note: Minor components were not measured therefore sum of oxides is $<100 \%$

\subsubsection{Viscosity}

Viscosity curves of the LDRD test matrix glasses are shown in Figures $6-8$. The viscosity curve of the commercial glass (HGMA) is included for reference in each figure as it is known to readily form HGMs. Based on the hysteresis approach, none of the glasses exhibited extensive volatilization or crystallization over the temperature range evaluated. As expected, viscosity decreases with decreasing silica concentration in the LDRD 1-7 glasses. The addition of alkali to vitreous silica reduces the connectivity of the network, thus decreasing the viscosity. Despite the greater silica content of the HGMA glass than all other glasses, the viscosity is still lower than the $+6 \mathrm{SiO}_{2}$ composition (LDRD-3), which may be a result of the total glass former concentration $\left(\mathrm{SiO}_{2}+\mathrm{B}_{2} \mathrm{O}_{3}\right)$. The $+6 \mathrm{SiO}_{2}$ composition (LDRD-3) is high in both $\mathrm{SiO}_{2}$ and $\mathrm{B}_{2} \mathrm{O}_{3}$ with a target total of $84 \mathrm{wt} \%$, as opposed to $76 \mathrm{wt} \%$ for HGMA. Viscosity, in glasses containing two glass formers (i.e. $\mathrm{SiO}_{2}$ and $\mathrm{B}_{2} \mathrm{O}_{3}$ ), has been shown to increase with increasing amounts of the second glassformer. ${ }^{3}$ There are slight variations in the viscosities of the "Charles" glasses, indicating that the addition of $\mathrm{F}$ and $\mathrm{SO}_{3}$ has very little influence on the viscosity for these particular compositions. It is possible that some of the $\mathrm{F}$ and/or $\mathrm{SO}_{3}$ volatilized during melting, however, the results do not indicate considerable differences in the target and measured values. ${ }^{14}$ The viscosity of glasses exhibiting phase separation is a function of the composition and connectivity of each phase. These results suggest that the silica-rich phase is the more highly connected and is the dominant phase in the LDRD 1-7 glasses, as viscosity changes with silica concentration. If, for example, these glasses were in a region of the immiscibility dome where silica droplets existed in a matrix of $\mathrm{B}_{2} \mathrm{O}_{3}$, there would be a considerable drop in viscosity as $\mathrm{B}_{2} \mathrm{O}_{3}$ is much more fluid than $\mathrm{SiO}_{2}$. 


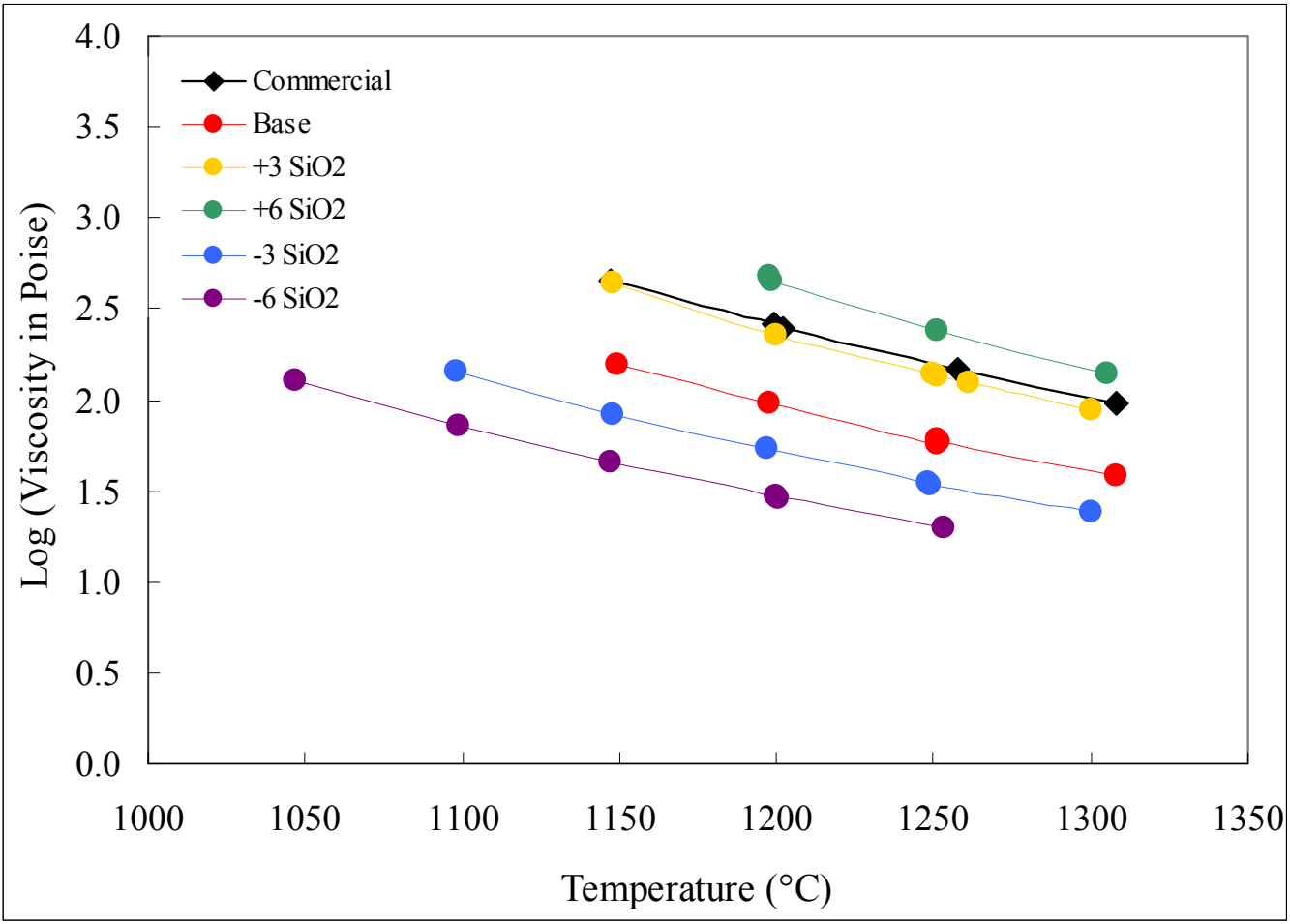

Figure 6. Measured viscosities as a function of temperature for glasses with variations in silica content. Viscosity of the commercial (HGMA) glass is included for reference.

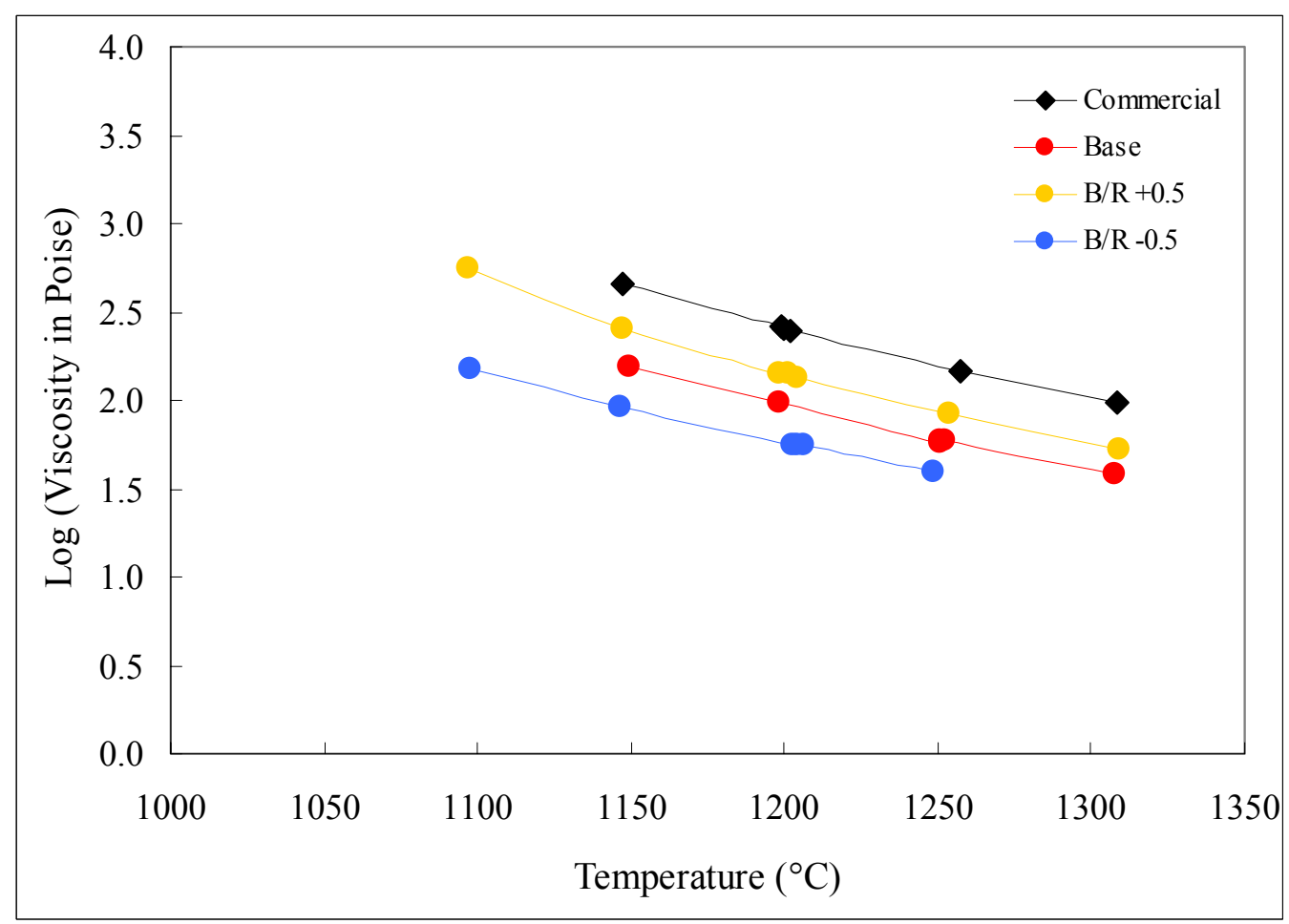

Figure 7. Measured viscosities as a function of temperature for glasses with variations in $\mathrm{B}_{2} \mathrm{O}_{3}$ content. Viscosity of the commercial (HGMA) glass is included for reference. 
WSRC-STI-2007-00605

Revision 0

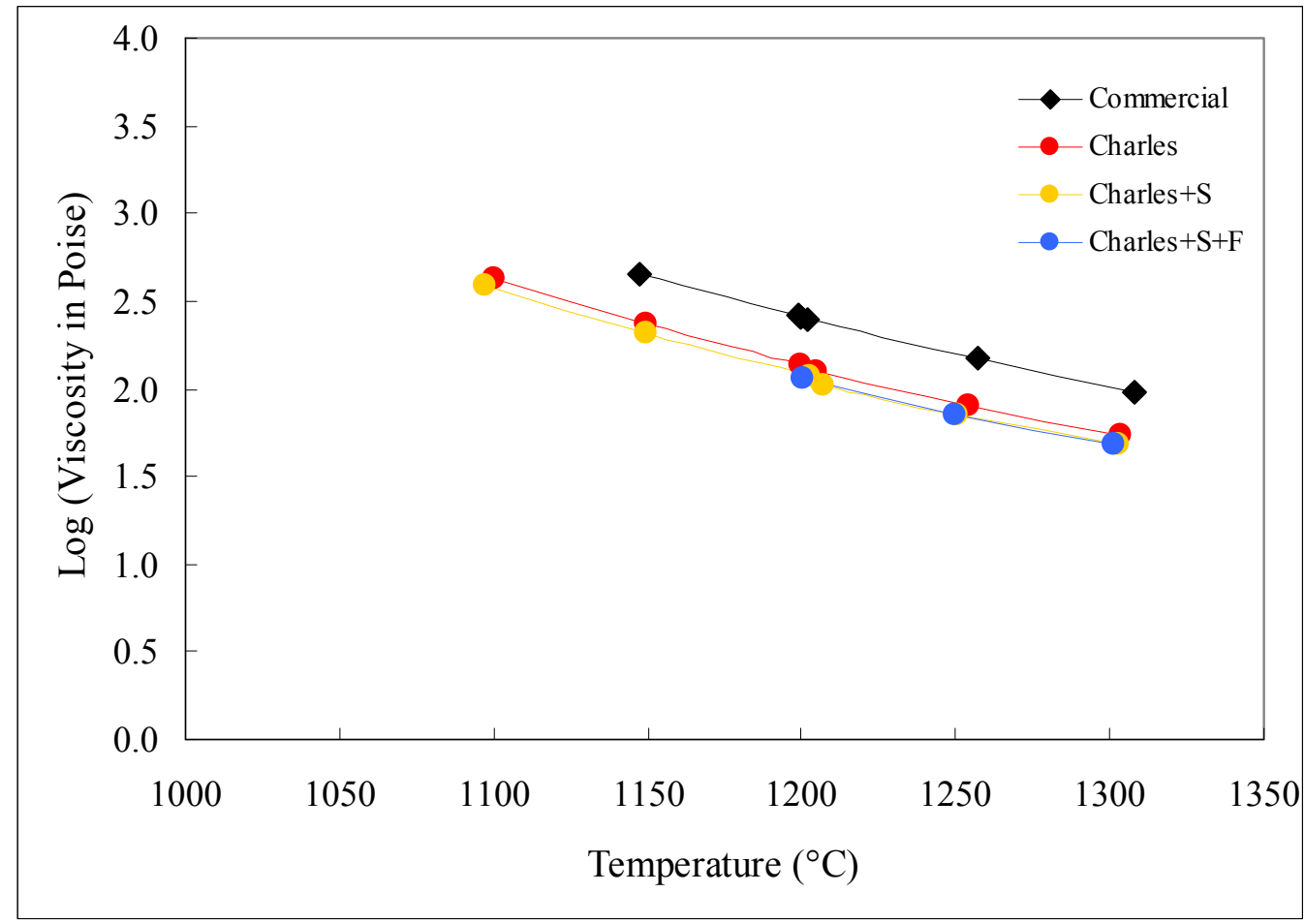

Figure 8. Measured viscosities as a function of temperature for the "Charles" series of glasses. Viscosity of the commercial (HGMA) glass is included for reference. 


\subsubsection{Plate Microstructure}

Images of the as-fabricated baseline (LDRD-1), $+6 \mathrm{SiO}_{2}$ (LDRD-3), $-6 \mathrm{SiO}_{2}$ (LDRD-5), $\mathrm{B} / \mathrm{R}$ +0.5 (LDRD-6) and B/R -0.5 (LDRD-7) glass plates are shown in Figures $9-13$. Micrographs were taken at the same magnification for ease of comparison. It is interesting to note that varying degrees of spinodal decomposition are present in these glasses, which suggests that the kinetics of phase separation are faster than the quench rate. The degree of phase separation appears to be similar for the baseline glass (LDRD-1) and the molar B/R ratio of -0.5 (LDRD-6). Coarsening of the microstructure is observed as the $\mathrm{SiO}_{2}$ content increases and for the molar $\mathrm{B} / \mathrm{R}$ ratio of +0.5 (LDRD-6), while a much finer microstructure is achieved when the $\mathrm{SiO}_{2}$ content is reduced. An example of the impact of both heat treatment time and temperature on microstructure of the $-6 \mathrm{SiO}_{2}$ (LDRD-6) glass is shown in Figure 14. Connectivity and coarsening of the phase separation is evident as heat treatment time and temperatures are increased. Similar results are observed in the other LDRD compositions. The use of higher temperatures increases the energy of the system and thus the diffusion rate, while increasing the heat treatment time allows for more diffusion to occur. This behavior is consistent for other phase separated borosilicate glasses. ${ }^{10}$

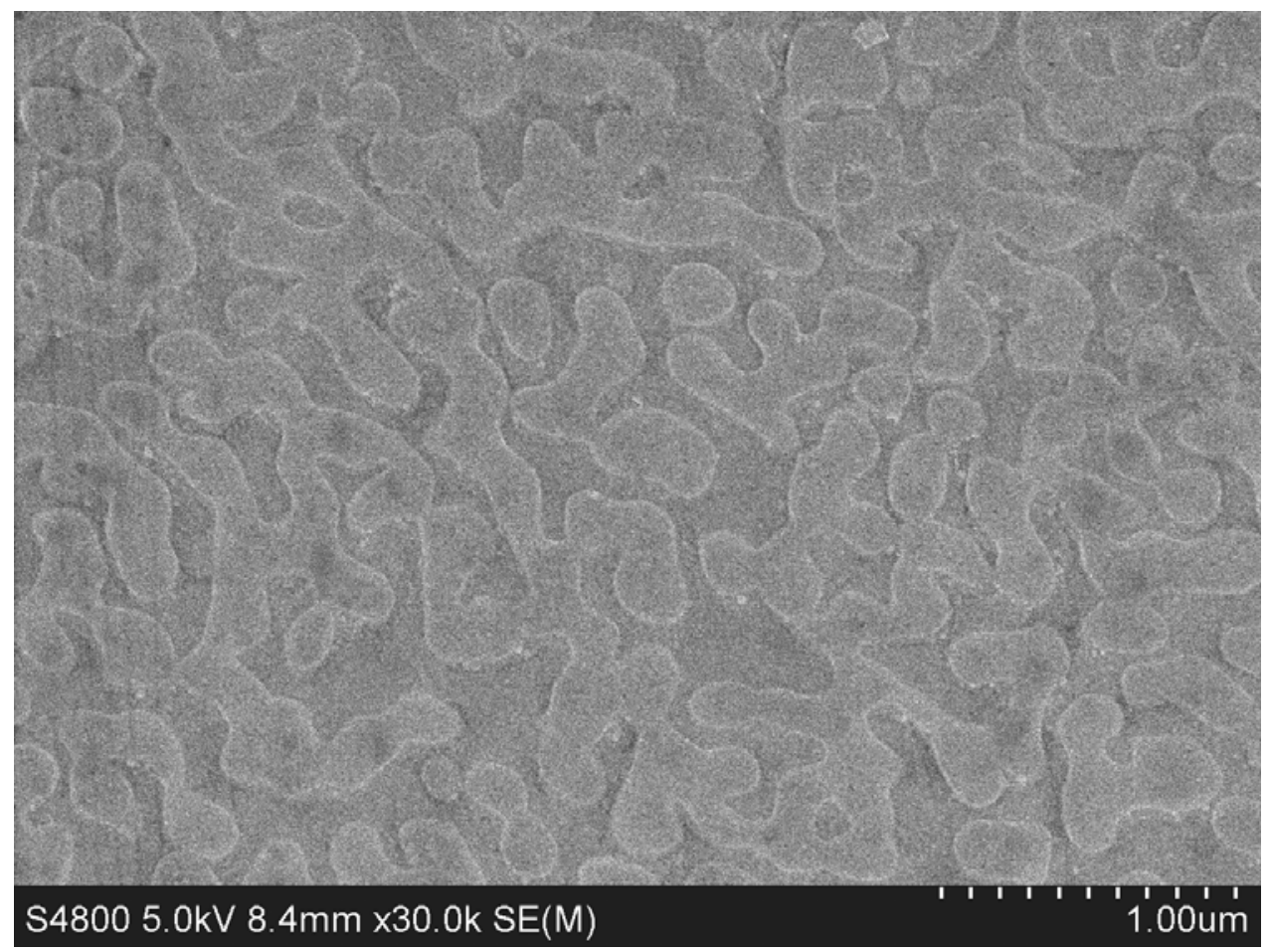

Figure 9. Scanning electron micrograph of the as-fabricated baseline (LDRD-1) bulk glass plate. 


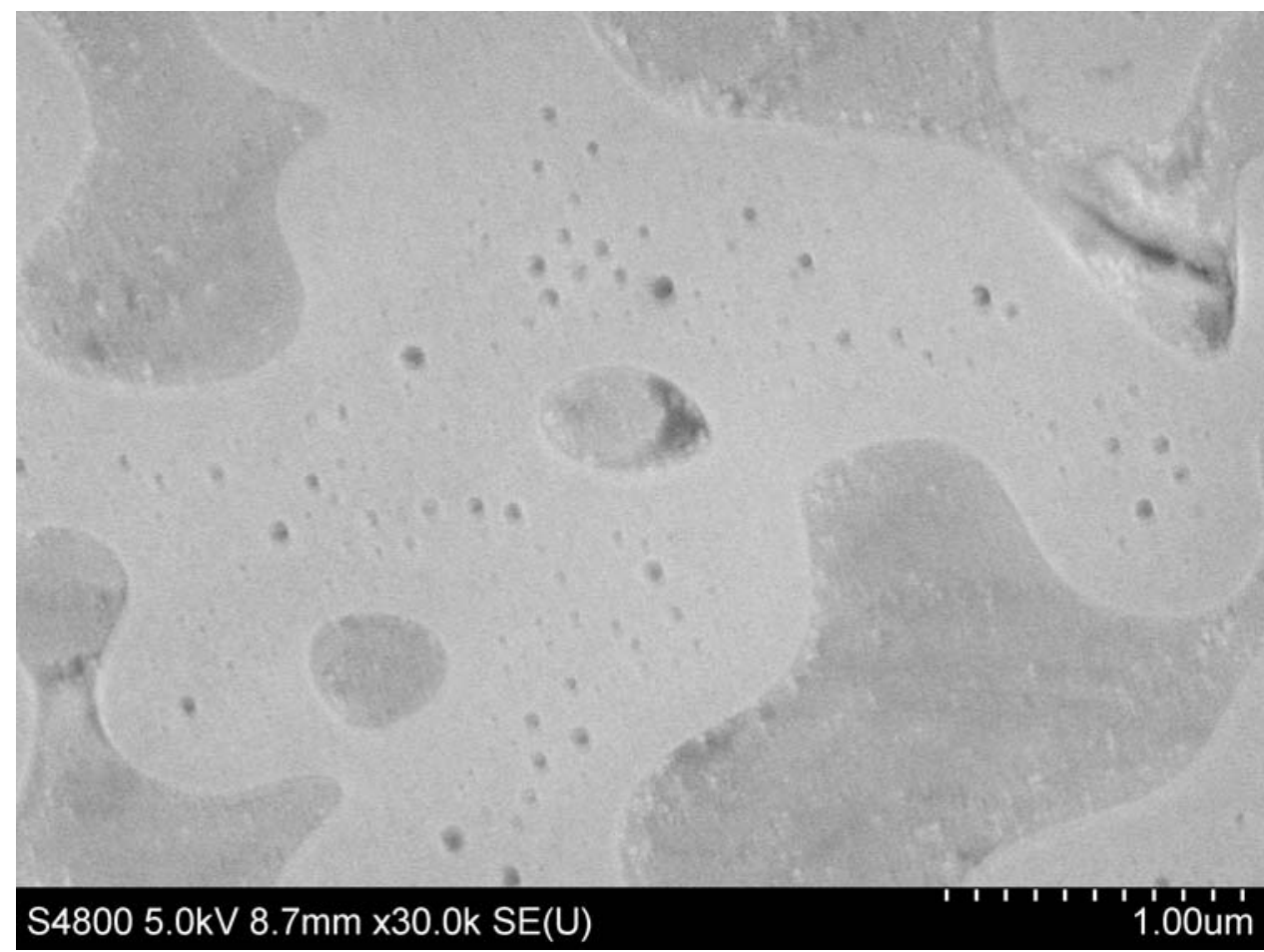

Figure 10. Scanning electron micrograph of the as-fabricated $+6 \mathrm{SiO}_{2}$ (LDRD-3) bulk glass plate.

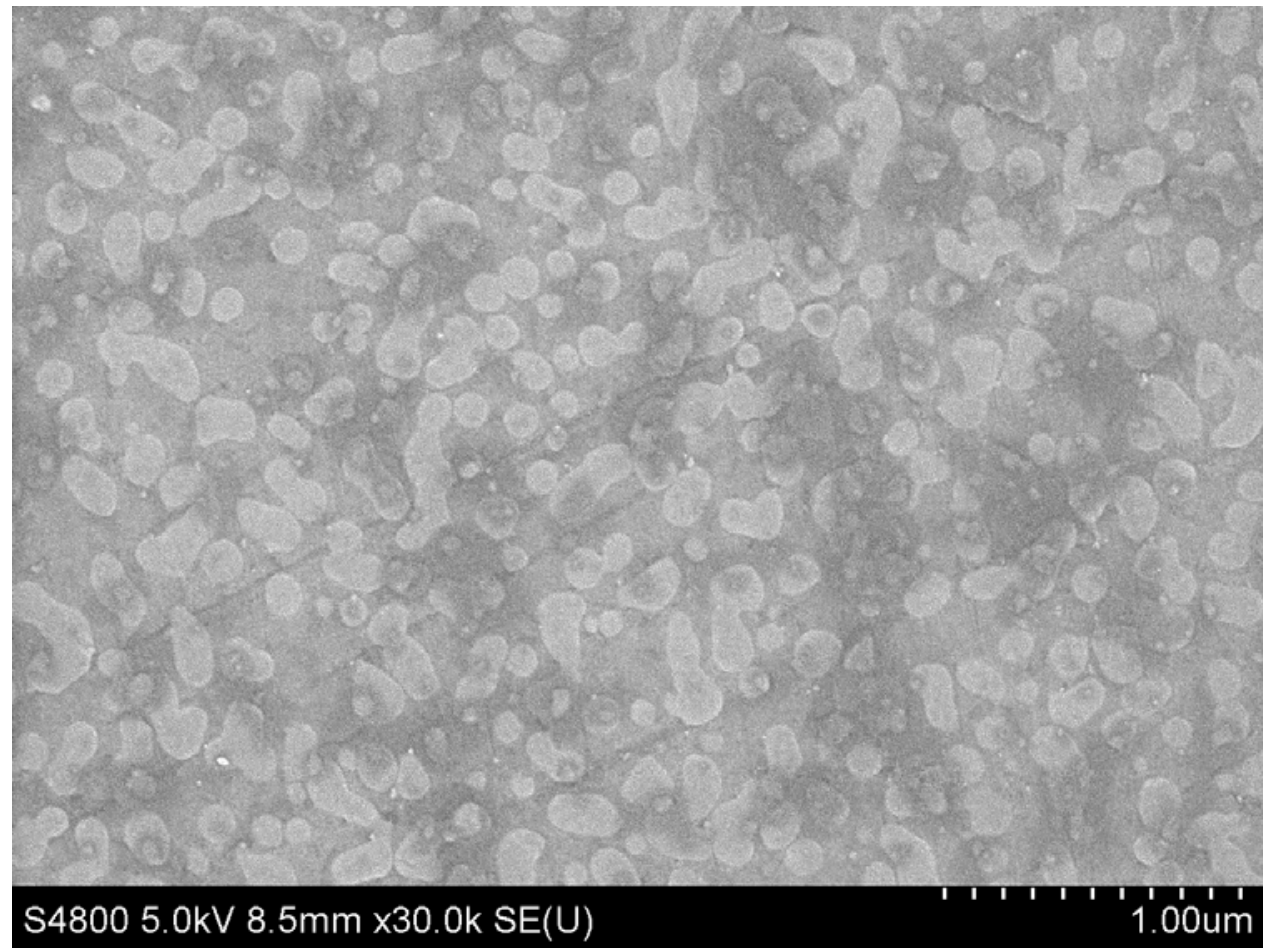

Figure 11. Scanning electron micrograph of the as-fabricated -6 $\mathrm{SiO}_{2}$ (LDRD-5) bulk glass plate. 


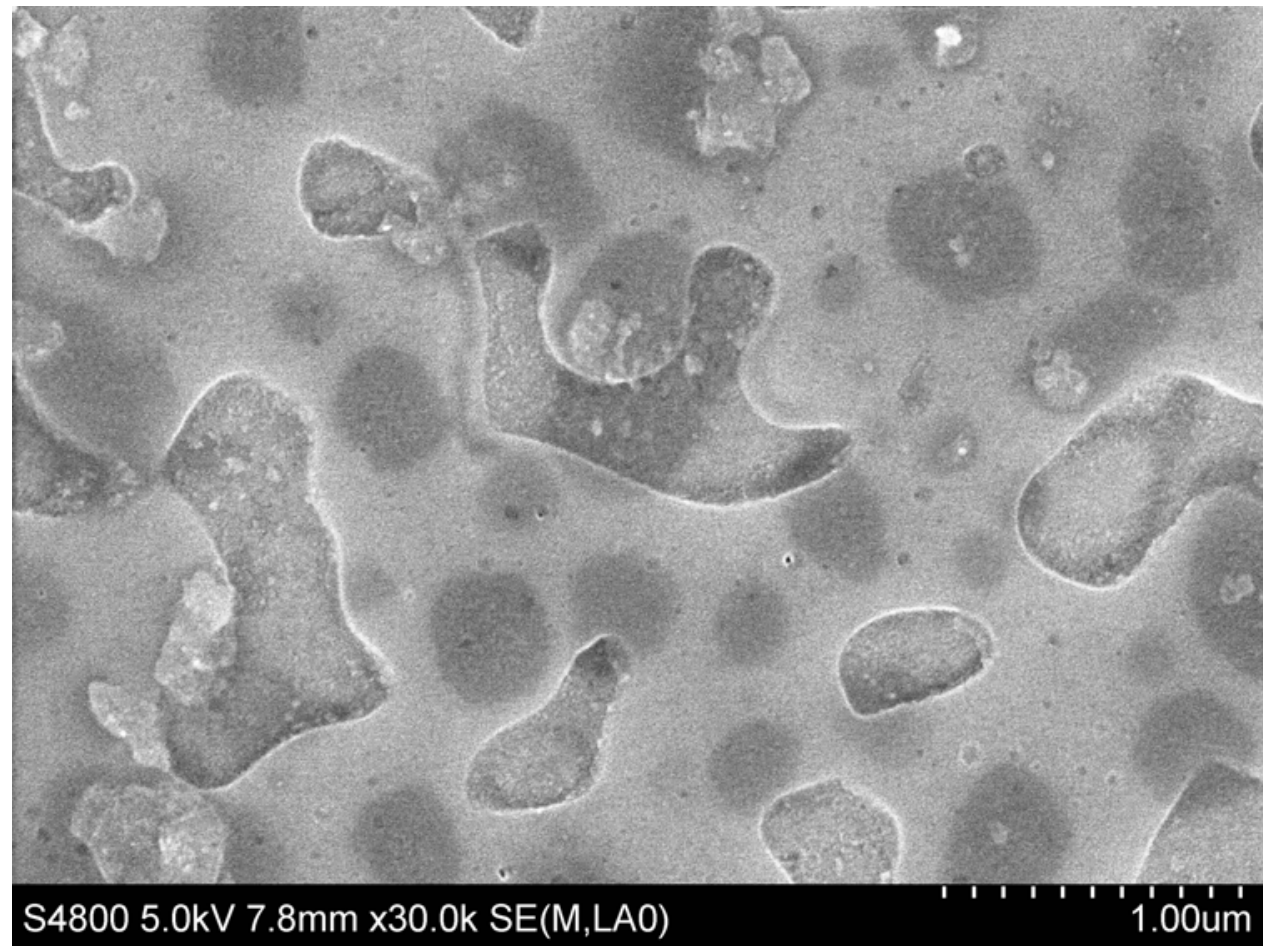

Figure 12. Scanning electron micrograph of the as-fabricated B/R +0.5 (LDRD-6) bulk glass plate.

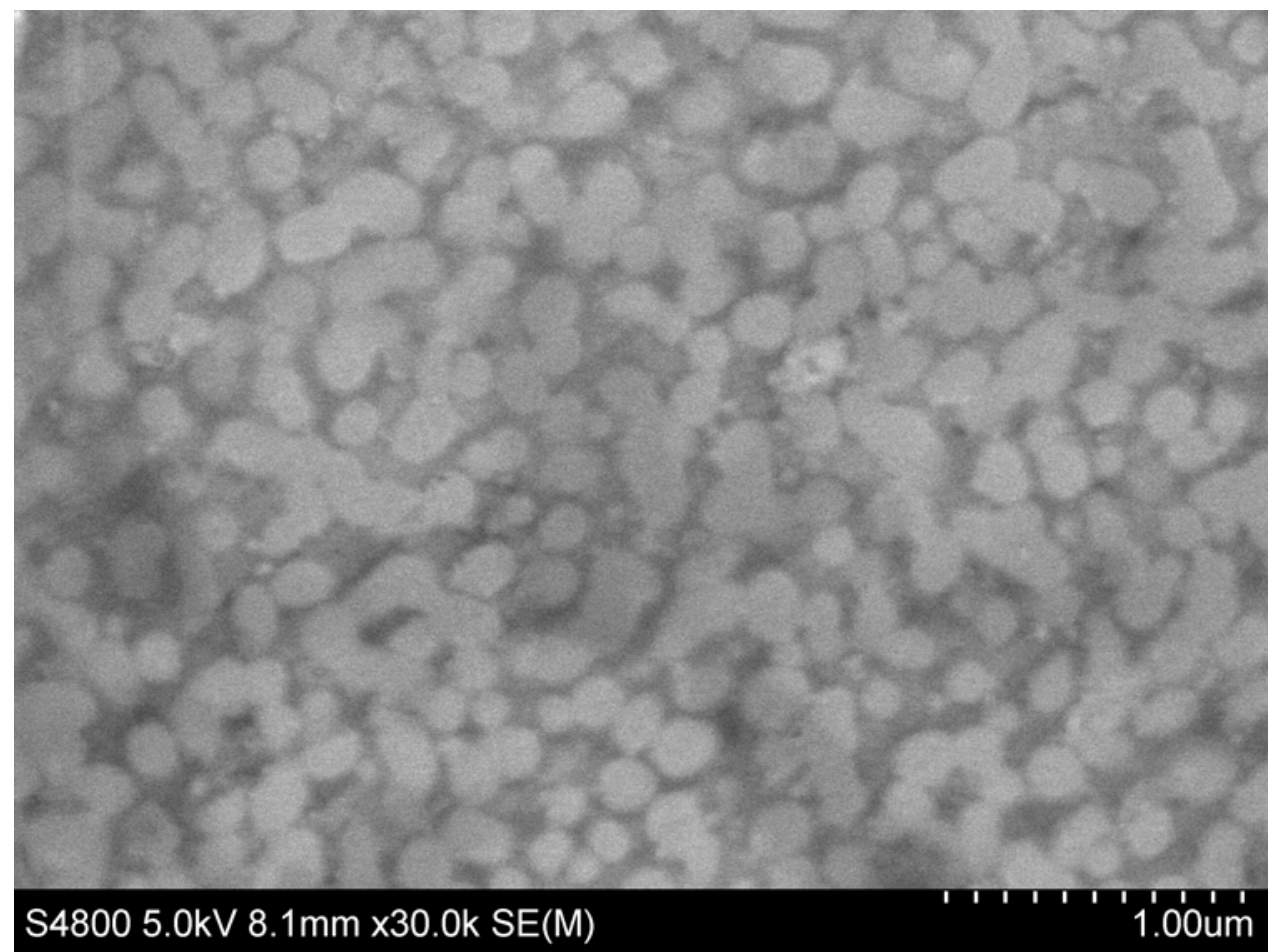

Figure 13. Scanning electron micrograph of the as-fabricated B/R -0.5 (LDRD-7) bulk glass plate. 

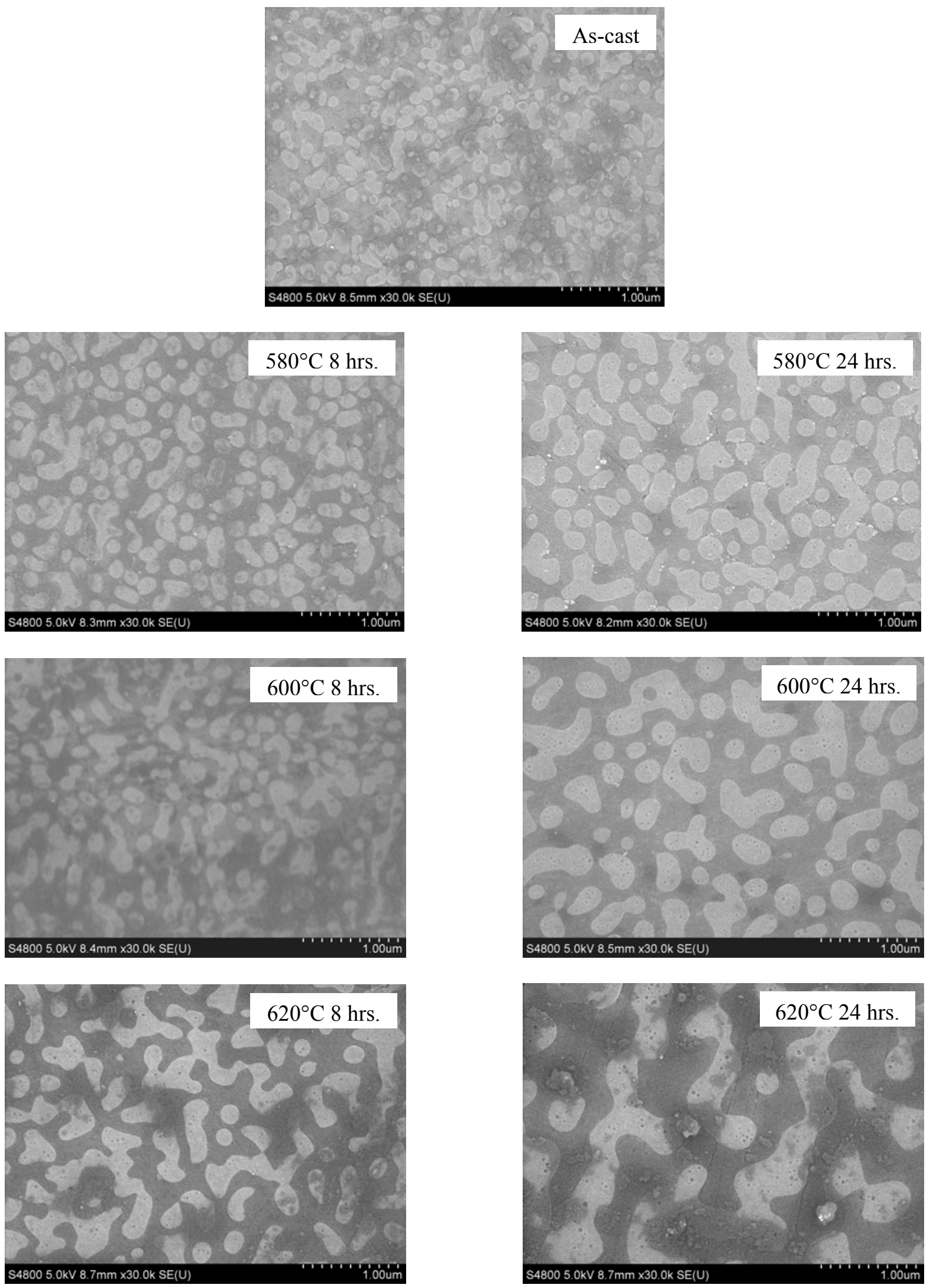

Figure 14. SEM micrographs of as-cast and heat treated $-6 \mathrm{SiO}_{2}$ bulk glass plates. 
While there is a change in the microstructure of glass plates as heat treatment time is increased from 8 hours to 24 hours, the change is minimal in PWHGMs (see Section 4.3.2 for more details). Such a difference may be a result of the considerable variation in size between a glass plate and PWHGM and the kinetics associated with phase separation in each geometric form. More specifically, cooling of a bulk glass plate will be exponentially slower than cooling rates experienced during the production of HGMs. This could lead to differences in microstructures (i.e., scale of phase separation), which in turn could complicate the translation of interactive effects observed in bulk plates to that expected in HGMs or PWHGMs.

\subsection{HGMs}

\subsubsection{Yield of HGMS}

The yields of HGMs for each composition processed through the flame former are listed in Table 7 . Viscosity data at $1200^{\circ} \mathrm{C}$ are provided for reference; this temperature was chosen as this is the approximate temperature of the flame. HGM yields of the LDRD 1-7 glasses as a function of $\mathrm{SiO}_{2}$ and $\mathrm{B}_{2} \mathrm{O}_{3}$ content are shown in Figures 15 and 16 . Viscosity data as a function of composition are shown for reference. The yield of the Charles $+\mathrm{S}+\mathrm{F}$ glass was very low, hence there was no attempt to process the other "Charles" glasses through the flame former. Despite the presence of blowing agents, it is obvious that the "Charles" glasses are lacking other components necessary for HGM formation. The baseline composition has the highest yield; however, it appears that the maximum yield may occur between 57 and $63 \mathrm{wt} \% \mathrm{SiO}_{2}$ with a molar $\mathrm{B} / \mathrm{R}$ ratio in the range of 0 and -0.5 . A considerable decrease in yield is observed as the $\mathrm{SiO}_{2}$ content is raised from 63 to $66 \mathrm{wt} \%$ and when the molar $\mathrm{B} / \mathrm{R}$ ratio is increased by 0.5 . It is likely that a composition with an optimum yield exists in the region shown in Figure 17. Table 7 also shows that the yields are fairly repeatable between independently batched materials, as indicated by the baseline (LDRD-1) and -6 $\mathrm{SiO}_{2}$ (LDRD-5) compositions, indicating the conditions of flame forming were relatively constant between batches. One would expect the yield to decrease with increasing viscosity, but the data suggest that yield is mostly influenced by the composition (Figures 15 and 16); yield data is parabolic with composition whereas viscosity data is linear. For example, poor yield is observed for glasses with low viscosities $\left(-6 \mathrm{SiO}_{2}\right.$ and $\left.\mathrm{B} / \mathrm{R}-0.5\right)$, while the $+3 \mathrm{SiO}_{2}$ composition, which is higher in viscosity, has reasonably high yield.

The yields of the "zero glasses" are also provided in Table 7 and are compared to the yield of the baseline compositions. There is little difference in yield when either fluorine, $\mathrm{ZnO}$ or $\mathrm{P}_{2} \mathrm{O}_{5}$ is removed, although when $\mathrm{CaO}$ is removed, the yield almost goes to zero and is comparable to that of Charles $+\mathrm{S}+\mathrm{F}$. The presence of $\mathrm{CaO}$ is not required for glass formation, but these results suggest that this component is very influential during the blowing process. At the present time the role of $\mathrm{CaO}$ in the formation of HGMs is unknown. The elimination of fluorine from the base composition, without having a significant effect on HGM yield, is advantageous in processing and personal safety issues, because the possible generation of HF is eliminated. 
Table 7. HGM Yields of the LDRD Test Matrix Glasses

\begin{tabular}{|c|c|c|c|}
\hline \multicolumn{2}{|c|}{ Glass ID } & Viscosity at $1200^{\circ} \mathrm{C}$ & HGM Yield \\
\hline HGMA & Commercial & 255 & 50 \\
\hline LDRD-1 & Baseline & 96 & $82,87^{*}$ \\
\hline LDRD-2 & $+3 \mathrm{SiO}_{2}$ & 229 & 77 \\
\hline LDRD-3 & $+6 \mathrm{SiO}_{2}$ & 463 & 17 \\
\hline LDRD-4 & $-3 \mathrm{SiO}_{2}$ & 53 & 61 \\
\hline LDRD-5 & $-6 \mathrm{SiO}_{2}$ & 29 & $24,27^{*}$ \\
\hline LDRD-6 & $\mathrm{B} / \mathrm{R}+0.5$ & 140 & 14 \\
\hline LDRD-7 & $\mathrm{B} / \mathrm{R}-0.5$ & 56 & 42 \\
\hline Charles & \multirow{3}{*}{ Literature } & 132 & na \\
\hline Charles $+\mathrm{S}$ & & 112 & na \\
\hline Charles $+\mathrm{S}+\mathrm{F}$ & & 115 & 0.47 \\
\hline Zero-1 & $0 \mathrm{wt} \% \mathrm{CaO}$ & NA & 0.81 \\
\hline Zero-2 & $0 \mathrm{wt} \% \mathrm{ZnO}$ & NA & 69 \\
\hline Zero-3 & $0 \mathrm{wt} \% \mathrm{P}_{2} \mathrm{O}_{5}$ & NA & 79 \\
\hline Zero-4 & $0 \mathrm{wt}^{2} \% \mathrm{~F}$ & NA & 75 \\
\hline
\end{tabular}

* Results from two independent runs, two feedstocks and two yield measurements

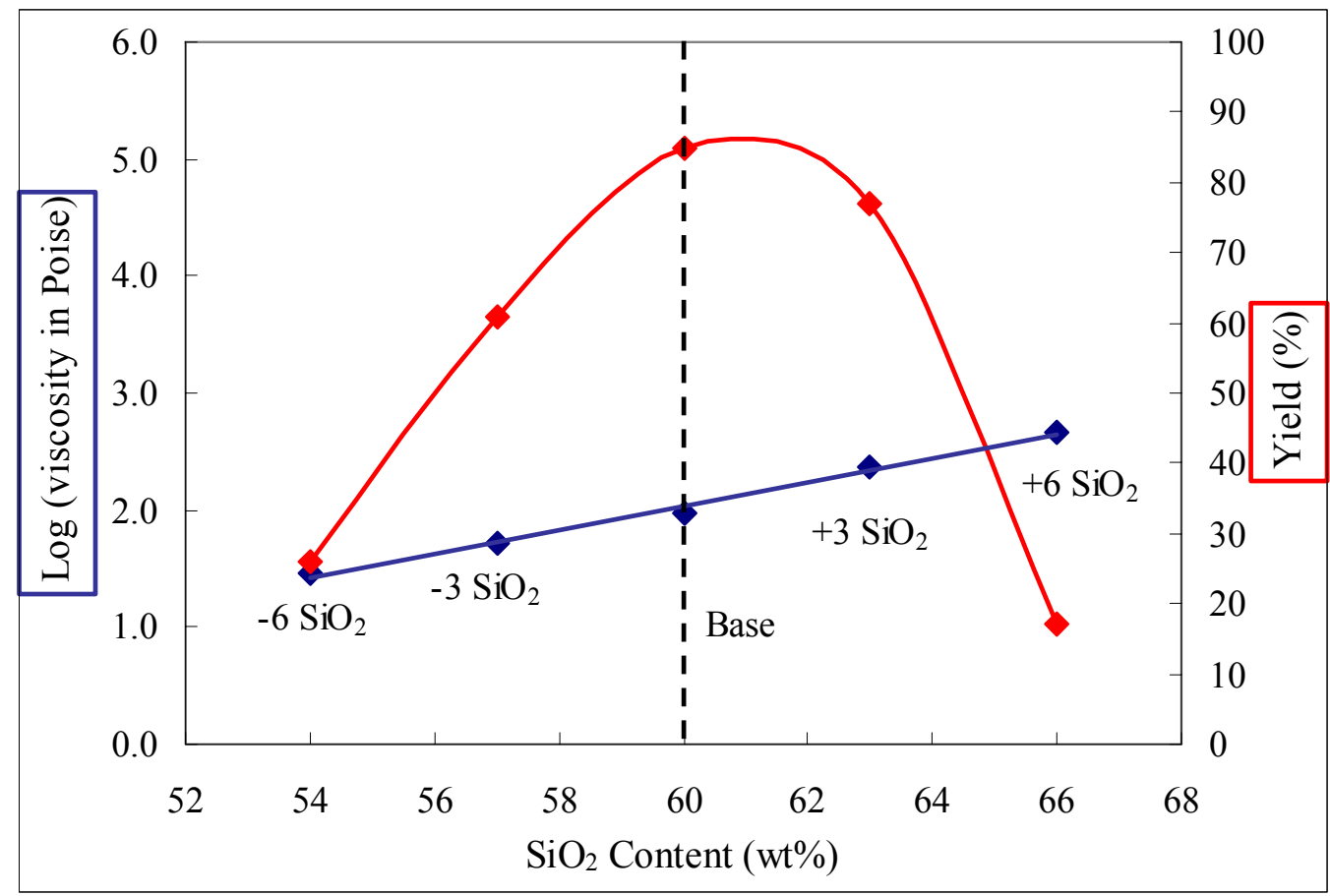

Figure 15. HGM yield and viscosity $\left(\right.$ at $1200^{\circ} \mathrm{C}$ ) as a function of $\mathrm{SiO}_{2}$ content. 


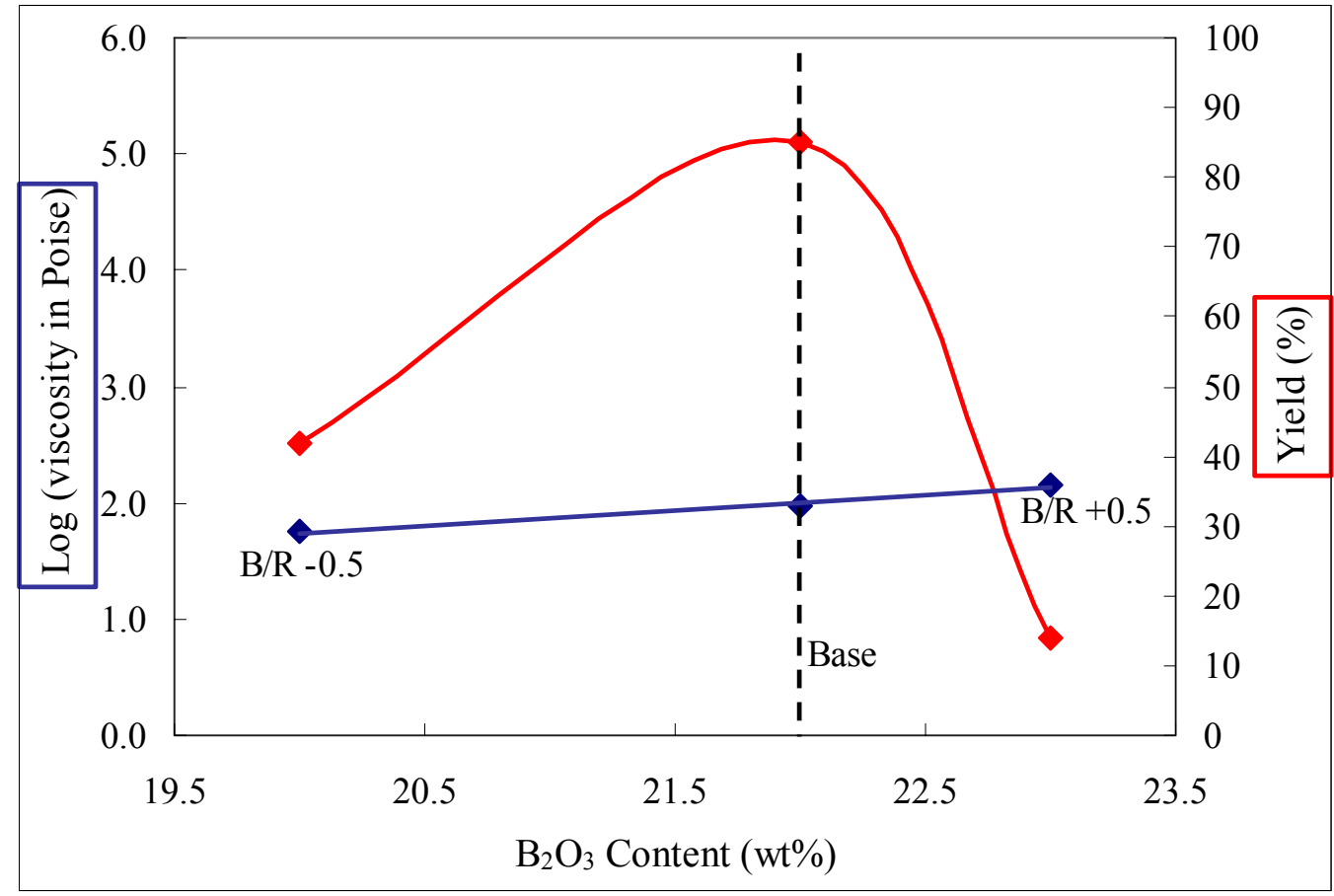

Figure 16. $\mathrm{HGM}$ yield and viscosity $\left(\right.$ at $\left.1200^{\circ} \mathrm{C}\right)$ and as a function of $\mathrm{B}_{2} \mathrm{O}_{3}$ content.

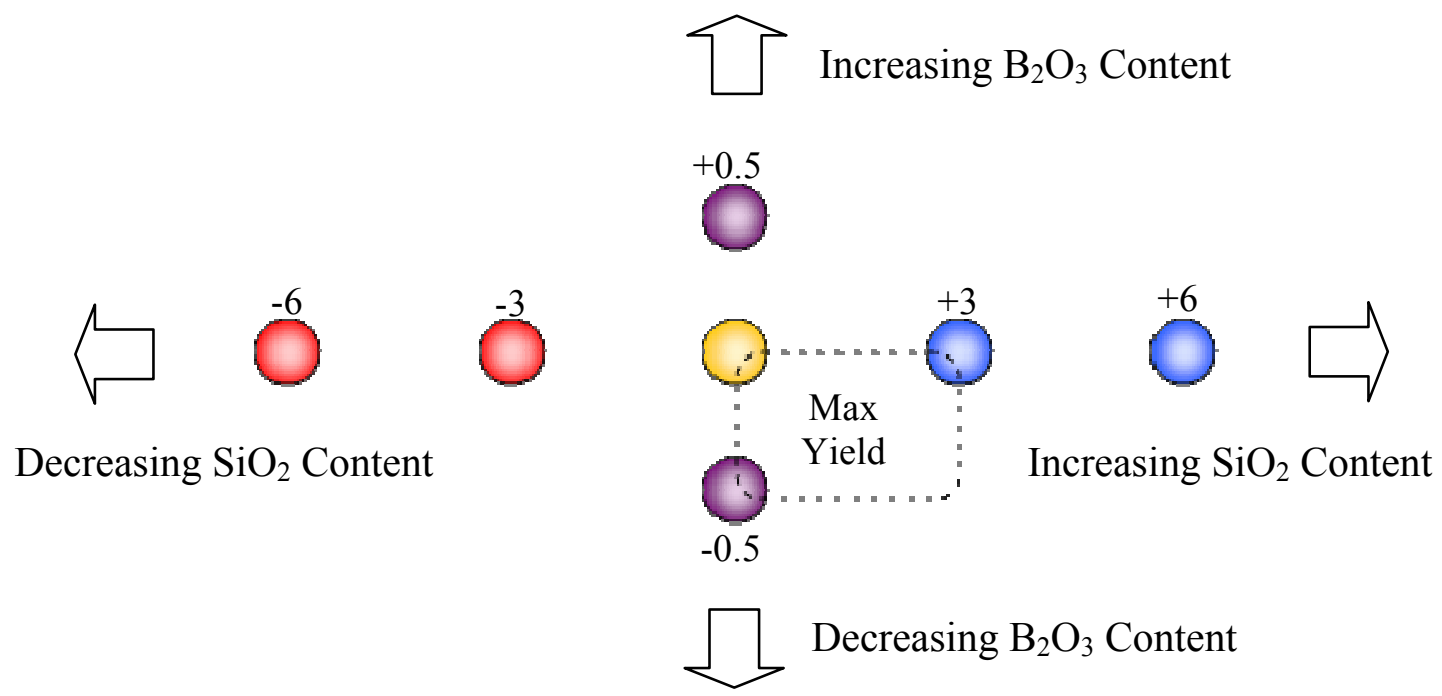

Figure 17. Schematic identifying region of maximum HGM yield in compositional space. 


\subsubsection{Particle Size Distribution}

Particle size distributions of HGMA and LDRD 1-5 HGMs are listed in Table 8. Low HGMs yields for B/R +0.5 (LDRD-6) and "Charles" HGMs resulted in no PSD data for these compositions. An attempt was made to measure B/R -0.5 (LDRD-7); however, there were issues with the HGMs sticking together, making this measurement meaningless. The $\mathrm{B} / \mathrm{R}$ 0.5 (LDRD-7) composition appeared to have much higher moisture content than the others measured. In general, a high percentage of HGMs have diameters within the range of $45-$ $75 \mu \mathrm{m}$, which is to be expected as the feed material is sized to $10-44 \mu \mathrm{m}$. Unlike any of the other compositions, the $+6 \mathrm{SiO}_{2}$ (LDRD-3) composition has a high fraction of small $\mathrm{HGMs}$, with diameters less than $45 \mu \mathrm{m}$. At $1200^{\circ} \mathrm{C}$, the viscosity of $+6 \mathrm{SiO}_{2}$ (LDRD-3) is 463 Poise (see Section 4.2.1), which is more than 200 Poise greater than any of the other compositions, suggesting the high silica content of this composition does not promote blowing.

Table 8. HGM Particle Size Distributions of Select LDRD Compositions

\begin{tabular}{|c|c|c|c|c|c|c|c|}
\hline Glass ID & $\begin{array}{l}\text { HGMA } \\
\text { Commercial }\end{array}$ & $\begin{array}{c}\text { LDRD-1 } \\
\text { Base }\end{array}$ & $\begin{array}{c}\text { LDRD-2 } \\
+3 \mathrm{SiO}_{2}\end{array}$ & $\begin{array}{c}\underset{+6 \mathrm{SiO}_{2}}{\mathrm{LDRD}-3} \\
\end{array}$ & $\begin{array}{c}\text { LDRD-4 } \\
-3 \mathrm{SiO}_{2}\end{array}$ & $\begin{array}{c}\text { LDRD-5 } \\
-6 \mathrm{SiO}_{2}\end{array}$ & $\begin{array}{c}\text { LDRD-5A } \\
{ }_{-6 \mathrm{SiO}_{2}}\end{array}$ \\
\hline $\begin{array}{c}\text { Diameter } \\
(\mu \mathrm{m})\end{array}$ & \multicolumn{7}{|c|}{ Particle Size Distribution (\%) } \\
\hline$>106$ & 0.10 & 0.66 & 0.68 & 2.16 & 1.19 & 1.85 & 2.90 \\
\hline $90-106$ & 0.81 & 2.33 & 1.25 & 1.87 & 1.84 & 2.37 & 3.34 \\
\hline $75-90$ & 3.35 & 19.05 & 2.04 & 2.16 & 3.34 & 2.88 & 2.90 \\
\hline $53-75$ & 28.19 & 65.23 & 90.24 & 11.10 & 88.13 & 56.17 & 74.11 \\
\hline $45-53$ & 32.86 & 7.86 & 3.86 & 17.68 & 2.70 & 26.44 & 11.06 \\
\hline $38-45$ & 12.58 & 1.33 & 0.79 & 33.20 & 0.97 & 7.92 & 4.62 \\
\hline$<38$ & 22.11 & 3.54 & 1.14 & 31.83 & 1.83 & 2.37 & 1.07 \\
\hline
\end{tabular}




\subsubsection{Density}

The true densities of LDRD 1-7 HGMs are listed in Table 9 and are shown as a function of $\mathrm{SiO}_{2}$ and $\mathrm{B}_{2} \mathrm{O}_{3}$ content in Figures 18 and 19. In general, the densities of LDRD 1-5 HGMs increase linearly with $\mathrm{SiO}_{2}$ content, while for the same $\mathrm{SiO}_{2}$ content, the densities of LDRD 6-7 HGMs increase with $\mathrm{B}_{2} \mathrm{O}_{3}$ content. As all of these glasses are primarily composed of glass formers $\left(\mathrm{SiO}_{2}\right.$ and $\left.\mathrm{B}_{2} \mathrm{O}_{3}\right)$, it is expected that density is influenced by the changes in the glass former content. Minor variations in alkali and alkaline earth content should not have a significant or measurable effect. Density is also not influenced by phase separation as density is a result of the averaged volumes of the phases present. ${ }^{3}$ In both curves, the density of the baseline composition is a little low compared to the linear fit of the data. This anomaly may be due to: i) instrumental error and/or ii) effectiveness of blowing during the flame process with this particular composition, however; neither of these reasons seem plausible at the present time. ${ }^{\mathrm{e}}$

Table 9. HGM Densities

\begin{tabular}{|c|c|c|c|c|}
\hline \multirow{2}{*}{\multicolumn{2}{|c|}{ Glass ID }} & \multicolumn{3}{|c|}{ Density (g/cc) } \\
\hline & & \multirow{2}{*}{$\begin{array}{c}\text { Trial 1 } \\
0.609\end{array}$} & \multirow{2}{*}{$\begin{array}{c}\text { Trial } 2 \\
0.601\end{array}$} & \multirow{2}{*}{$\begin{array}{c}\text { Trial } 3 \\
\text { NA }\end{array}$} \\
\hline HGMA & Commercial & & & \\
\hline LDRD-1 & \multirow{2}{*}{ Base } & \multirow{2}{*}{0.437} & \multirow{2}{*}{0.497} & \multirow{2}{*}{ NA } \\
\hline Batch 1 & & & & \\
\hline LDRD-1 & \multirow{2}{*}{ Base } & \multirow{2}{*}{0.422} & \multirow{2}{*}{0.422} & \multirow{2}{*}{ NA } \\
\hline Batch 2 & & & & \\
\hline LDRD-2 & $+3 \mathrm{SiO}_{2}$ & 0.658 & 0.644 & NA \\
\hline LDRD-3 & $+6 \mathrm{SiO}_{2}$ & 0.744 & NA & NA \\
\hline LDRD-4 & $-3 \mathrm{SiO}_{2}$ & 0.514 & 0.510 & NA \\
\hline LDRD-5 & $-6 \mathrm{SiO}_{2}$ & 0.456 & 0.435 & 0.441 \\
\hline LDRD-6 & $\mathrm{B} / \mathrm{R}+0.5$ & 0.741 & 0.681 & NA \\
\hline LDRD-7 & $\mathrm{B} / \mathrm{R}-0.5$ & 0.374 & 0.369 & NA \\
\hline
\end{tabular}

\footnotetext{
${ }^{\mathrm{e}}$ PSD analysis of the feedstock could provide additional insight into the relationships among composition, potential for HGM formation, and void volume.
} 


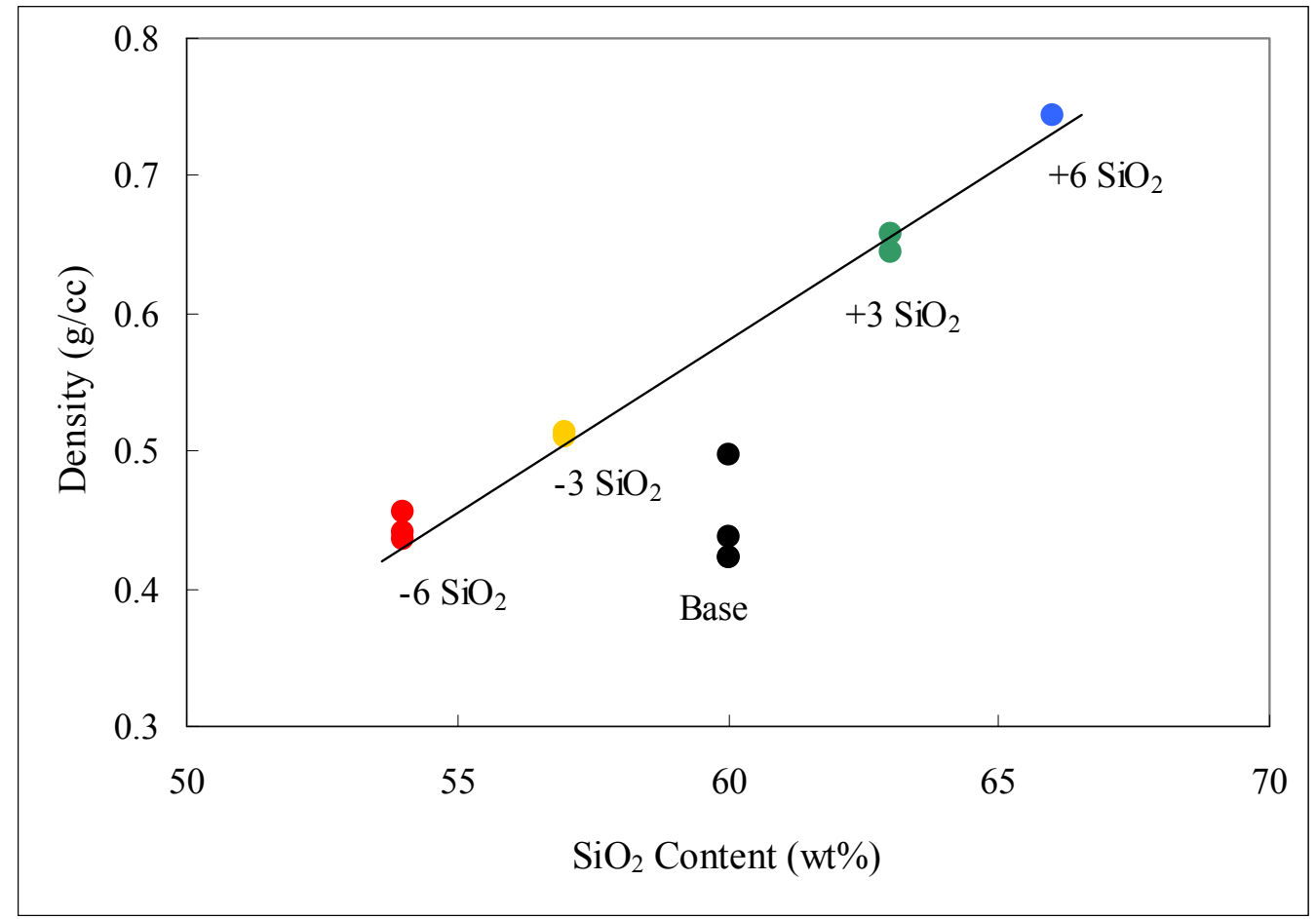

Figure 18. HGM density as a function of silica content.

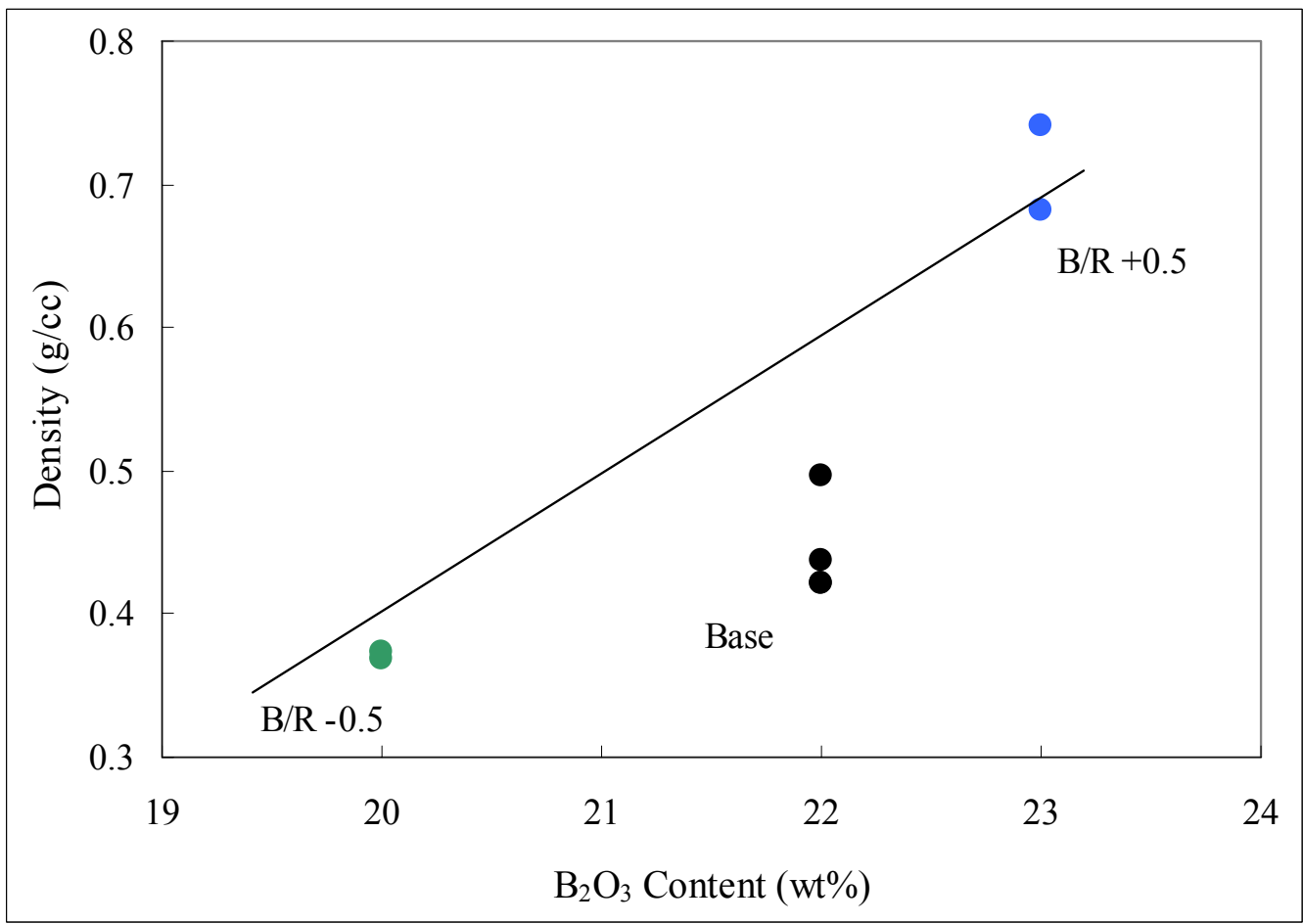

Figure 19. HGM density as a function of $\mathrm{B}_{2} \mathrm{O}_{3}$ content. 


\subsubsection{Microscopy}

As HGMs of each composition are similar in appearance, a representative micrograph of HGMs produced (and washed using the standard procedure) from the baseline (LDRD-1) composition is shown in Figure 20. This figure also shows that additional washing of the feed stock is recommended to yield a more uniform PSD yield and eliminate a majority of the HGMs with diameters less than $10 \mu \mathrm{m}$. Although not shown in this particular image, there are a number of HGMs that are not perfectly spherical.

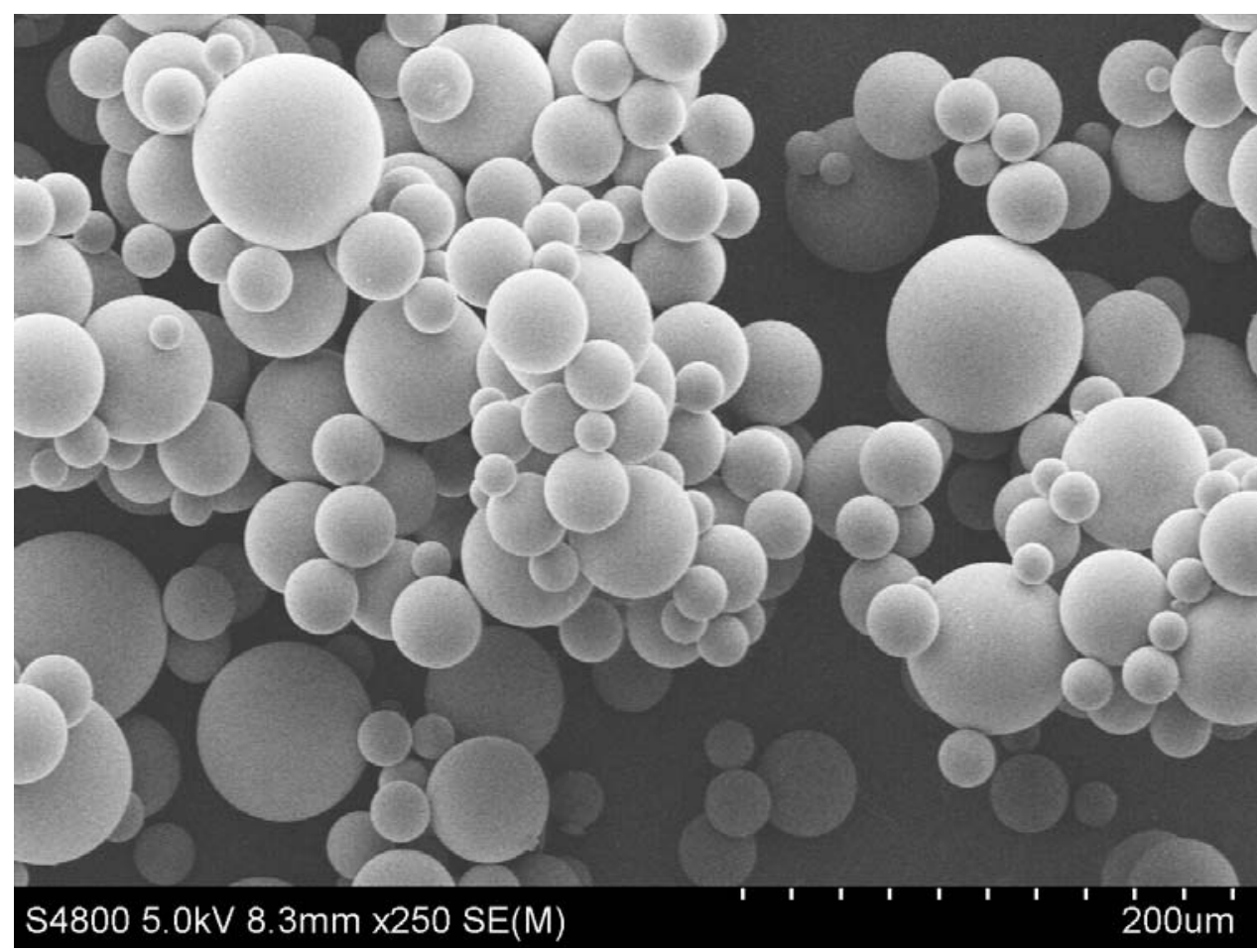

Figure 20. SEM micrograph of baseline (LDRD-1) HGMs.

\subsection{PWHGMs}

\subsubsection{Yield}

During the production of PWHGMs from HGMs, there are a number of process steps that can contribute to the errors that influence the accuracy of the yield calculation. Thus, the yields discussed in this section are only approximate values. Actual values may be lower or higher depending on the quantity of PWHGMs lost during acid leaching and the quantity of moisture in the PWHGMs after drying. A summary of yield data is presented in Table 10. Yield as a function of silica content for non-heat treated samples and samples treated at $600^{\circ} \mathrm{C}$ for 8 hours are shown in Figures 21 and 22. There does not appear to be a trend in the yield as a function of composition for either set of data. PWHGM yield remains relatively constant with changes in $\mathrm{SiO}_{2}$ content in either the non-heat treated and treated at $600^{\circ} \mathrm{C}$ for 
8 hours samples. The $-3 \mathrm{SiO}_{2}$ (non-heat treated LDRD-4) and $+3 \mathrm{SiO}_{2}$ (LDRD-2 treated at $600^{\circ} \mathrm{C}$ for 8 hours) yields are abnormally high; however, these samples retained a lot of moisture, even after drying at $90^{\circ} \mathrm{C}$ overnight, and thus only appear to have superior yields. Additional drying was not performed to provide more realistic yield data for these two systems. It is expected that if properly dried, the yields would be within the range of the other samples.

There is an observable increase in yield when the HGMs are heat treated prior to acid leaching (i.e., a comparison of non-heated to heat treated yields for a fixed composition). In general, implementation of an 8 or 24 hour heat treatment (compared to no heat treatment) results in a coarsening of the microstructure, i.e. more of the highly soluble, silica-poor phase is available for removal. Thus, a higher fraction of material is leached during the acid treatment and more PWHGMs are formed (yield increases).

Due to the amount of error associated with the leaching procedure and therefore the yield calculation, there does not appear to be much difference in yield as the treatment time is increased from 8 hours to 24 hours or when the heat treatment temperature is raised from $580^{\circ} \mathrm{C}$ to $600^{\circ} \mathrm{C}$. It should be noted that there are ambiguous results for the $-6 \mathrm{SiO}_{2}$ (LDRD5) sample, i.e. the yield of the sample treated at 24 hours at $600^{\circ} \mathrm{C}$ is less than the yield at 8 hours. These results are unexpected and cannot be explained at this time.

Table 10. PWHGM Yield

\begin{tabular}{|c|c|c|c|c|c|}
\hline \multirow{2}{*}{\multicolumn{2}{|c|}{ Glass ID }} & \multicolumn{2}{|c|}{ Heat Treatment Conditions } & \multirow{3}{*}{$\begin{array}{c}\begin{array}{c}\text { Initial Sample } \\
\text { Mass (g) }\end{array} \\
2.953 \\
\end{array}$} & \multirow{3}{*}{$\begin{array}{c}\text { Yield (\%) } \\
40 \\
\end{array}$} \\
\hline & & Temperature & Time & & \\
\hline \multirow{5}{*}{ LDRD-1 } & \multirow{5}{*}{ Base } & \multicolumn{2}{|c|}{ No Heat Treatment } & & \\
\hline & & $580^{\circ} \mathrm{C}$ & $8 \mathrm{hrs}$. & 14.158 & 43 \\
\hline & & $580^{\circ} \mathrm{C}$ & 24 hrs. & 14.221 & 50 \\
\hline & & $600^{\circ} \mathrm{C}$ & $8 \mathrm{hrs}$. & 27.92 & 51 \\
\hline & & $600^{\circ} \mathrm{C}$ & $24 \mathrm{hrs}$. & 13.807 & 53 \\
\hline \multirow{2}{*}{ LDRD-2 } & \multirow{2}{*}{$+3 \mathrm{SiO}_{2}$} & \multicolumn{2}{|c|}{ No Heat Treatment } & 20.05 & 37 \\
\hline & & $600^{\circ} \mathrm{C}$ & $8 \mathrm{hrs}$. & 18.877 & 99 \\
\hline \multirow{2}{*}{ LDRD-3 } & \multirow{2}{*}{$+6 \mathrm{SiO}_{2}$} & \multicolumn{2}{|c|}{ No Heat Treatment } & 10.876 & 48 \\
\hline & & $600^{\circ} \mathrm{C}$ & $8 \mathrm{hrs}$. & 9.254 & 59 \\
\hline \multirow{2}{*}{ LDRD-4 } & \multirow{2}{*}{$-3 \mathrm{SiO}_{2}$} & \multicolumn{2}{|c|}{ No Heat Treatment } & 15.109 & 85 \\
\hline & & $600^{\circ} \mathrm{C}$ & $8 \mathrm{hrs.}$ & 14.49 & 61 \\
\hline \multirow{3}{*}{ LDRD-5 } & \multirow{3}{*}{$-6 \mathrm{SiO}_{2}$} & \multicolumn{2}{|c|}{ No Heat Treatment } & 7.278 & 24 \\
\hline & & $600^{\circ} \mathrm{C}$ & $8 \mathrm{hrs.}$ & 15.798 & 63 \\
\hline & & $600^{\circ} \mathrm{C}$ & $24 \mathrm{hrs.}$ & 14.073 & 47 \\
\hline LDRD-6 & $\mathrm{B} / \mathrm{R}+0.5$ & $600^{\circ} \mathrm{C}$ & 8 hrs. & 9.647 & 75 \\
\hline \multirow{2}{*}{ LDRD-7 } & \multirow{2}{*}{$\mathrm{B} / \mathrm{R}-0.5$} & \multicolumn{2}{|c|}{ No Heat Treatment } & 15.042 & 13 \\
\hline & & $600^{\circ} \mathrm{C}$ & $8 \mathrm{hrs}$. & 15.531 & 50 \\
\hline
\end{tabular}

Initial sample mass (prior to acid leaching) is included to demonstrate variability in samples. 


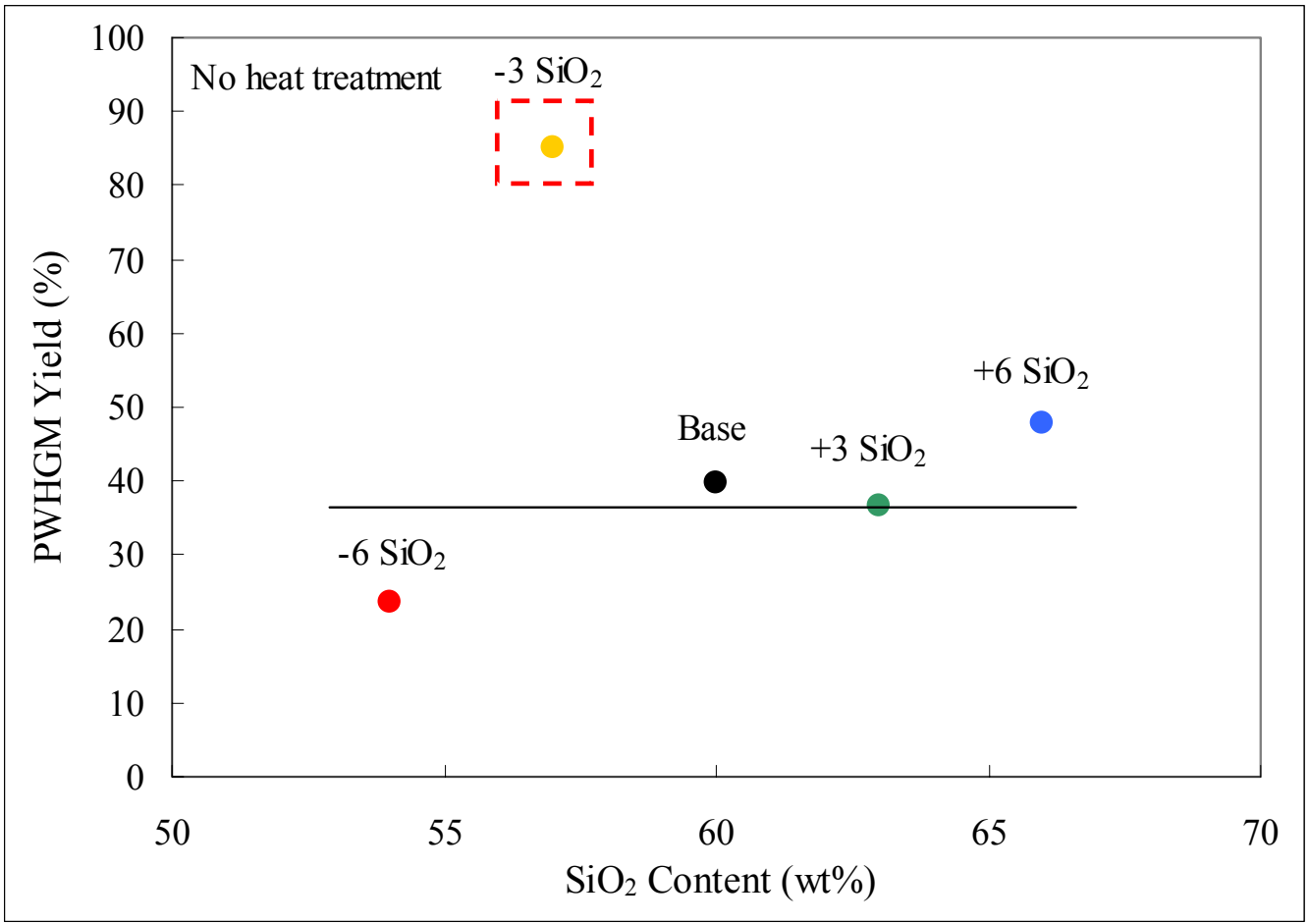

Figure 21. PWHGM yield as a function of silica content for non heat treated samples.

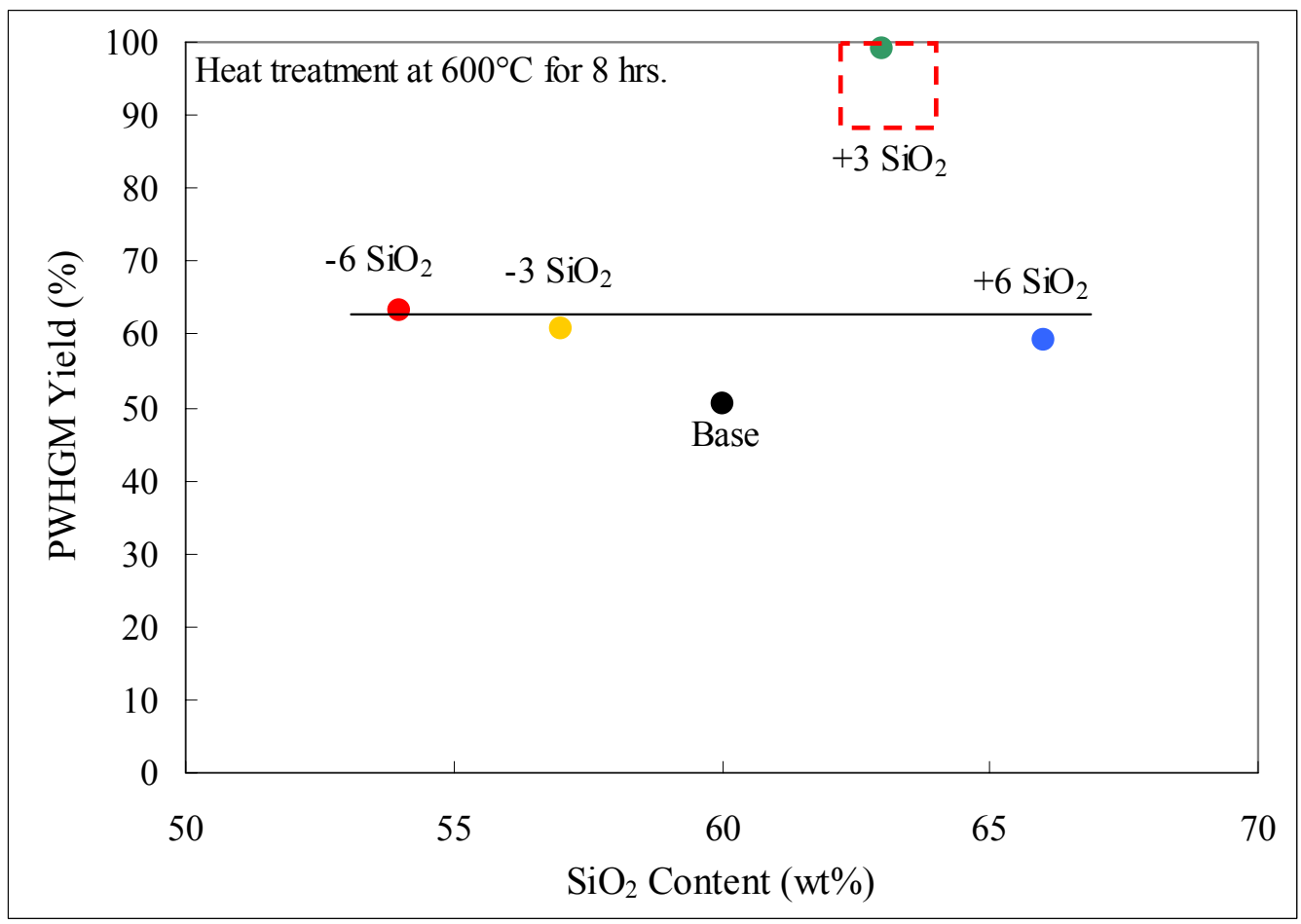

Figure 22. PWHGM yield as a function of silica content for samples treated at $600^{\circ} \mathrm{C}$ for 8 hours. 
WSRC-STI-2007-00605

Revision 0

\subsubsection{Microstructure}

\subsubsection{Impact of Heat Treatment}

A comparison of the microstructures of non-heat treated and heat treated of LDRD-1 PWHGMs prior to acid leaching are shown in Figures 23 and 24. While the non-heat treated sample is porous (Figure 23), the pores are barely observable at high magnification. There is a considerable difference in the porosity of the heat treated $\left(600^{\circ} \mathrm{C}\right.$ for 8 hours) sample (Figure 24); the interconnected microstructure is clearly defined and the porosity can easily be observed at lower magnification. As will be discussed in Section 4.3.3, the average pore size of the non-heat treated sample was estimated to be $100 \AA$ based on the mercury porosimetry data, while that of the heat treated sample was approximately $1000 \AA$. These data provide semi-quantitative support to the visual or qualitative assessment via the electron micrographs. Although not shown, other compositions exhibit similar changes in microstructure with heat treatment.

\subsubsection{Impact of Heat Treatment Time}

As the heat treatment time is increased from 8 hours to 24 hours (at a fixed heat treatment temperature of $580^{\circ} \mathrm{C}$ ), there is very little change in the microstructure of the baseline composition as shown in Figures 25 and 26. Results are comparable at a heat treatment temperature of $600^{\circ} \mathrm{C}$ which suggest that heat treatment time (up to 24 hours) has little impact on the resulting microstructure.

\subsubsection{Impact of Heat Treatment Temperature}

Coarsening of the microstructure occurs as the heat treatment temperature is raised from $580^{\circ} \mathrm{C}$ to $600^{\circ} \mathrm{C}$ for the LDRD-1 composition, which can be distinguished when comparing Figure 24 and Figure 25. Significant differences in the resulting microstructure are evident with only a $20^{\circ} \mathrm{C}$ change in heat treatment temperature for the LDRD-1 composition.

These results suggest that heat treatment times used in this task are not as effective as the heat treatment temperatures in changing the porosity (or phase separation) in HGMs and the resulting PWHGMs.

\subsubsection{Impact of Compositional Changes}

A comparison of the microstructures of PWHGMs of each composition treated under the same heat treatment conditions $\left(600^{\circ} \mathrm{C}\right.$ for 8 hours) is shown in Figure 27 . After heat treatment, all of the compositions form PWHGMs in which the interconnected microstructure is clearly defined; however, the scale of the morphology is not the same. The results suggest that the microstructures of the baseline (LDRD-1), $+3 \mathrm{SiO}_{2}$ (LDRD-2) and $\mathrm{B} / \mathrm{R}-0.5$ (LDRD7) glasses are similar in nature (i.e., larger pore sizes as compared the $-3 \mathrm{SiO}_{2}$ (LDRD-4), and $\mathrm{B} / \mathrm{R}+0.5$ (LDRD-6) glasses). Unfortunately the mercury porosimetry data was inconclusive for select samples and definitive conclusions cannot be made at this time regarding whether composition is a primary factor in controlling the microstructure. 


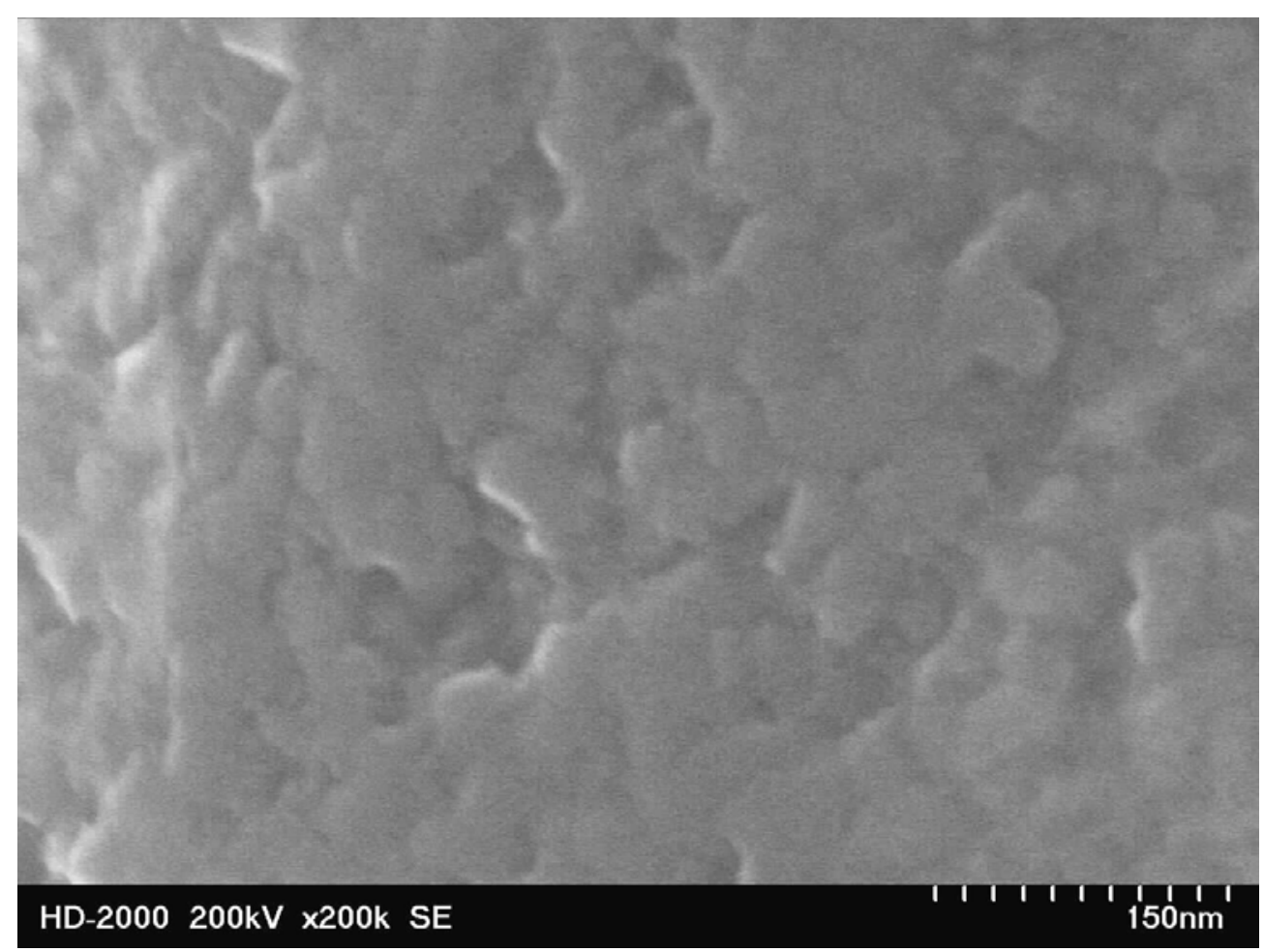

Figure 23. Scanning electron micrograph of a baseline (LDRD-1) PWHGM that was not heat treated prior to acid leaching.

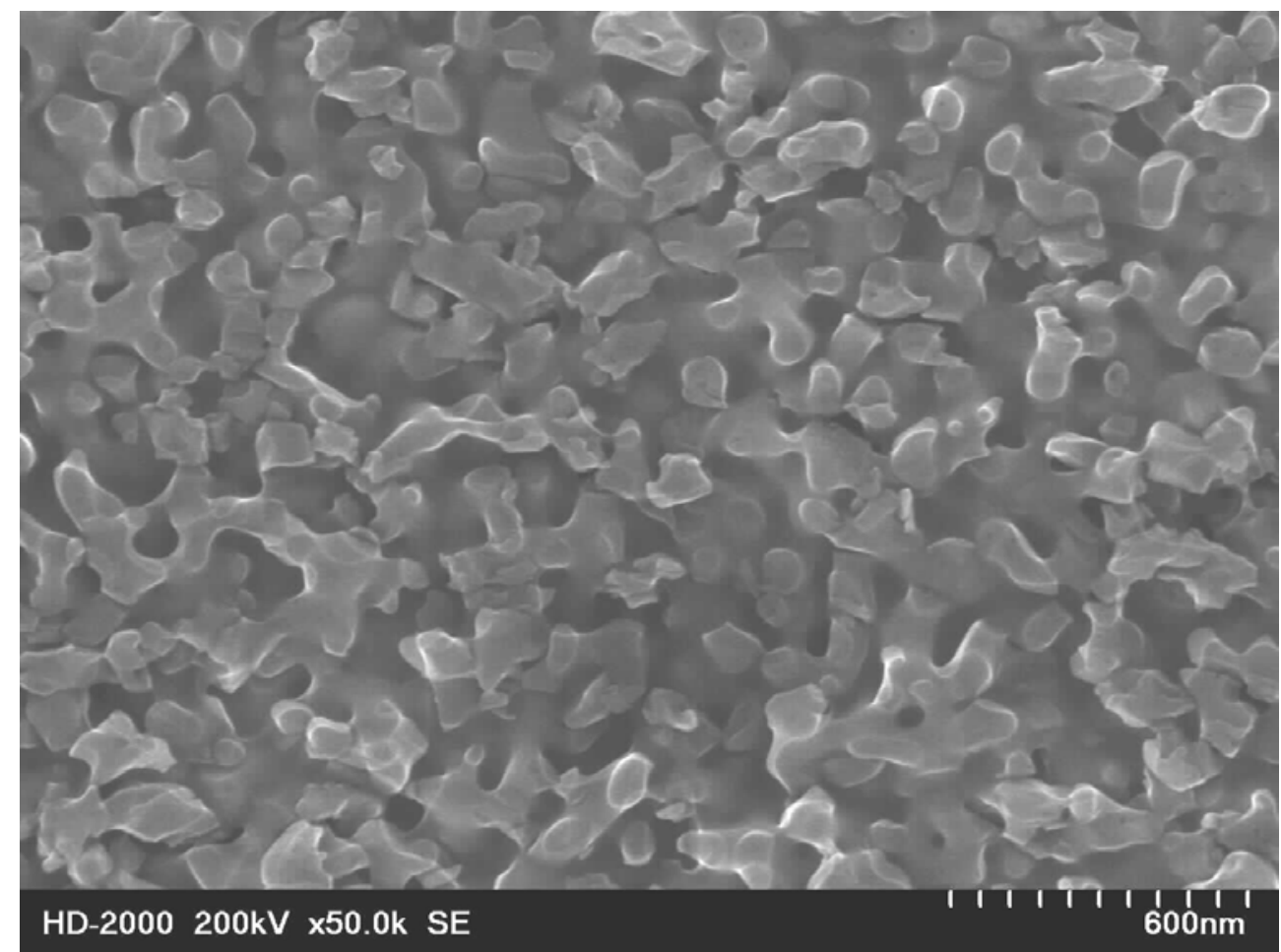

Figure 24. Scanning electron micrograph of a baseline (LDRD-1) PWHGM that was heat treated at $600^{\circ} \mathrm{C}$ for 8 hours prior to acid leaching. 


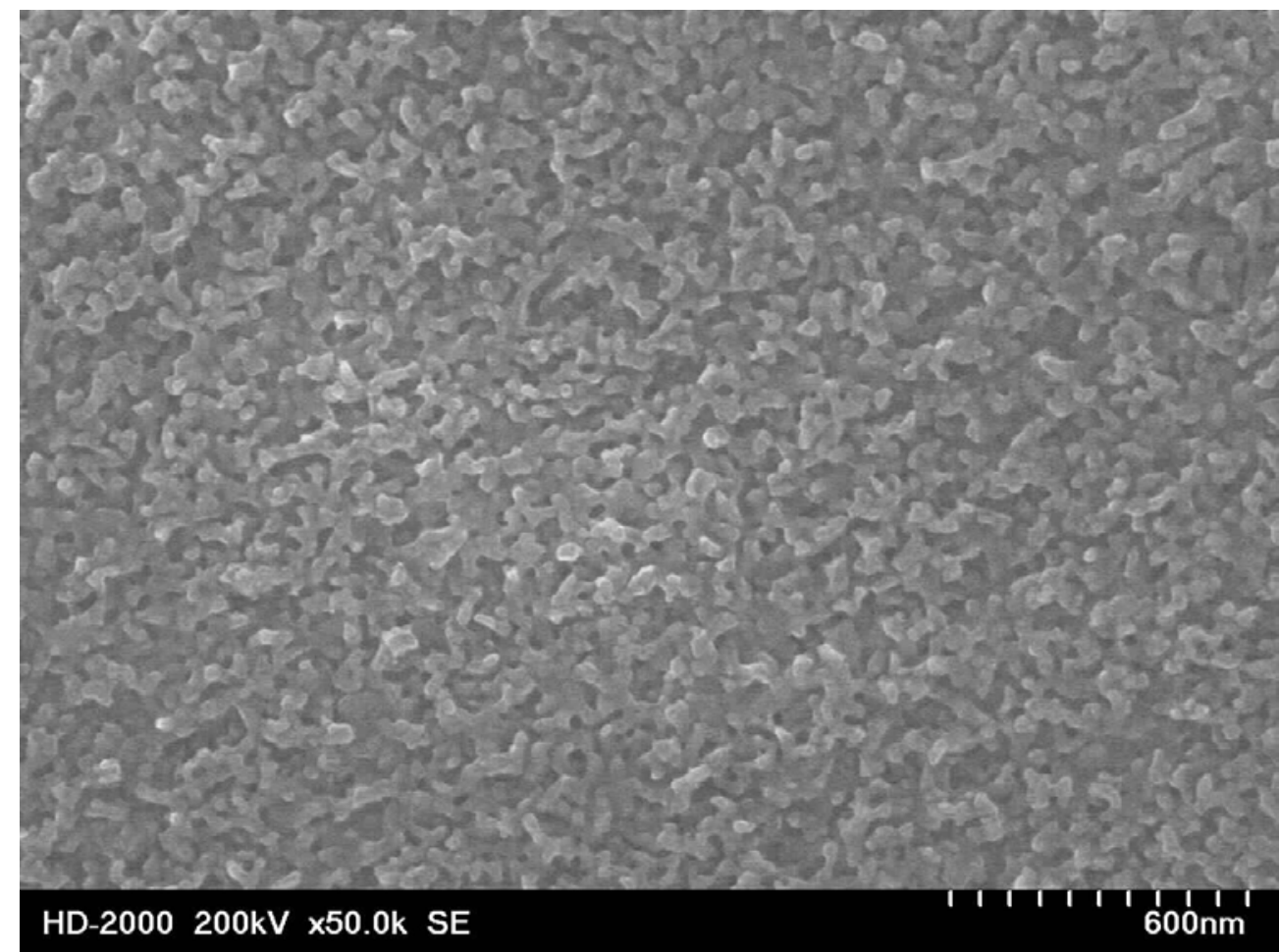

Figure 25. Scanning electron micrograph of a baseline (LDRD-1) PWHGM treated at $580^{\circ} \mathrm{C}$ for 8 hours.

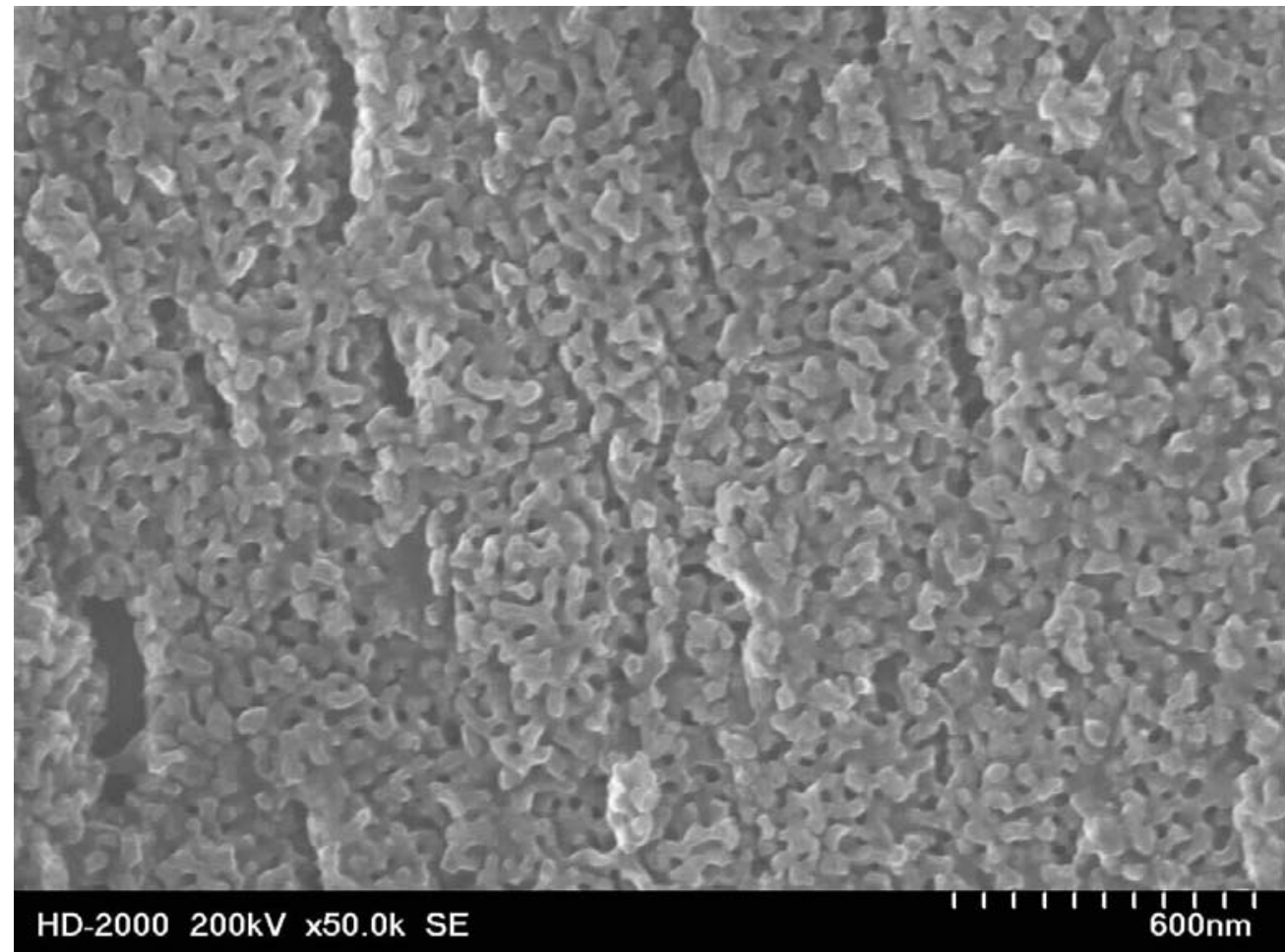

Figure 26. Scanning electron micrograph of a baseline (LDRD-1) PWHGM treated at $580^{\circ} \mathrm{C}$ for 24 hours. Note that apparent cracking is due to sample preparation. 
WSRC-STI-2007-00605

Revision 0
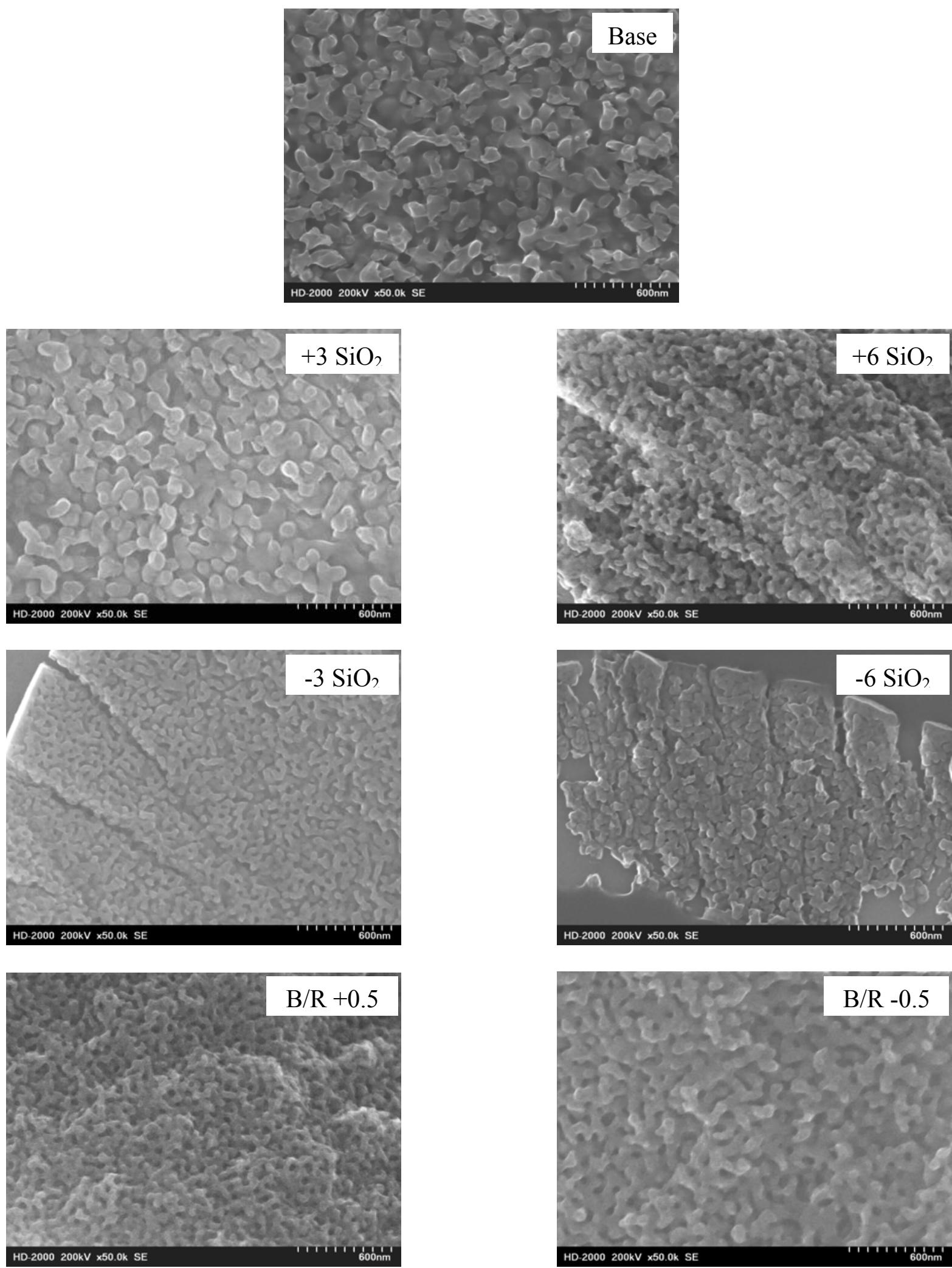

Figure 27. Scanning electron micrographs of LDRD 1-7 PWHGMs treated at $600^{\circ} \mathrm{C}$ for 8 hours prior to acid leaching. All images were taken at the same magnification. 


\subsubsection{Porosity}

The interpretation of mercury porosimetry data is both complex and time consuming. Due to time and budget restraints, a thorough analysis of all of the data has not been performed. This discussion pertains to the mercury intrusion data from the baseline (LDRD-1) composition only.

A typical mercury porosimetry plot is shown in Figure 28. The y-axis, log differential intrusion volume is calculated by dividing the difference in volume $(\mathrm{V})$ by the difference in the logarithms of diameters (D) and is given by: ${ }^{15}$

$$
\frac{\Delta V}{\Delta \log D}=\frac{V_{i+1}-V_{i}}{\log D_{i+1}-\log D_{i}}
$$

The $\mathrm{x}$-axis is simply the $\log$ of the pore diameter. Peak area is a representation of pore volume. The curve in Figure 28 is composed of two main regions, which are labeled on the graph: a.) this group of peaks is proposed to represent the interstitial volume of the HGMs as well as the interior void volume of the HGMs and are typically tens to hundreds of micrometers in diameter, b.) peaks in this region are thought to represent the volume in the pores of the PWHGM and are typically $100-2000 \AA$ in diameter. Since this study is only concerned with the volume of the pores, region "b" will be the primary focus and region "a" will be disregarded.

The impact of heat treatment on the porosity of the baseline composition (LDRD-1) is shown in Figure 29. While the non-heat treated sample consists of a high fraction of pores that are approximately $100 \AA$ in diameter, heat treatment causes the pore diameter to increase to approximately $1000 \AA$, confirming the microscopy results. There is little variation in the porosity as the heat treatment time is increased from 8 hours to 24 hours for the sample treated at $600^{\circ} \mathrm{C}$; there is a very slight shift in pore diameter and very little increase (if any) in pore volume, also confirming the microscopy results. Mercury porosimetry results are inconclusive for the samples treated at $580^{\circ} \mathrm{C}$. 


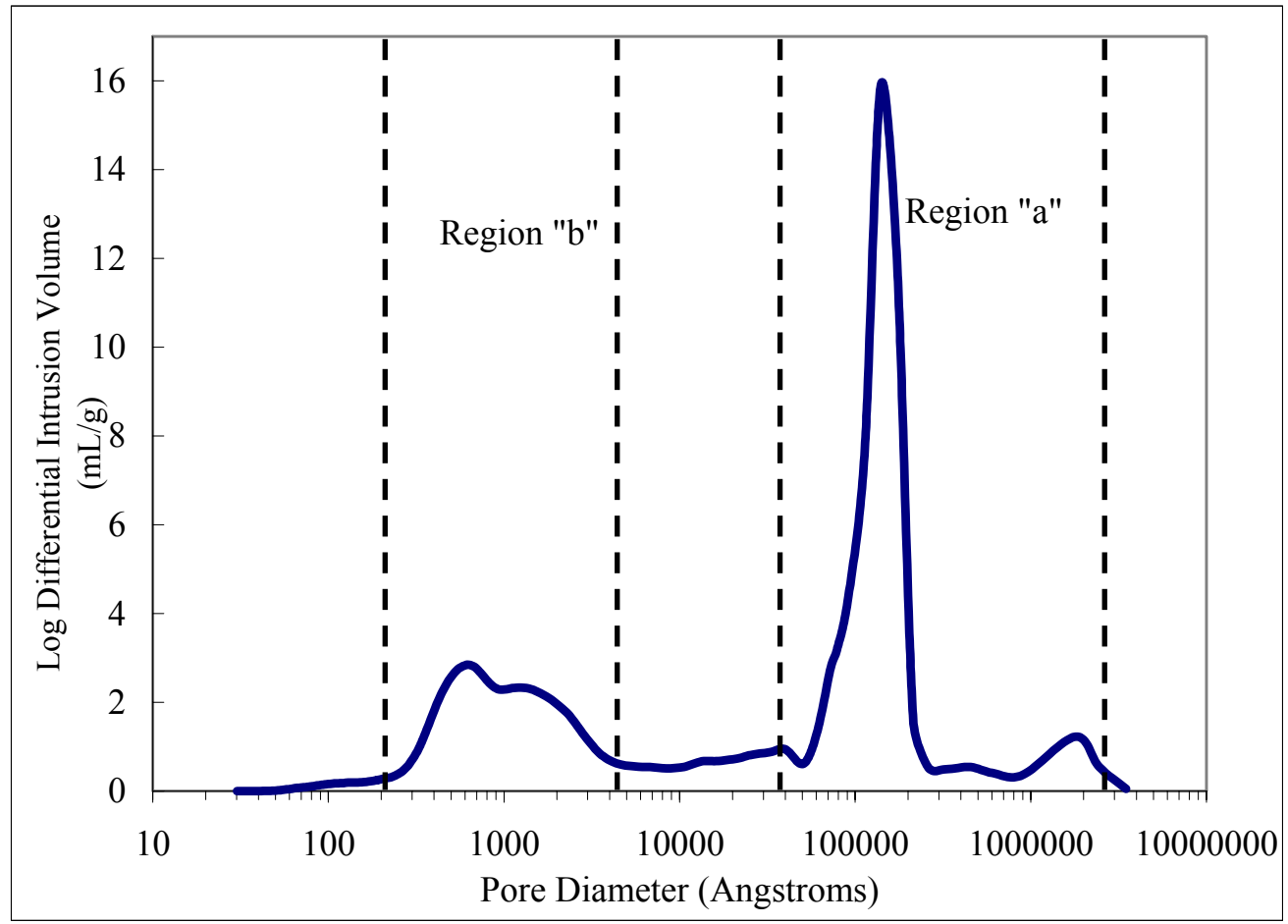

Figure 28. Typical mercury porosimetry curve.

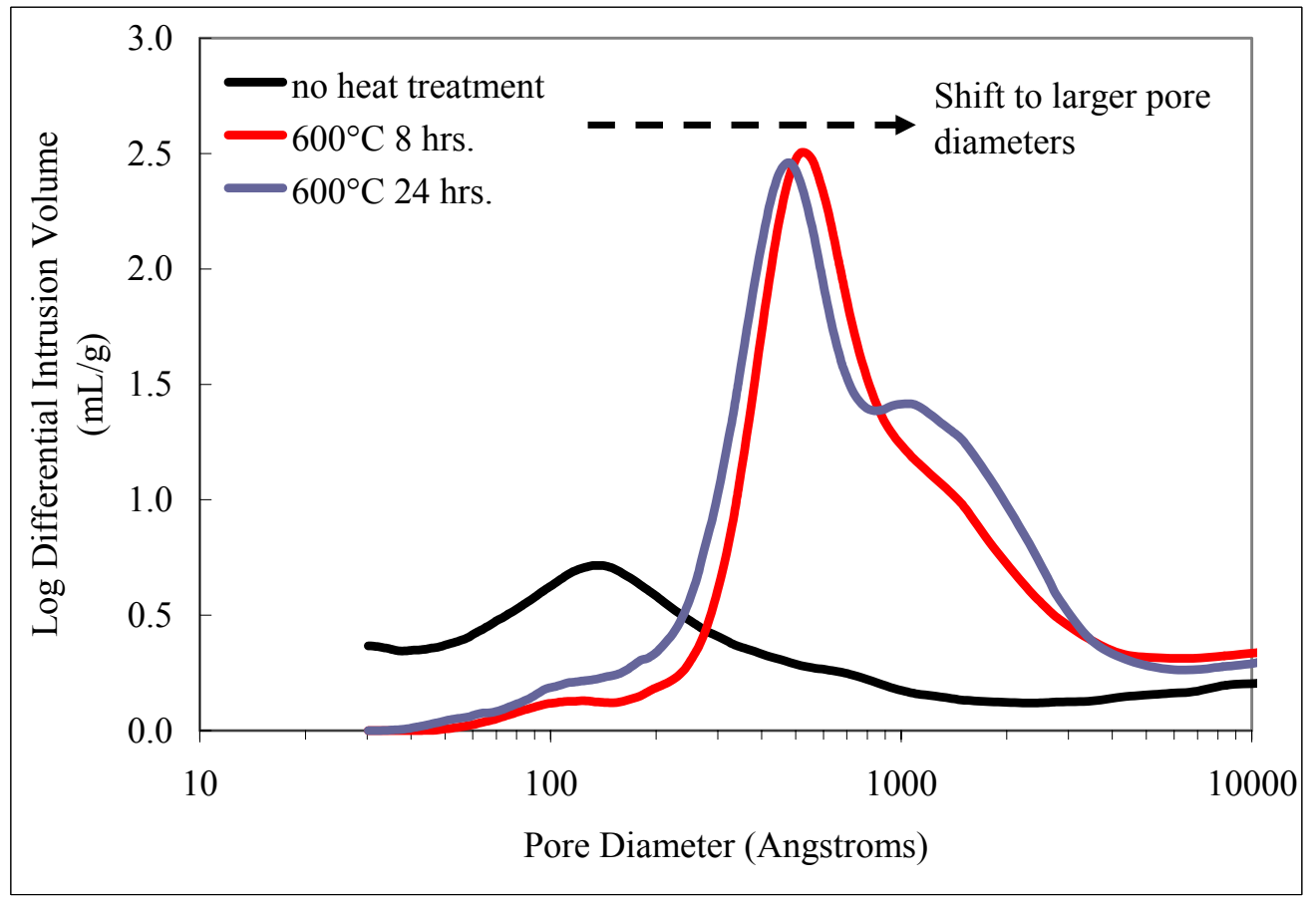

Figure 29. Porosity as a function of heat treatment conditions for the baseline (LDRD1) composition. 


\subsection{Conclusions}

The Savannah River National Laboratory (SRNL) developed a new geometric form: hollow glass microspheres (HGMs) with unique porous walls. The new geometric form combines the existing technology of HGM with basic glass science knowledge in the realm of glass-inglass phase separation. Conceptually, the development of a HGM with porous walls (referred to as a PWHGM) provides a unique system in which various media or filling agents can be incorporated into the PWHGM (via transport through the porous walls) and ultimately has the capacity to serve as a functional delivery system in various industrial applications. Applications of these types of systems could range from hydrogen storage, molecular sieves, drug and bioactive delivery systems, to environmental, as well as chemical and biological indicators, relevant to Energy, Environmental Processing and Homeland Security fields. As a specific example, previous studies at SRNL have introduced materials capable of hydrogen storage (as well as other materials) into the interior of the PWHGMs.

The objective of this project was to determine if the microstructure (i.e. pore size and pore size distribution) of a hollow glass microsphere could be changed by varying composition and/or heat treatment (time and/or temperature) conditions. To meet this objective, HGMs of various alkali borosilicate compositions were fabricated using a flame forming apparatus installed at the Aiken County Technical Laboratory (ACTL). HGMs were treated under various heat treatment conditions to induce and/or enhance glass-in-glass phase separation. Heat treatment temperatures ranged from $580^{\circ} \mathrm{C}$ to $620^{\circ} \mathrm{C}$ while heat treatment times were either 8 or 24 hours.

Specific conclusions drawn from the data include:

1. Microstructure or porosity has been found to be mostly influenced by heat treatment temperature

- The degree of phase separation/porosity increases with increasing heat treatment temperature (with significant differences being observed with a $20^{\circ} \mathrm{C}$ temperature change)

- Pore diameter is increased by a factor of 10 , from $100 \AA$ in non-heat treated samples to $1000 \AA$ in samples heat treated at $600^{\circ} \mathrm{C}$ for 8 hours

2. Composition may have a secondary effect on microstructure/porosity

- Each PWHGM composition exhibits an interconnected microstructure

- Micrographs indicate variations in the degree of porosity but quantitative porosity information could not confirm microscopy results

o Based on glass science theory, composition changes should have an impact on microstructure. Processing conditions through the flame forming system may also affect microstructure, but have not been traced in this study. 
WSRC-STI-2007-00605

Revision 0

3. Heat treatment time $(8-24$ hours $)$ has little, if any, effect on PWHGM microstructures

- Change in microstructure is minimal

- Slight shift in pore diameter and little to no increase in pore volume

4. Yields as a Function of Composition

- Baseline composition (LDRD-1) has the highest yield

- Yield is maximized in the region of $\sim 60-62 \mathrm{wt} \% \mathrm{SiO}_{2}$ and $\sim 21.5-22 \mathrm{wt} \%$ $\mathrm{B}_{2} \mathrm{O}_{3}$

- The elimination of $\mathrm{ZnO}, \mathrm{P}_{2} \mathrm{O}_{5}$ or $\mathrm{F}$ from the baseline composition (LDRD-1) has no influence on yield

- Yield is considerably reduced $(<1 \%)$ when $\mathrm{CaO}$ is removed from the baseline composition (LDRD-1)

5. Results from the glass plates do not appear to be directly transferable to the HGM or PWHGM systems.

The results of this study suggest that PWHGM microstructures (pore size and pore volume) can be tailored or specifically designed to meet different end-user needs within certain limitations. The primary effect on the resulting microstructure is heat treatment temperature which can result in a significant shift in pore size (100 to $1000 \AA$ ) or volume with a very small difference in heat treatment temperature (i.e., $20^{\circ} \mathrm{C}$ or less). The ability to control the microstructure of the PWHGMs provides the opportunity to design the PWHGM system to accommodate different additives or fill agents.

\subsection{Recommendations and Future Work}

1. Simplify the LDRD base composition while still maintaining the desired microstructure

- Determine if the amount of $\mathrm{ZnO}, \mathrm{P}_{2} \mathrm{O}_{5}$ and $\mathrm{F}$ can be reduced or eliminated

- Determine the influence of $\mathrm{Al}_{2} \mathrm{O}_{3}$ on pore size and pore size distribution

2. Optimize compositions and begin work on controlling microstructure and porosity for intended applications

3. Use both gas adsorption and mercury porosimetry to quantify the shift in pore diameter

- Determine a better method in sample preparation when using mercury intrusion

4. Optimize heat treatment time for desired microstructure

5. Determine if gel layer formed on the inner and outer surface of the PWHGM can be minimized or eliminated by processing, etc. (see Appendix) 
6. Compositional analysis of HGMs and PWHGMs using SEM-EDS

- Verify compositions of the "gel" layers (see Appendix)

7. Explore the influence of flame forming conditions on HGM formation and microstructure

8. Perform compositional analysis between processing steps using ICP - AES to determine change in composition after flame process and acid leaching 
WSRC-STI-2007-00605

Revision 0

\subsection{References}

1. F. Janowski and D. Enke, "Porous Glasses," pp. 1432-542 in Vol. 3, Handbook of Porous Solids. Edited by F. Schuth, K. S. Sing, and J. Weitkamp. Wiley-VCH, Weinheim, Germany, 2002.

2. R.F. Schumacher, G.G. Wicks, and L. Heung, "Porous Hollow Glass Microspheres for Encapsulating Hydrogen Absorbents," Savannah River National Laboratory, Aiken, SC, Report No. WSRC-TR-2005-00121 Rev. 0, October 2005.

3. J.E. Shelby, Introduction to Glass Science and Technology; pp. 107-31. Royal Society of Chemistry, Cambridge, UK, 1997.

4. B.R. Wheaton and A.G. Clare, "Evaluation of Phase Separation in Glasses with the Use of Atomic Force Microscopy," J. Non-Cryst. Solids, In Press, Corrected Proof.

5. D.K. Peeler and E.K. Hansen, "Application of Strategic Glass Formulation and Heat Treatment Effects to Control Pore Size and Pore Size Distribution of HGMs: Research Proposal," (April 2006).

6. P.A. Howell, "Glass Bubbles of Increased Collapse Strength," US Pat 4391646, July 1983.

7. R.F. Schumacher, E.K. Hansen, D.K. Peeler, G.G. Wicks, and L. Heung, "Impacts of Composition and Heat Treatment on Pore Size for Hollow Glass Microspheres: A Glass Selection Strategy," Savannah River National Laboratory, Aiken, SC, Report No. SRNLPSE-2006-00289 Rev. 0, November 2006.

8. T.J. Rockett, W.R. Foster, and R.G. Ferguson, "Metastable Liquid Immiscibility in the System Silica—Sodium Tetraborate," J. Am. Ceram. Soc., 48 [6] 329-31 (1965).

9. M.B. Volf, Chemical Approach to Glass; pp. 183-90. Elsevier, New York, 1984.

10. W. Haller, D.H. Blackburn, F.E. Wagstaff, and R.J. Charles, "Metastable Immiscibility Surface in the System $\mathrm{Na}_{2} \mathrm{O}-\mathrm{B}_{2} \mathrm{O}_{3}-\mathrm{SiO}_{2}$," J. Am. Ceram. Soc., 53 [1] 34-9 (1970).

11. "Standard Practice for Measuring Viscosity of Glass above the Softening Point," ASTM International, West Conshohocken, PA, Report No. ASTM C965-81.

12. "Pore Volume Distribution" (2007) Micromeritics Analytical Services. Accessed on: October 23, 2007. Available at $<$ http://www.particletesting.com/pore volume dist.aspx $>$

13. W. Vogel, Chemistry of Glass; pp. 113-4. American Ceramic Society, Columbus, OH, 1985.

14. T.B. Edwards, "A Statistical Review of the Initial Chemical Compositions of Glasses Batched as a Part of SRNL's HGM LDRD Study," Savannah River National Laboratory, Aiken, SC, Report No. SRNL-SCS-2007-00039.

15. P.A. Webb and C. Orr, "Pore Structure by Mercury Intrusion Porosimetry," in Analytical Methods in Fine Particle Technology. Micromeritics Instrument Corporation, Norcross, GA, 1997. 


\section{APPENDIX}

Formation of a Gel Layer in the PWHGM: A High Level Discussion 
Examination of the cross-section of a typical PWHGM (heat treated and acid leached) by SEM indicates that the wall is composed of three layers as shown in Figure A1. The thin outer layer (layer 1), which occasionally appears to spall off the surface of the PWHGM, may be the result of volatilization of the alkali and boron during the flame forming operation. This volatilization is also observed by the color change of the flame when feeding of the glass powder is initiated and maintained. The normally blue gas flame turns a bright sodium orange color as the feed enters the flame. The outer layer appears to have the beginning of some of the pores which are evenly distributed on the outer surface of the PWHGM wall as shown in Figure A2. In some cases, there are openings in this layer that reveal the interconnected microstructure, shown in Figure A3. As the heat treatment time is increased from 8 hours to 24 hours, the size of the surface pores increase (Figure A4). The structure of the inner layer (layer 2, Figure A1) shows the interconnected pores characteristic of the spinodal phase separation and leaching of the alkali and borate phase. The interior of the wall (layer 3) appears to be coated with a membrane containing small openings (Figure A5), which in some cases appears to spall off the surface (Figure A6), revealing the spinodal phase separation. It is believed (or speculated at this time) this membrane is formed when the acid solution of alkali borate enters the interior of the PWHGM and is dried. While effort is made to remove the alkali borate by rinsing after the acid leaching process, some of the alkali and borate still remain on the interior side of the PWHGM causing the formation of a residual alkali borate membrane.

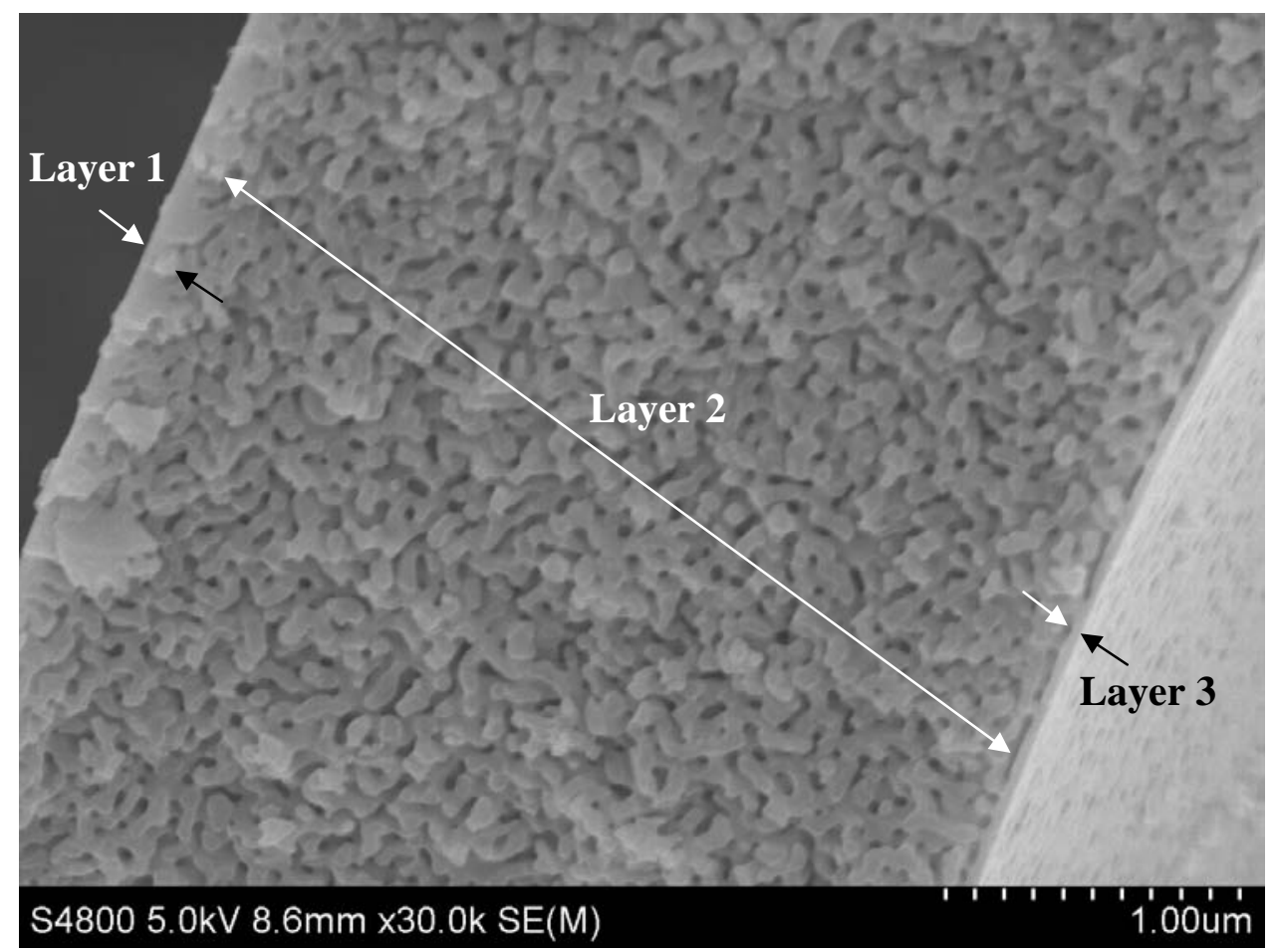

Figure A1. Scanning electron micrograph of the cross-section of a typical PWHGM. 


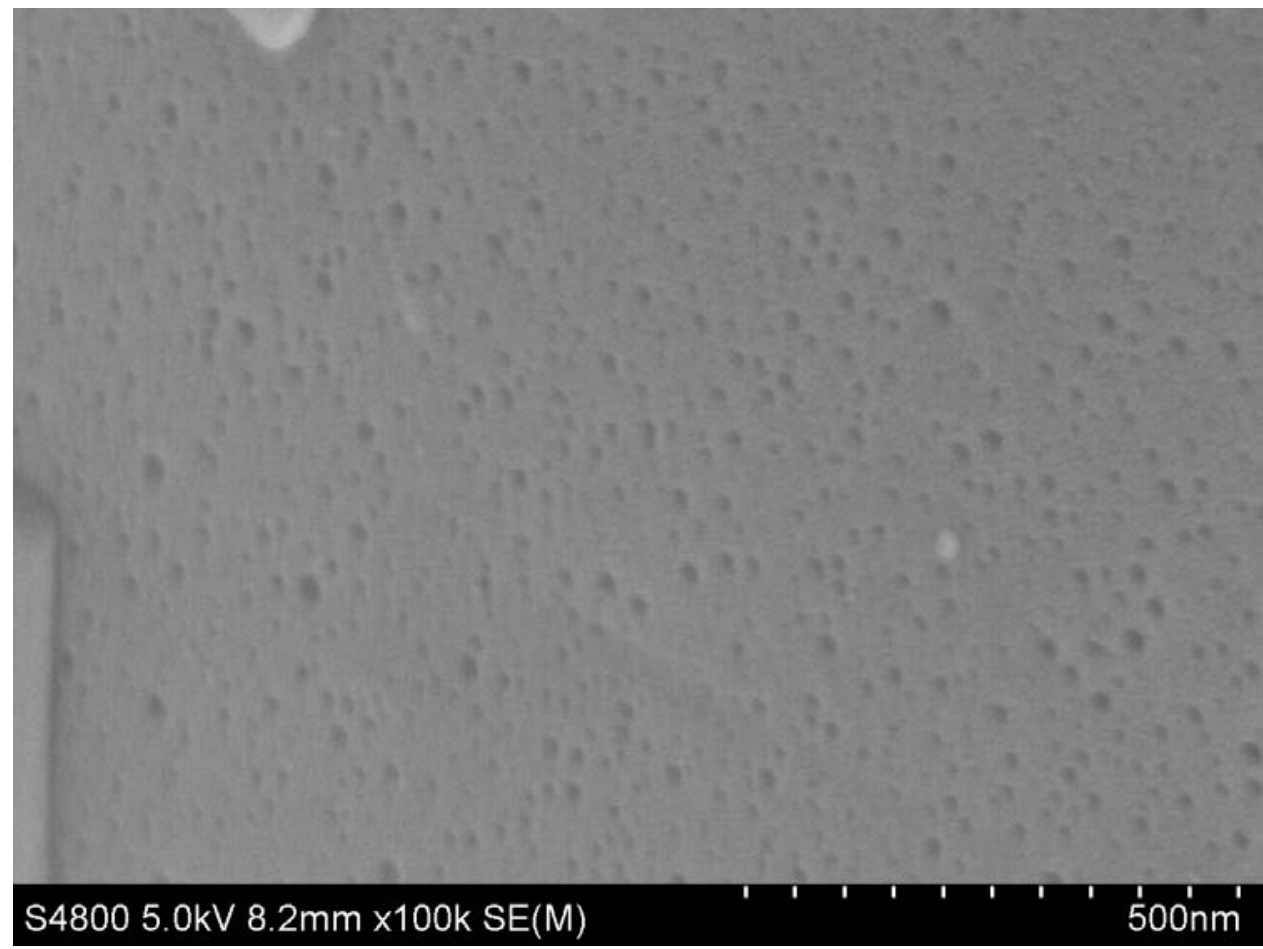

Figure A2. Scanning electron micrograph of the outer layer (layer 1) of the PWHGM.

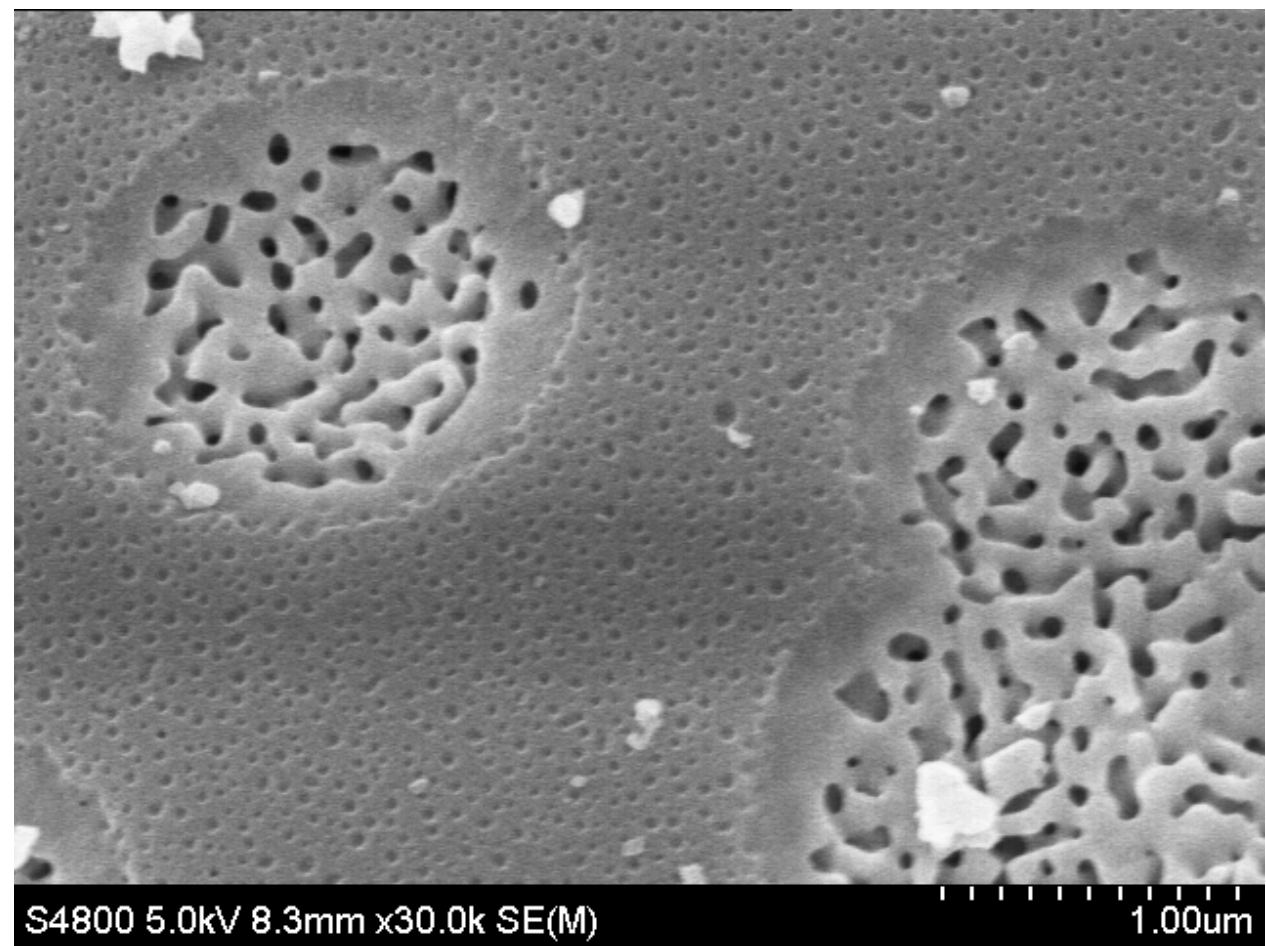

Figure A3. Scanning electron micrograph of the outer layer in which layer 2 is exposed. 


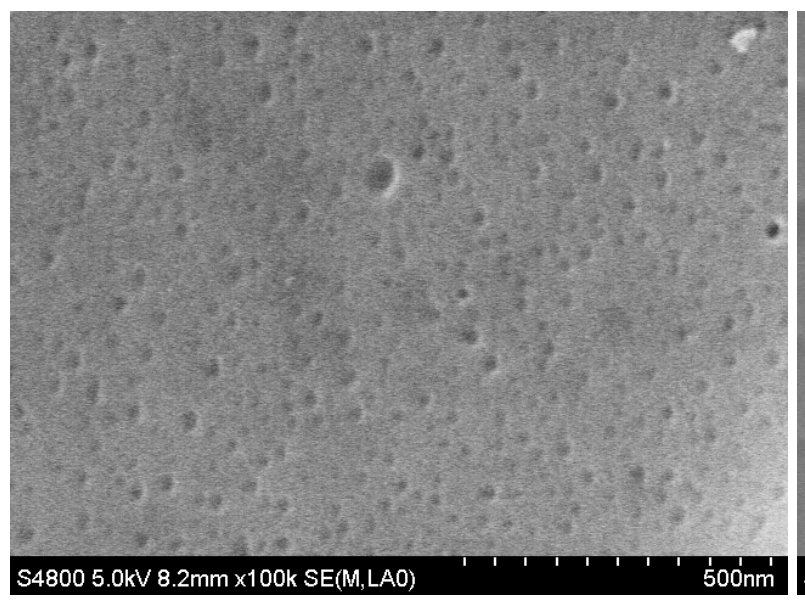

a.) $600^{\circ} \mathrm{C}$ for 8 hours

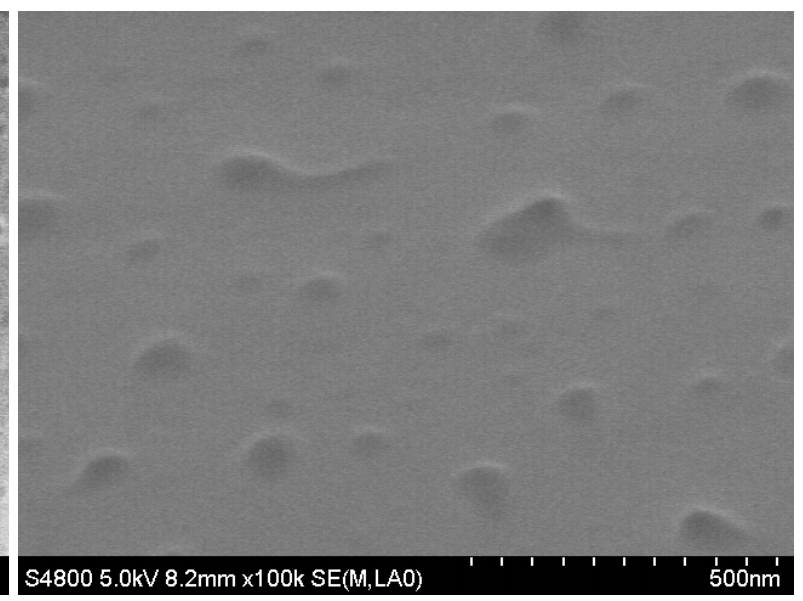

b.) $600^{\circ} \mathrm{C}$ for 24 hours

Figure A4. Comparison of the outer layer microstructures of the same composition as a function of heat treatment time.

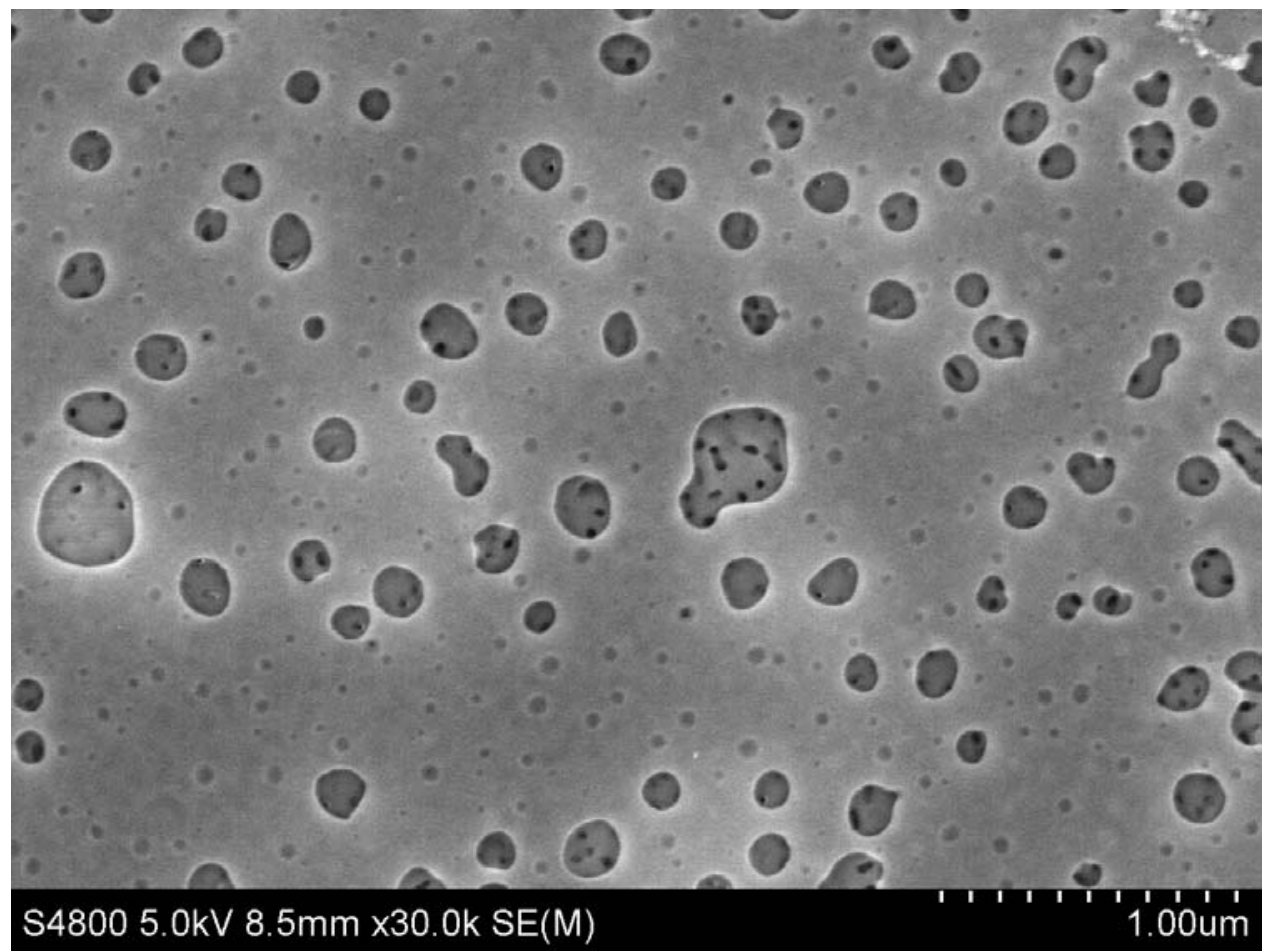

Figure A5. Scanning electron micrograph of the inner layer (layer 3) of a PWHGM. 


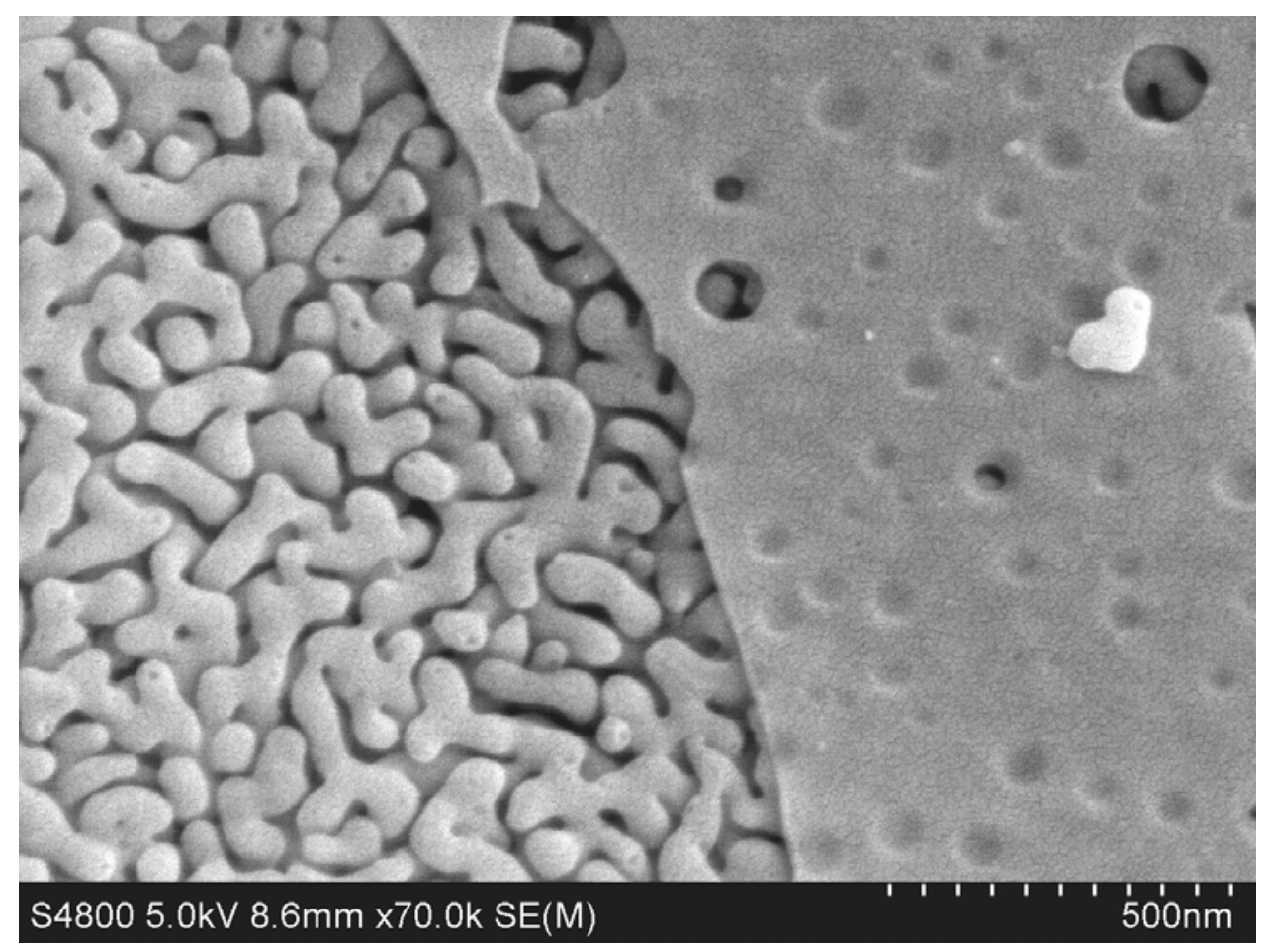

Figure A6. Scanning electron micrograph of the PWHGM outer layer (layer 1) that has spalled off to reveal the interconnected microstructure of layer 2. 


\section{Distribution:}
A.B. Barnes, 999-W
D.B. Burns, 786-A
D.A. Crowley, 999-W
R.E. Edwards, 773-A
T.B. Edwards, 999-W
K.M. Fox, 999-W
T.J. French, 773-A
J.C. Griffin, 773-A
E.K. Hansen, 999-W
C.C. Herman, 999-W
L.K. Heung, 773-A
C.M. Jantzen, 773-A
J.E. Marra, 773-A
J.D. Newell, 999-W
D.K. Peeler, 999-W
F.C. Raszewski, 999-W
R.F. Schumacher, 999-W
A.L. Youchak, 999-W
G.G. Wicks, 773-A 